\title{
Modifications of Porphyrins and Hydroporphyrins for Their Solubilization in Aqueous Media
}

\author{
Michael Luciano and Christian Brückner* \\ Department of Chemistry, University of Connecticut, Storrs, CT 06269-3060, USA; michael.luciano@uconn.edu \\ * Correspondence: c.bruckner@uconn.edu; Tel.: +1-860-486-2743
}

Received: 19 May 2017; Accepted: 9 June 2017; Published: 13 June 2017

\begin{abstract}
The increasing popularity of porphyrins and hydroporphyrins for use in a variety of biomedical (photodynamic therapy, fluorescence tagging and imaging, photoacoustic imaging) and technical (chemosensing, catalysis, light harvesting) applications is also associated with the growing number of methodologies that enable their solubilization in aqueous media. Natively, the vast majority of synthetic porphyrinic compounds are not water-soluble. Moreover, any water-solubility imposes several restrictions on the synthetic chemist on when to install solubilizing groups in the synthetic sequence, and how to isolate and purify these compounds. This review summarizes the chemical modifications to render synthetic porphyrins water-soluble, with a focus on the work disclosed since 2000. Where available, practical data such as solubility, indicators for the degree of aggregation, and special notes for the practitioner are listed. We hope that this review will guide synthetic chemists through the many strategies known to make porphyrins and hydroporphyrins water soluble.
\end{abstract}

Keywords: water-solubility; porphyrin; chlorin; bacteriochlorin; PEGylation; bioconjugation; photodynamic therapy; bioimaging

\section{Introduction}

The utility of porphyrins and hydroporphyrins (chlorins and bacteriochlorins) in a variety of biomedical applications has been demonstrated [1]. These include photodynamic cancer therapy [2-5], antifungal photodynamic therapy [6], their use as photoantimicrobials [7], as fluorescence and photo-acoustic imaging agents [5,8-14], (single) cell imaging [15] and fluorescence labelling [16], and as in vivo chemosensors $[17,18]$. In addition, they have shown value in a number of technical applications, such as chemosensing [17], electronic devices and materials [19-21], catalysis [22], photocatalysis [23,24], and light harvesting [25-28]. These applications rest on the favorable optical, chemical and electronic properties of these porphyrinoids: their intense absorbance in the visible to near infrared (NIR) region, high fluorescence or singlet oxygen quantum yields, good photoacoustic signal generation efficiency, ease of ejection of a photo-excited electron, etc. Many of these applications would greatly benefit from an inherent solubility of the porphyrins in aqueous media, i.e., not requiring any surfactants or liposome vesicles to mediate solubility. However, even though the methodologies for preparing synthetic porphyrins [29,30], hydroporphyrins [2,31-34], and their analogues [34-39], have advanced enormously in the past decades, the vast majority of the synthetic porphyrinoids presented are not natively water-soluble, preventing—or at least complicating —-their utilization in, for example, biological contexts.

Initial efforts to impart water-solubility relied on the utilization of meso-pyridyl and meso-p-sulfonatophenyl-substituents in (mostly) symmetric porphyrins. These porphyrins were based on Adler syntheses of tetrapyridyl- and tetraphenylporphyrin, followed by quarternization with a suitable alkyl halide or direct sulfonation, respectively. Albeit simple, both methods have drawbacks. 
They are difficult to translate to $\beta$-alkyl-substituted porphyrins, the sulfonation reaction conditions are harsh and therefore incompatible with many hydroporphyrin chromophores or substituents that convey desirable properties onto the porphyrin. This led to the development of a range of alternative methods to impart water-solubility that are mild, selective, and that generate the water-soluble porphyrin derivative late in the synthetic sequence, thus facilitating its isolation and purification.

Rather than attempting to be comprehensive, we aim to present here a tutorial-style review that highlights recent (since 2000 ) synthetic strategies. Where data are available, we compare the resulting solubilities, and report on other notable practical considerations. This summary extends a review on water-soluble porphyrins published in the year 2000 [40] that provides a detailed account of the acid-base properties and aggregation behavior of conventional water-soluble porphyrins. A 2014 review on amphiphilic porphyrins by Gryko and co-workers [41] is also available; overlap with this review is minimized and these reviews are thus complementary. Porphyrins linked to sugars, many of which are also water-soluble, have been reported [41-43]. We chose not to include them here because glycosylation strategies are frequently not driven by achieving water-solubility but to increase tumor targeting; they were also reviewed in the context of amphiphilic porphyrins [41]. Water-soluble porphyrins conjugated to biomolecules (e.g., oligonucleotides and peptides), appended to functionalities such as cyclodextrans [44], crown ethers [45,46], porphyrin nanoparticles [47-50], or porphyrins that were solubilized with the help of surfactants or vesicles [51-53] are also beyond the scope of this discussion. Likewise, we do not cover the solubilization of expanded porphyrins or most other porphyrinoids.

The review is organized along the charge the solubilization groups introduce: Cationic (amine/ammonium, pyridyl/pyridinium), anionic (sulfonate, phosphonate, carboxylic acid/carboxylate) and neutral (polyethylene glycol (PEG) chains). Each section discusses the examples loosely in increasing order of complexity and the position of the solubilizing group. Three principle strategies for the introduction of solubilizing groups can be distinguished (Scheme 1). Strategy A encompasses the synthesis of a porphyrin macrocycle using building blocks bearing solubilizing groups (protected or not). Strategy $B$ involves the synthesis of a porphyrin macrocycle with precursor functionalities, that can later be manipulated to hydrophilic groups. Strategy $C$ employs synthetic modifications of an already-formed porphyrin to impart water solubility.

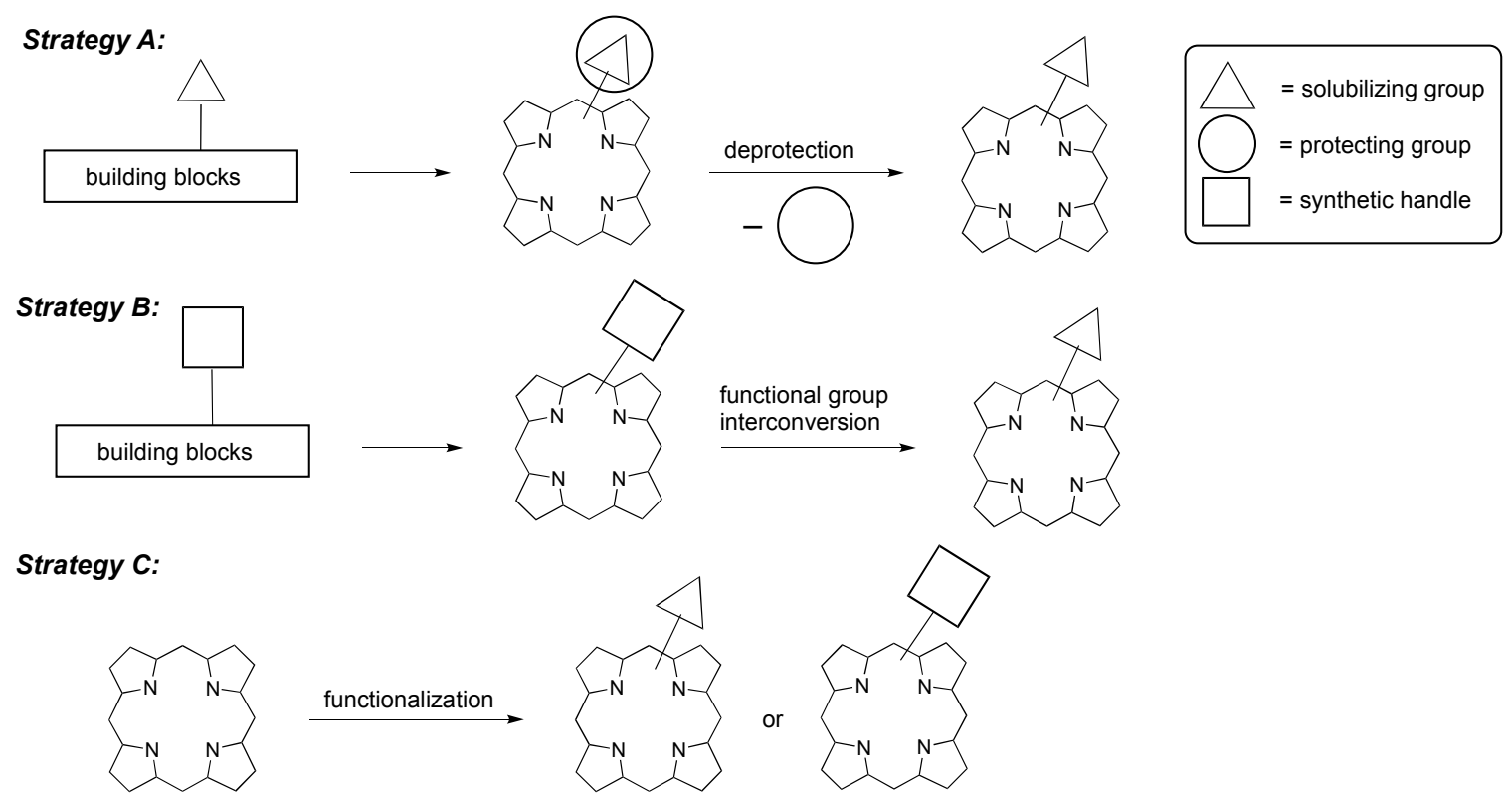

Scheme 1. Principle strategies toward hydrophilic porphyrin derivatives. 


\section{Water-Soluble Porphyrins Bearing Cationic Substituents}

Cationic porphyrins were among the first synthetic water-soluble porphyrins to be discovered [54]. These early methods of solubilization relied on the $\mathrm{N}$-alkylation of meso-tetrapyridylporphyrins and their metal complexes (see also Section 2.2.1) [41]. These types of cationic porphyrins were widely studied for their association with the polyanion DNA [55,56], as part of the quest for new photosensitizers for photodynamic therapy (PDT), and for their promise as photoantimicrobials for gram positive and gram negative bacteria [57]. Tetra-pyridyl/pyridiniumporphyrins are also commercially available [58].

\subsection{Amine/Ammonium Functionalized Porphyrins}

One possibility for the preparation of cationic water-soluble porphyrins and hydroporphyrins is through derivatization with amines or polyamines. Porphyrinoids with amine functional groups may be soluble in aqueous media at low $\mathrm{pH}$, but quarternization of the amines with suitable electrophiles is frequently employed to furnish freely water-soluble derivatives. The resulting (poly)cationic derivatives are usually purified by crystallization protocols or reverse phase chromatography. Ion-exchange chromatography offers an option to subsequently exchange the halide counter ion (typically $\mathrm{Br}^{-}$or $\mathrm{I}^{-}$) to another anion [59].

A number of symmetric and asymmetric amphiphilic meso-aryl porphyrins bearing amine functional groups have been reported [41]. The strategies toward their generation often rely on Adler or Lindsey porphyrin syntheses incorporating amine-containing building blocks, or through modification of other functionalities, such as phenols.

Krausz and co-workers, for example, synthesized polyamine-meso-arylporphyrin conjugates by DCC-mediated amide-coupling of carboxylic acid-functionalized $\mathrm{A}_{3} \mathrm{~B}$ porphyrin 2 , made by functionalization of phenol $\mathbf{1}$ with di-Boc-protected-spermidine or tri-Boc-protected-spermine (Scheme 2) [60]. The ultimate starting $\mathrm{A}_{3} \mathrm{~B}$ porphyrin 1 was synthesized using a mixed aldehyde Adler condensation, followed by alkylation of the phenolic oxygen with ethyl 4-bromobutanoate and saponification. The thus generated polyamines were submitted to standard Boc-deprotection conditions to afford the polyamine-porphyrin conjugates 3 and 4 , respectively.

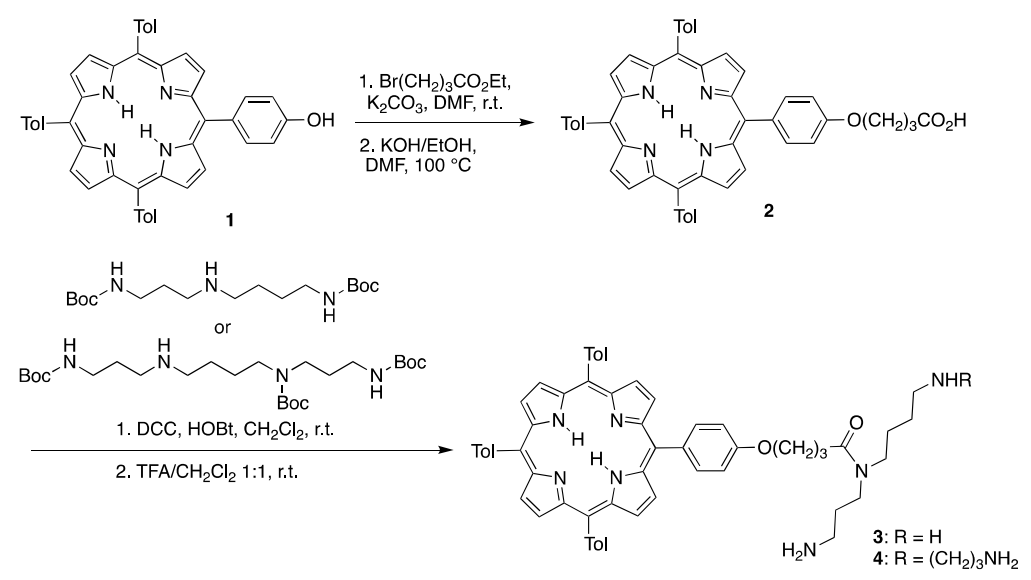

Scheme 2. Spermine- and spermidine-porphyrin conjugates, as described by the group of Krausz [60]. DCC $=$ dicyclohexylcarbodiimide, $\mathrm{HOBt}=1$-hydroxybenzotriazole.

Bacteriochlorins derived from natural sources and bearing an anhydride functionality could also be derivatized by amide formation with polyamines [61]. Sol and co-workers prepared water-soluble chlorin polyamine derivative 6 through amidation of a chlorin extracted from Spirulina maxima (Scheme 3). The polyamine groups were introduced by nucleophilic ring opening of anhydride 5 with polyethyleneimine (PEI, MW $600 \mathrm{Da}$ ). Alternatively, polyamination was performed at the 
propionic acid side chain. The anhydride moiety in chlorin 5 was first converted to an acetate-protected cycloimide chlorin 7 by treatment with hydroxylamine, followed by acylation. The subsequent polyamination at the propionic acid side chain required activation of the carboxylic acid moiety, followed by reaction with PEI. In a similar fashion, water-soluble polyaminated bacteriochlorins 9 and 10 were prepared starting from bacteriochlorins extracted from Rhodobacter spaeroides. In water, the resulting compounds exhibited split and/or broadened Soret bands, indicating some degree of aggregation.
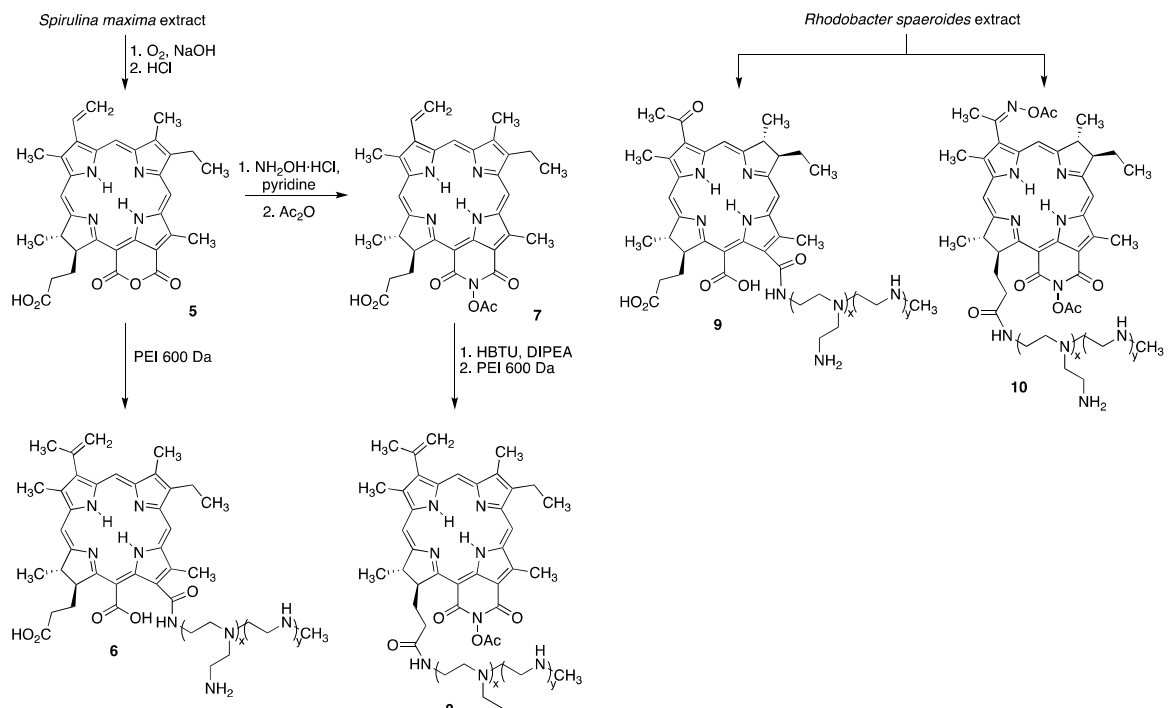

Scheme 3. Chlorin and bacteriochlorin polyamines derived from Spirulina maxima and Rhodobacter spaeroides, respectively, as described by the group of Sol [61]. PEI = polyethyleneimine (PEI, MW 600 Da), HBTU = (2-(1H-benzotriazol-1-yl)-1,1,3,3-tetramethyluronium hexafluorophosphate), DIPEA $=N, N$-diisopropylethylamine.

Amine groups were also introduced to porphyrins bearing carboxylic acid groups by esterification with an amino-alcohol. An example of this strategy was the preparation of a tricationic water-soluble ester of chlorin e6 11 (Scheme 4) [62]. Methyl pheophorbide $a$ was saponified, and the acid groups in product 11 were activated as acid chlorides and esterified with $N, N$-dimethylamino-ethanol to provide triamine 12. Quarternization by reaction with $\mathrm{CH}_{3} \mathrm{I}$ gave the tricationic water-soluble chlorin derivative 13 [62].

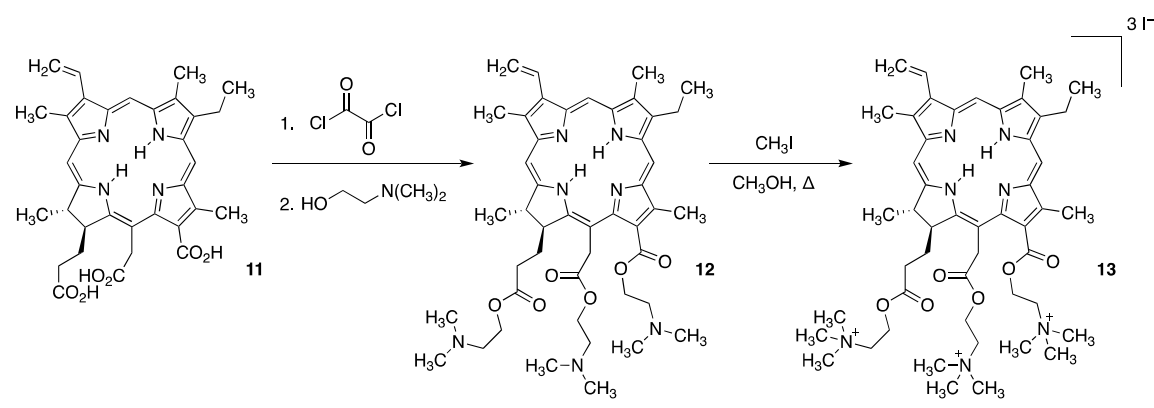

Scheme 4. Cationic esters of chlorin e6 with terminal ammonium groups, as described by the group of Inoue [62].

Amine groups have been introduced to the $\beta$-positions of hydroporphyrins by transition metal-mediated coupling strategies using $\beta$-bromo precursors. Thus, Lindsey and co-workers 
prepared a range of water-soluble cationic bacteriochlorin derivatives utilizing the versatile 3,13-dibromo-bacteriochlorin building block 14. The bromo groups are susceptible to a variety of transition metal-mediated C-C bond forming coupling reactions (Scheme 5) [63]. For example, bacteriochlorins 15a-15c were prepared from 14 through a carbonylation $\rightarrow$ acid chloride reaction with secondary amines. Additionally, reaction of amide salts with $\mathbf{1 4}$ in a carbonylation $\rightarrow$ amidation sequence gave the aminobacteriochlorins 16a and 16b. Sonogashira coupling of 14 with an ethynyl-amine, followed by reduction gave the bacteriochlorin $\mathbf{1 7}$ with amine-terminated alkyl chains. Lastly, a variety of secondary amines were employed in a $\beta$-formylation $\rightarrow$ reductive-amination strategy to produce amine-functionalized bacteriochlorins 18a-18e. The resulting amines were amenable to purification by silica gel column chromatography (EtOAc or $\mathrm{CH}_{2} \mathrm{Cl}_{2} / \mathrm{MeOH} / \mathrm{NH}_{4} \mathrm{OH}$ as eluents). Subsequent $\mathrm{N}$-alkylation of the amines was achieved using standard conditions, and the water-soluble cationic products that precipitated from the $\mathrm{CHCl}_{3}$ reaction mixtures were isolated by precipitation and centrifugation. Some of these compounds were investigated for their efficacy as antimicrobial photosensitizers [64].

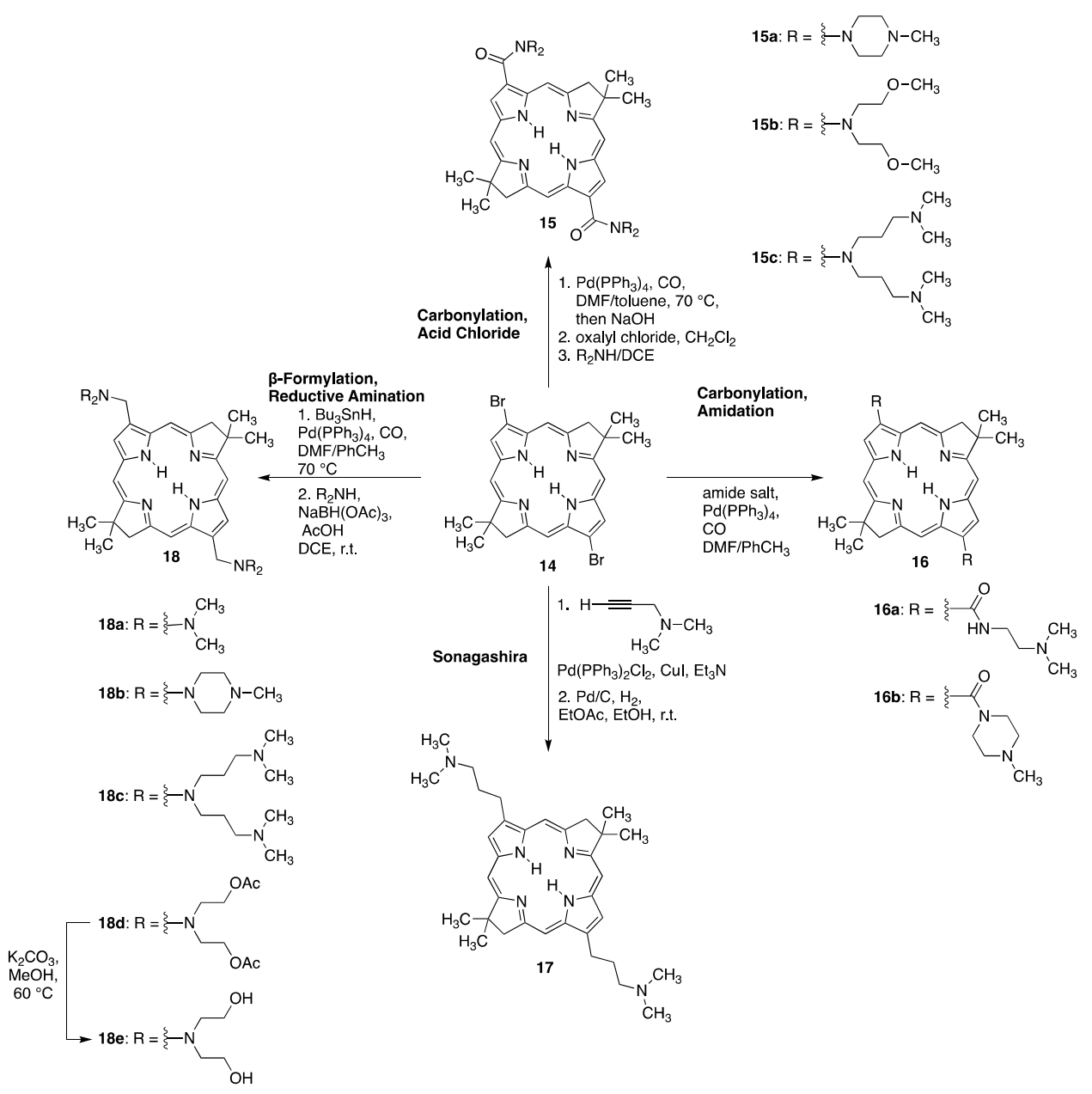

Scheme 5. $\beta$-substituted cationic ammonium bacteriochlorin derivatives, as described by the group of Lindsey [63]. DCE = dichloroethane.

Lindsey and co-workers also used similar dibromobacteriochlorin 19 to directly introduce arylamines to the $\beta$-positions via Suzuki couplings (Scheme 6) [65]. After the coupling of dibromo-bacteriochlorin 19 with an aryl boronic ester bearing two Boc-protected amines, the Boc groups in product 20 were removed, and the free amine quarternized by treatment with $\mathrm{CH}_{3} \mathrm{I}$ to afford the final ammonium-functionalized bacteriochlorin product 21. 


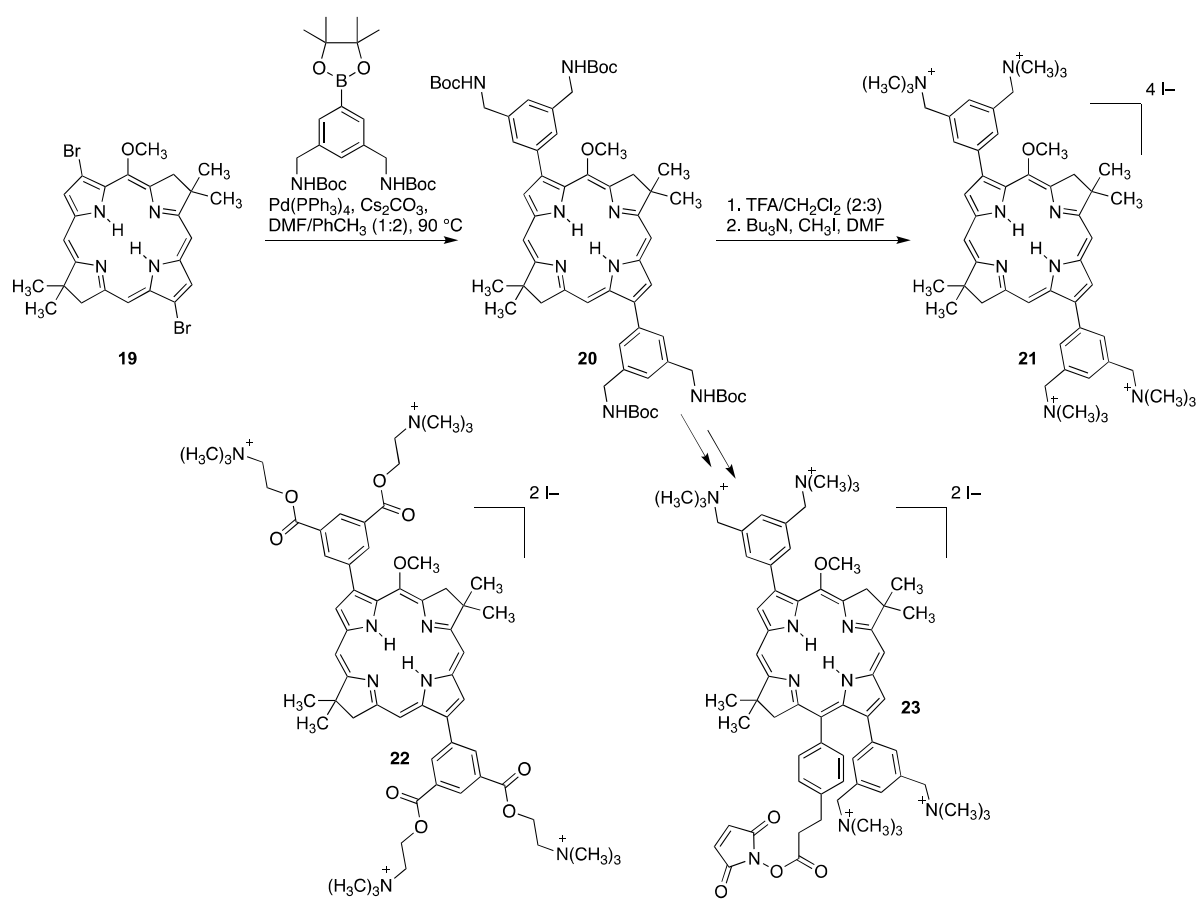

Scheme 6. $\beta$-Substituted cationic ammonium bacteriochlorin derivatives prepared by Suzuki coupling, as described by the group of Lindsey [65].

Related compounds with terminal amine functional groups, such as 3,13-diaryl bacteriochlorin 22, were prepared using similar Suzuki coupling strategies. Bioconjugatable derivatives of these compounds carrying an NHS-ester functional group, such as $\mathbf{2 3}$, were also prepared by a regio-selective meso-bromination $\rightarrow$ Suzuki coupling sequence (see also Section 2.2.2) [65].

The group of Lindsey also prepared a range of amphiphilic bacteriochlorins of limited aqueous solubility bearing one amine side chain by reductive amination of a $\beta$-formylated bacteriochlorin (see also Scheme 5) [66]. A representative example is bacteriochlorin 24, which possesses an ammonium-terminated dialkyl chain, a so-called swallowtail functionality. This moiety was designed to project solubilizing groups above and below the plane of the macrocycle, leading to facial encumbrance that inhibits macrocycle stacking and increases hydrophilicity. A similar strategy was used to solubilize meso-aryl porphyrins in organic solvents [67,68].

Other ammonium-based water-soluble derivatives were also prepared by the Lindsey group by introduction of spiro-linked piperidine moieties at the $\beta$-positions of a bacteriochlorin [69]. The integral spiropiperidine functional groups were quarternized using standard conditions to furnish water-soluble derivatives, such as bacteriochlorin 25 (Figure 1).

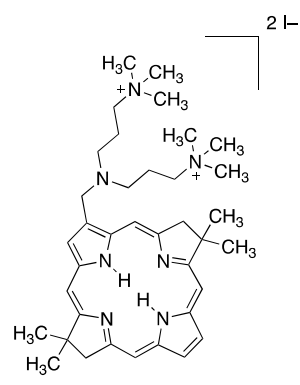

24

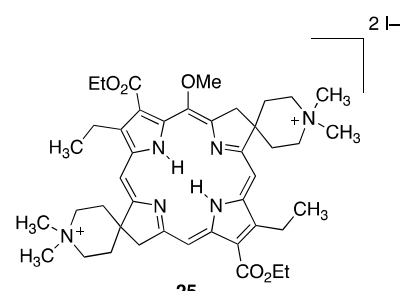

25

Figure 1. Molecular structures of ammonium-substituted bacteriochlorins 24 and 25. 
The direct introduction of ammonium groups using a nucleophilic Senge arylation strategy was performed by Anderson and co-workers on 1,15 diaryl porphyrin 26Zn (Scheme 7) [70]. Porphyrin 26 was functionalized at the meso-position with a Boc-protected amino-phenyl group. The resulting derivative $\mathbf{2 7}$ was carried through multiple steps to afford porphyrin dimer $\mathbf{2 8}$ that was rendered water-soluble by quarternization of the amine functionality with $\mathrm{CH}_{3} \mathrm{I}$.

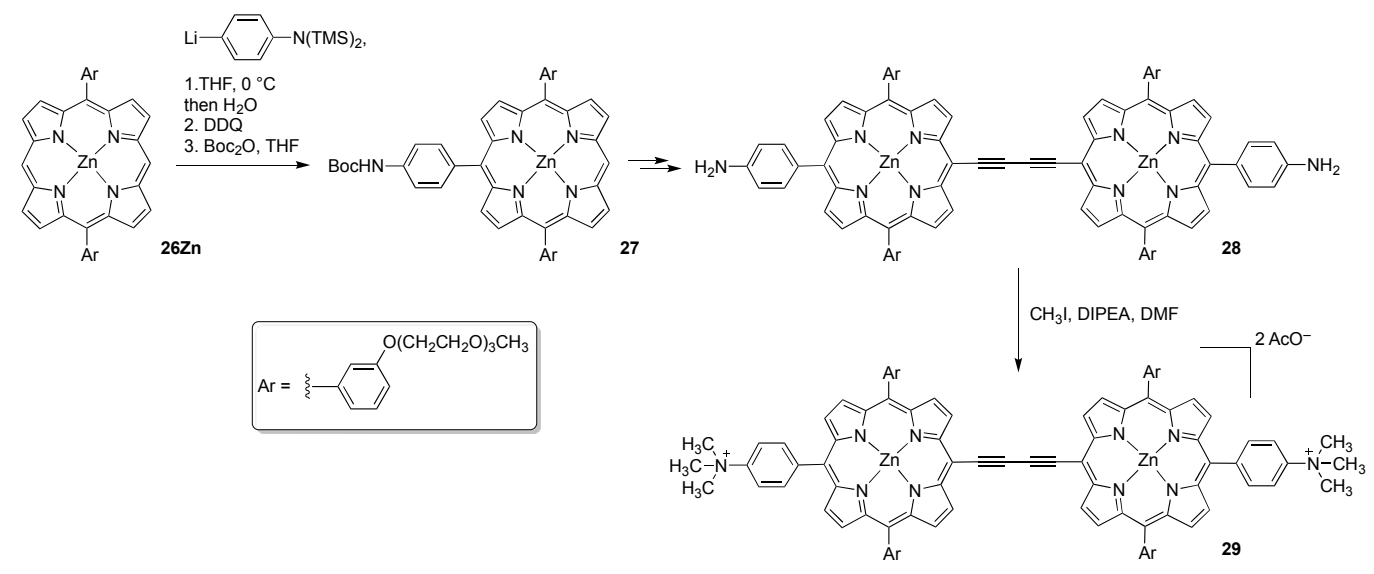

Scheme 7. meso-Aryl-ammonium bis-acetylene linked porphyrin dimers prepared via Senge arylation, as described by the Anderson group [70]. DIPEA = N,N-diisopropylethylamine.

\subsection{Porphyrins Carrying Pyridyl/Pyridinium Groups}

\subsection{1. meso-Tetrakispyridiniumporphyrins}

meso-Tetrapyridylporphyrins and the corresponding meso-tetrakis(methylpyridinium)-porphyrins are long known, and their intercalation into DNA was studied in detail [55,56]. Pyridinium porphyrins continue to attract attention as next generation photosensitizers for PDT. Various new meso-tetrakispyridiniumporphyrin derivatives were prepared using a range of electrophiles to quarternize the pyridine nitrogens (Scheme 8).

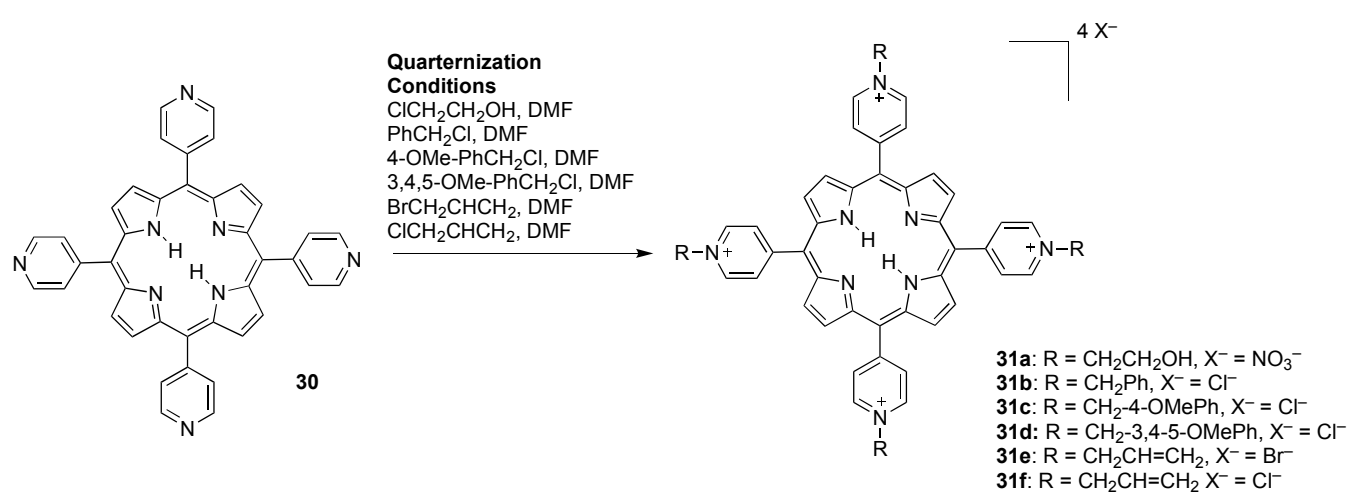

Scheme 8. Quarternization options of meso-tetrakis(4-pyridyl)porphyrin.

Orlandi and co-workers prepared meso-tetrakis(4-pyridinium)porphyrins (31) by reaction of meso-tetra(4-pyridyl)porphyrin (30) with various benzyl chlorides to study the effect of polar alkylating groups on their antibacterial activity [71]. The benzylation conditions required were more vigorous (reflux in DMF for $24 \mathrm{~h}$ ) than typical for pyridine alkylations using alkyl halides. The water-soluble products were recovered by precipitation with $\mathrm{Et}_{2} \mathrm{O}$ and filtration. Similarly, Ghazaryan and co-workers prepared a variety of meso-substituted $\mathrm{N}$-substituted tetrapyridiniumporphyrins with different central metals (Ag, Zn, Co and Fe) and alkylating agents (allyl-, oxyethyl-, butyl- and 
methallyl-substituted derivatives) [72]. A PEGylated derivative of meso-tetrakispyridiniumporphyrin was also prepared by alkylation of meso-tetra(4-pyridyl)-porphyrin with a short PEG-bromide [73,74].

Fluorinated derivatives of $m$ - or $p$-linked meso-pyridyl porphyrins were prepared along Adler synthesis routes [75]. $N$-Alkylation of the pyridyl substituents by treatment with $\left(\mathrm{CH}_{3}\right)_{3} \mathrm{O}^{+} \mathrm{BF}_{4}{ }^{-}$ afforded the tetra-alkylated products 32 and 33, respectively, as their tetrafluoroborate salts (Figure 2).
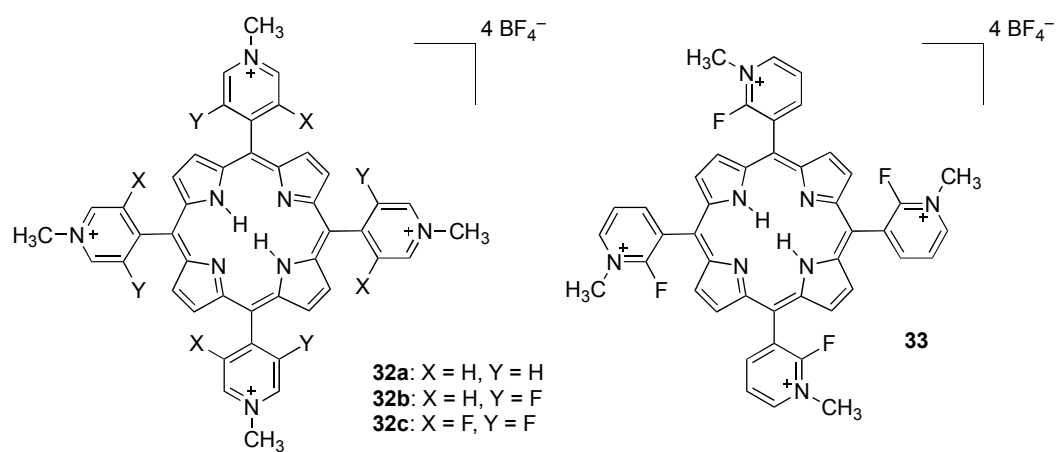

Figure 2. Molecular structures of meso-pyridinium-substituted porphyrins 32 and 33.

In search of dual-action photo- and cytotoxic anti-cancer agents, various metal complexes were coordinated to the outer pyridyl nitrogens in tetrapyridylporphyrins (Scheme 9). Ruthenium, rhodium and iridium complexes were thus prepared by Therrien and co-workers [76] by treatment of meso-tetrapyridylporphyrin 30 with various metal arene salts to afford the water-soluble organic metallic complexes of type 34. They also prepared mixed arene-ruthenium substituted porphyrins in a similar manner, producing mono- and tetrametallated derivatives of 3- and 4-tetrapyridyl-porphyrins [77]. Both cis- and trans-platin conjugates of porphyrins were prepared by treatment of $\mathbf{3 0}$ with cis- or trans-Pt(II) complexes, respectively [77]. The gallium complexes of these compounds (such as 35) were prepared by Odani and co-workers [78] and also tested as photosensitizers for cancer therapy. In addition, tetrapyridylporphyrins with ruthenium nitrosyl groups substituted at their periphery were reported by the group of Alessio, generated by reaction of 30 with ruthenium nitrosyls and purified by column chromatography $\left(\mathrm{CHCl}_{3} / 5 \% \mathrm{EtOH}\right.$ as eluent) [79].

\subsection{2. $\mathrm{A}_{3} \mathrm{~B}$ and Other meso-Pyridiniumporphyrins}

A number of symmetrically substituted pyridylporphyrins have been prepared in the search for the next generation of anticancer PDT agents. However, to further optimize their tumor-targeting and biodistribution properties, the porphyrin needs to be amenable to further modifications that will allow, for example, the conjugation of the porphyrin to a targeting molecule. Thus, a variety of examples emerged that use $\mathrm{A}_{3} \mathrm{~B}$ porphyrins bearing three meso-pyridinium groups as the water-soluble framework of the chromophore, with the fourth meso-aryl ring available for further manipulations (Scheme 10). The parent $\mathrm{A}_{3} \mathrm{~B}$ porphyrins are typically synthesized as statistical mixtures by Adler condensation of pyridylaldehyde, the desired arylaldehydes, and pyrrole, followed by chromatographic separation of the product mixture. The $\mathrm{A}_{3} \mathrm{~B}$ porphyrin precursors are functionalized at the remaining meso-aryl group and $\mathrm{N}$-alkylated with $\mathrm{CH}_{3} \mathrm{I}$, with the order of these operations depending on the functionality present (see below).

Using this strategy, a pyrene-substituted trispyridyl $\mathrm{A}_{3} \mathrm{~B}$ porphyrin could be prepared [80] (Scheme 10). Its $N$-alkylation with methyl $p$-toluenesulfonate in refluxing $\mathrm{CHCl}_{3} / \mathrm{CH}_{3} \mathrm{NO}_{2}$ afforded the tris- $N$-methyl pyridiniumporphyrin $\mathbf{3 7 b}$. The group of Boyle synthesized tripyridyl $\mathrm{A}_{3} \mathrm{~B}$ porphyrin 37a with the fourth aryl ring bearing a bioconjugatable isocyanate group. 


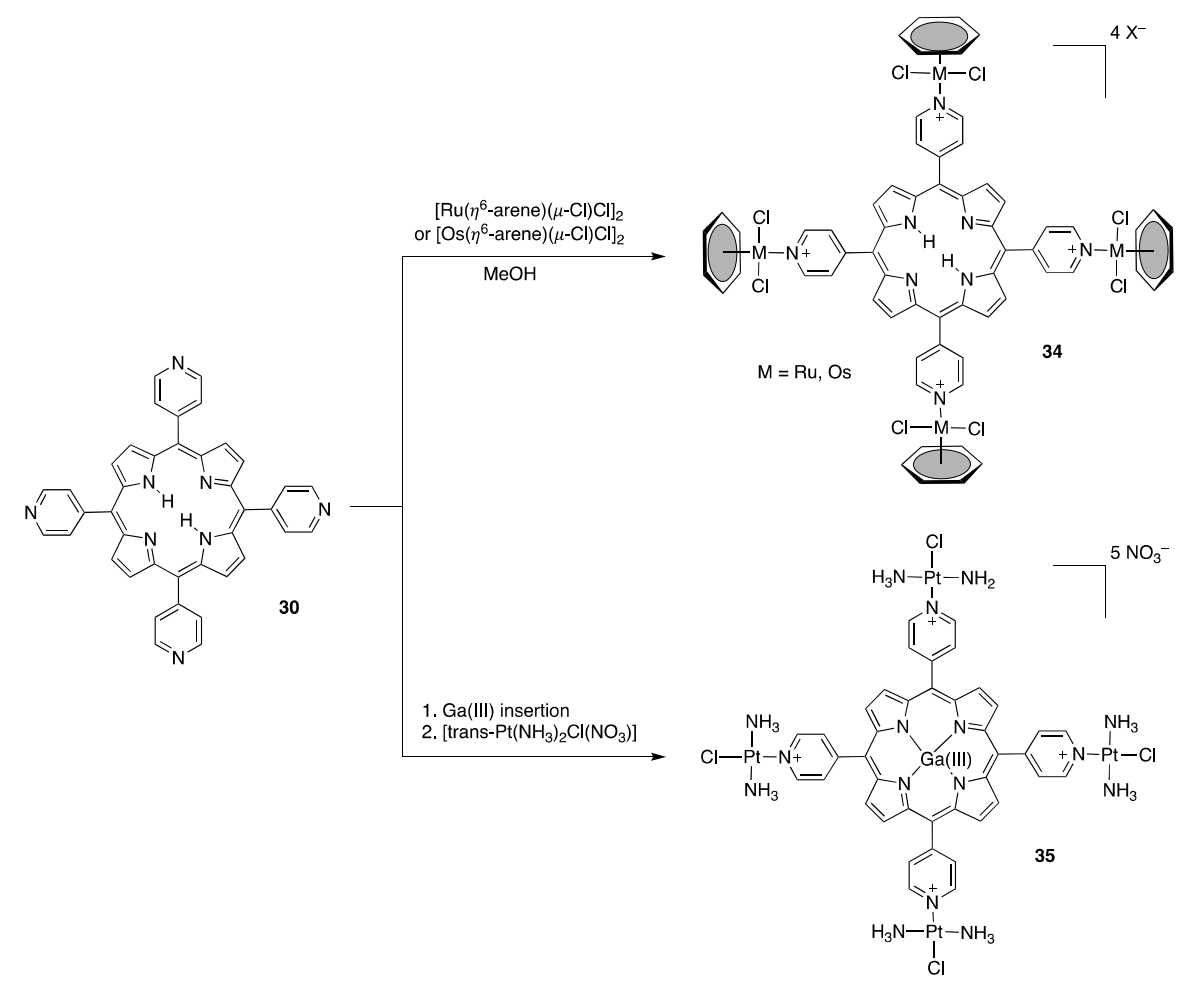

Scheme 9. M-Arene complexes of meso-tetra(4-pyridyl)porphyrin, as described by the groups of Therrien [76,77], and Odani [78].

The $\mathrm{N}$-alkylation step (standard $\mathrm{CH}_{3} \mathrm{I}$ alkylation conditions) needed to be performed after the formation of the isocyanate group to avoid unwanted $\mathrm{N}$-alkylation of the amine precursors [81]. A number of $p$-substituted phenyl derivatives allowed a wide range of functionalizations. For instance, Song et al. synthesized $A_{3} B$ pyridyl porphyrin $37 \mathbf{j}$ with the fourth aryl group bearing a $\mathrm{Pt}(\mathrm{II})$ complex linked to the hydroxyl group of the meso-phenol group by a triethylene glycol linker [82]. $N$-Alkylation of the three pyridyl groups, followed by Boc-deprotection and complexation with the $\mathrm{Pt}(\mathrm{II})$ precursor, yielded the $\mathrm{A}_{3} \mathrm{~B}$ platinum-porphyrin conjugate 37j. A similar approach was taken by the group of Alessio to synthesize water-soluble ${ }^{99 \mathrm{~m}} \mathrm{Tc}(\mathrm{I}) / \operatorname{Re}(\mathrm{I})$-porphyrin conjugates, such as 371, utilizing an amide-linked spacer between the aryl group and the ${ }^{99 \mathrm{~m}} \mathrm{Tc}(\mathrm{I}) / \operatorname{Re}(\mathrm{I})$ ion $[83,84]$. The water-soluble derivatives were purified by normal phase silica gel column chromatography $\left(\mathrm{CH}_{2} \mathrm{Cl}_{2} / \mathrm{MeOH}\right.$ mixtures). These types of compounds can also be conjugated to cancer-targeting peptides for use in cancer therapy [85]. $\mathrm{Cu}$ (II)-based acylhydrazone porphyrin-derivatives $37 \mathrm{~m}$ and 37n could be obtained using a similar strategy [86]. The group of Boyle synthesized an $A_{3} B$ porphyrin that could be further functionalized to establish an azide group [87]. The azide functionality was used in a click reaction to introduce an ${ }^{18} \mathrm{~F}$-terminated short PEG chain to generate water-soluble porphyrin 37k for PDT/PET theranostic applications [87]. After $N$-methylation of the pyridyl nitrogens, the subsequent synthetic steps required precipitation of the product using $\mathrm{Et}_{2} \mathrm{O} / \mathrm{MeOH}$ mixtures. The final products were purified by passing through a column of neutral alumina.

Gasparyan and co-workers synthesized an $\mathrm{A}_{3} \mathrm{~B}$ amphiphilic trispyridylporphyrin with one meso-aryl group carrying a long alkyl chain using a mixed aldehyde Adler condensation [88]. Quarternization of the pyridyl groups with 3-bromopropene provided the water-soluble vinyl-substituted trispyridiniumporphyrins 38 and $\mathbf{3 8 A g}$ (Figure 3 ) that were isolated by precipitation with acetone. 


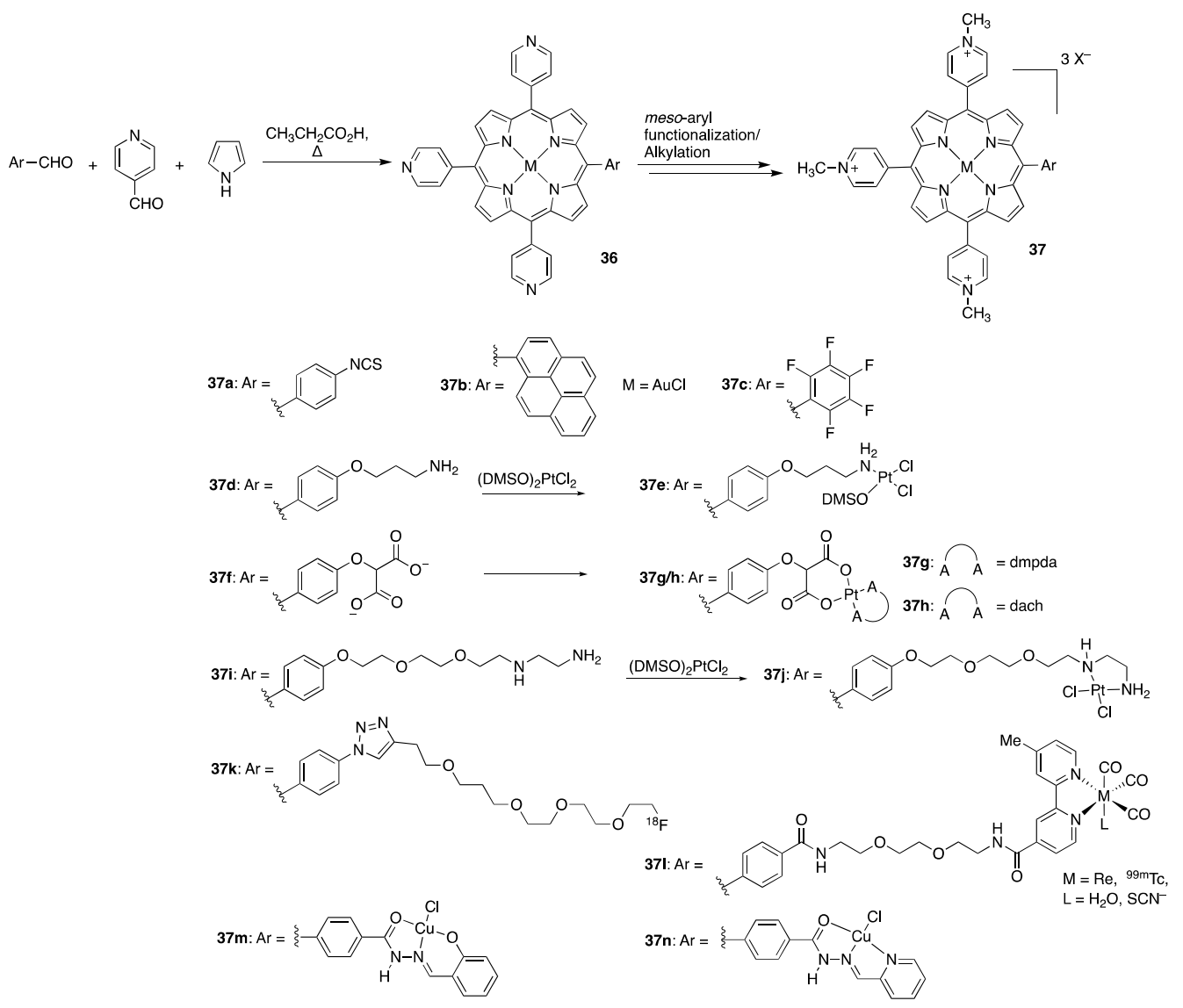

Scheme 10. $\mathrm{A}_{3} \mathrm{~B}$ tri-pyridyl porphyrins prepared by Adler synthesis and subsequent synthetic modification. dmpda $=N, N^{\prime}$-dimethyl-1,3-propanediamine, dach = 1,2-diaminocyclohexane.

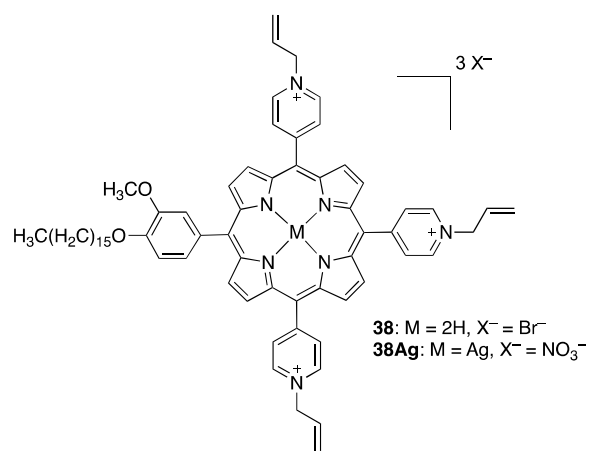

Figure 3. Molecular structure of meso-pyridinium-substituted porphyrin 38/38Ag.

Yasuda and co-workers prepared $\mathrm{AB}_{3}$ phosphorus porphyrin 39 [89]. Its axial chloro-ligands could be exchanged for simple alcohols and oligoethylene glycol chains to generate hydrophilic phosphorus porphyrins 40 and 41 . N-Alkylation of the meso-pyridyl group in 40a-40d or $\mathbf{4 1}$ then furnished water-soluble derivatives, with solubility in water of around $\sim 10 \mathrm{mM}$ for compounds 42a-42d and 43. (Scheme 11) [89]. An equivalent methodology was used to introduce axial PEG chains [90].

Using a fundamentally different strategy toward meso-pyridyl porphyrins, pyridyl substituents can be introduced to meso-brominated porphyrins by using Suzuki couplings. For instance, the group of Lindsey reported the synthesis of a series of amphiphilic hydroporphyrins prepared by Suzuki coupling of a pyridyl boronic ester with meso-bromo-chlorins or bacteriochlorins [34]. Key chlorin building 
block 45 was prepared by regioselective meso-bromination of chlorin 44 using NBS (Scheme 12) [91]. In the final step of the synthesis, the pyridyl functional group was quarternized with $\mathrm{CH}_{3} \mathrm{I}$ to furnish bacteriochlorin 46. This strategy is flexible and tolerant of a number of other substituents on the hydroporphyrin framework. Thus, chlorin 47 and bacteriochlorin 48 were prepared along analogous routes.

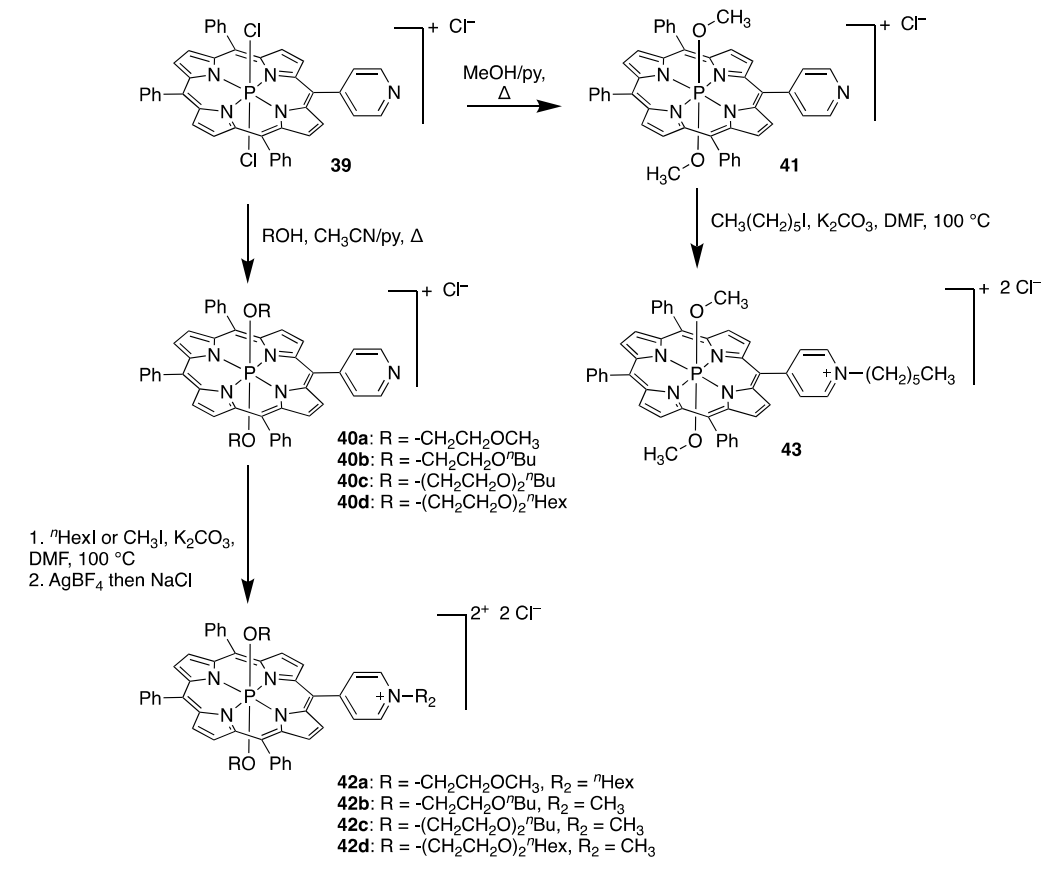

Scheme 11. Water-soluble $\mathrm{AB}_{3}$ phosphorus porphyrins, as described by the group of Yasuda [89].

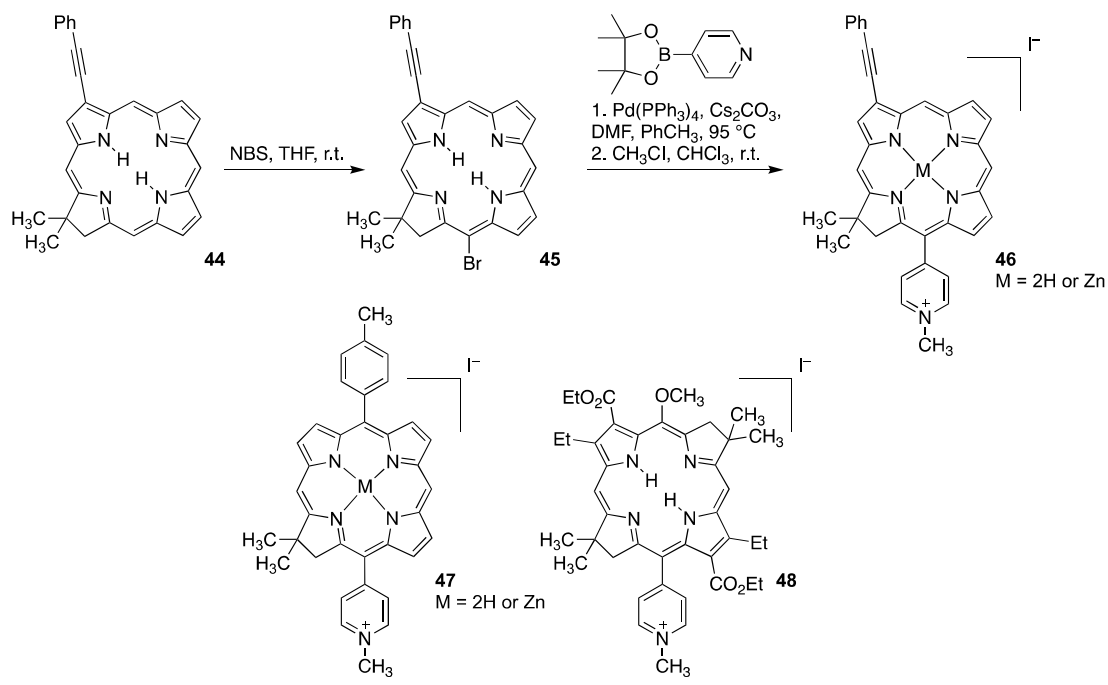

Scheme 12. Amphiphilic meso-pryridyl chlorins and bacteriochlorins, as described by the group of Lindsey [91].

In an analogous manner, Anderson and co-workers employed a Suzuki coupling strategy to introduce pyridyl functional groups to meso-dibrominated bis-acetylene linked porphyrin dimer 49 (Scheme 13) [70]. After coupling with 4-pyridinylboronic acid, both meso-pyridyl functional groups in 50 were methylated under standard conditions to afford the dicationic product $\mathbf{5 1}$. This water-soluble porphyrin dimer was purified by precipitation from $\mathrm{DMF} / \mathrm{Et}_{2} \mathrm{O}$. 


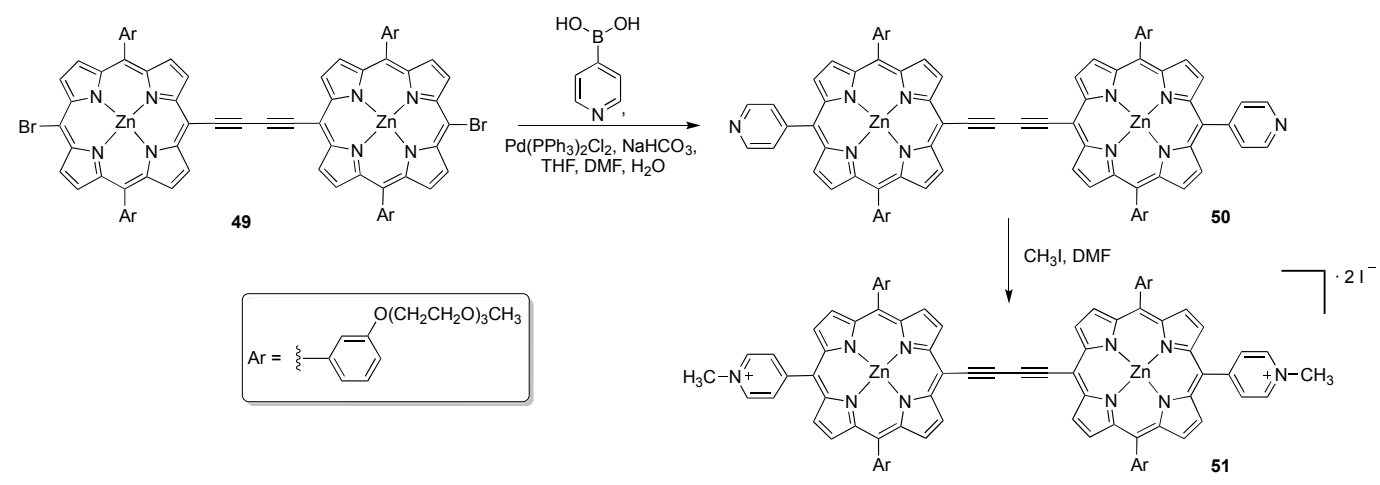

Scheme 13. Preparation of a meso-pyridinium-functionalized bis-acetylene linked porphyrin dimer, as described by the group of Anderson [70].

Anderson and coworkers also introduced pyridyl substituents to the meso-position of trans-AB porphyrins by Sonogashira coupling of meso-alkynyl porphyrin with 4-iodopyridine. The pyridyl groups were then quarternized with the electrophiles $\mathrm{CH}_{3} \mathrm{I}, 1,4$-butane sultone or 5-iodo- $N, N, N$-tri-methylpentan-1-ammonium [92-94].

\subsubsection{Other Pyridyl-Substituted Porphyrins}

Porphyrins bearing alkylated pyridinium substituents in positions not directly linked to the mesoor $\beta$-positions of the macrocycle were also prepared. For example, Marzilli and co-workers synthesized porphyrins 52 (Figure 4) with the pyridyl groups linked through sulfonamide linkages to the $p$-phenyl positions of meso-tetraarylporphyrins $[59,95]$. They investigated whether distant pyridinium groups are equally competent in mediating DNA-intercalation. Dipicolylamine (DPA) substituents could also be linked through the sulfonamide group (53), to prepare rhenium-based radiopharmaceuticals [96].

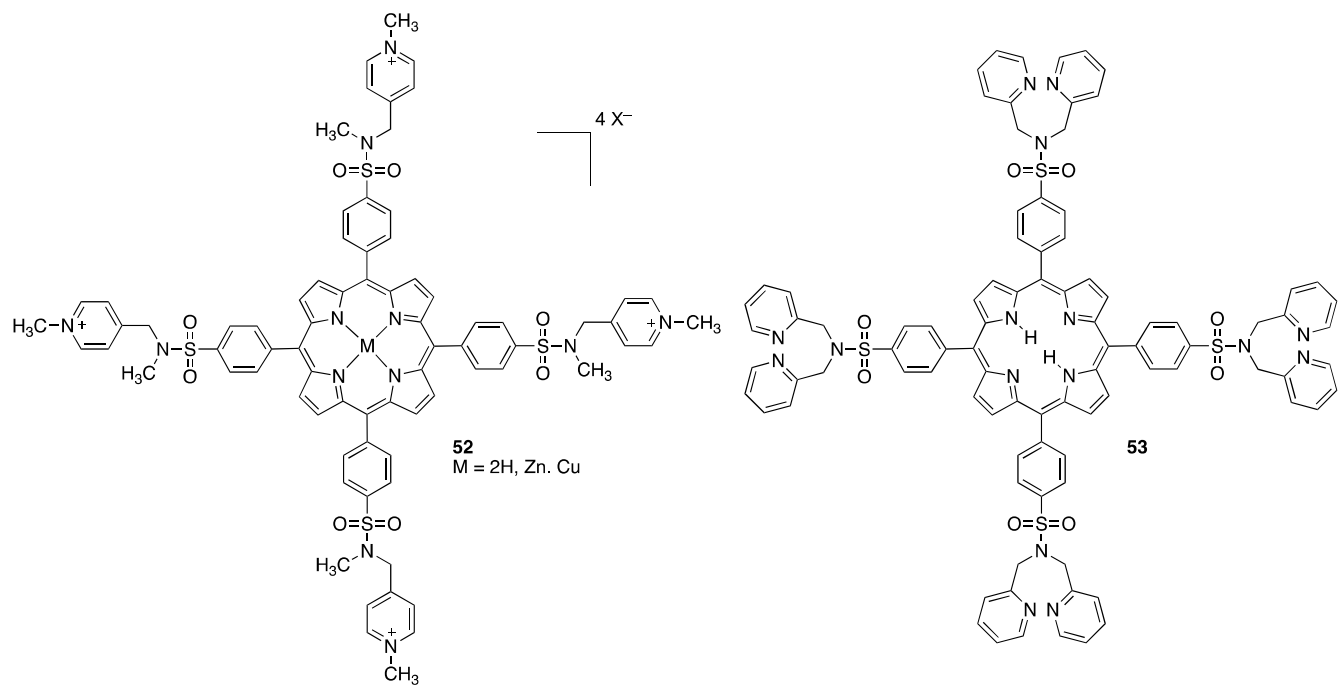

Figure 4. Molecular structures of sulfonamide-linked pyridinium/dipicolylamine-substituted porphyrins 52 and 53 .

A remarkable octapyridiniumporphyrin 55 was prepared by Prato and co-workers [97] by treatment of meso-tetrakis(2,6-bis-(bromomethyl)-4-t-butylphenyl) porphyrin 54 with $t$-butylpyridine (Scheme 14). The octapyridyl porphyrin 55 was purified by crystallization from $\mathrm{Et}_{2} \mathrm{O} / \mathrm{MeOH}$. The octacationic compound 55 was used in studies toward assemblies for light-harvesting applications. 


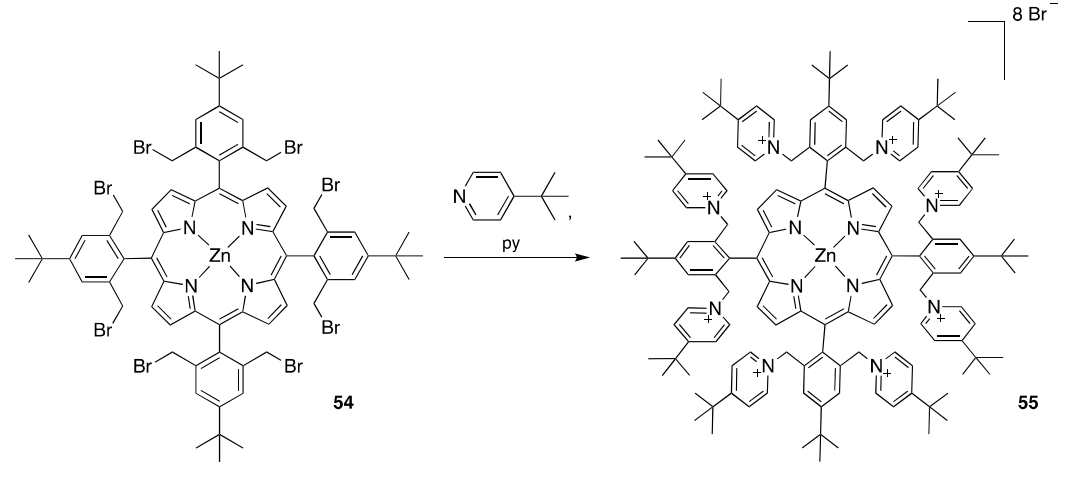

Scheme 14. An octapyridiniumporphyrin, as described by the group of Prato [97].

The introduction of pyridinium groups can also be achieved by esterification of a $\beta$-alkylester with a suitable pyridine-derivatized alcohol. Thus, cationic water-soluble ester $\mathbf{5 6}$ was prepared from chlorin e6 (11) by esterification with 2-(2-hydroxyethyl)pyridine, followed by quarternization with $\mathrm{CH}_{3} \mathrm{I}$ (cf. Scheme 4) [62]. Derivatives 56 (Figure 5) and related 13 possess sharp absorbance spectra in Tris- $\mathrm{HCl}$ buffer at $\mathrm{pH} 7.6$, indicating little aggregation of the chromophores.
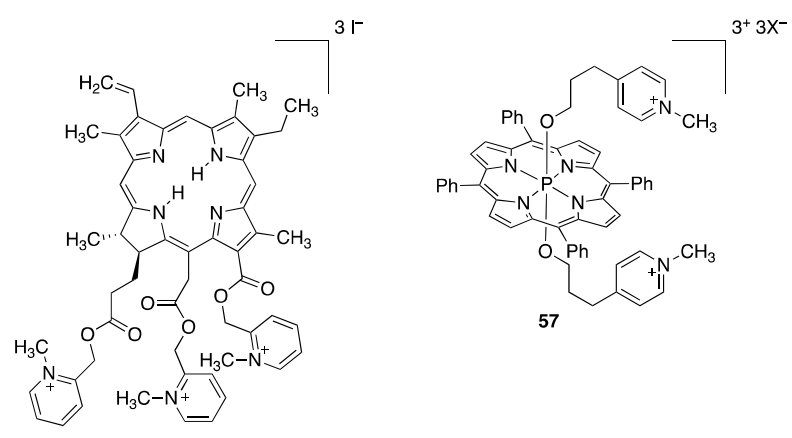

Figure 5. Molecular structures of pyridinium-substituted chlorin $\mathbf{5 6}$ and phosphorus porphyrin 57.

Pyridinium substituents have also been introduced in the axial positions of phosphorus and antimony meso-tetraphenyl porphyrins by axial exchange using a pyridine-derivatized alcohol (cf. to Scheme 11) $[89,98]$. Alkylation of the axial pyridyl moiety with a range of alkyl bromides furnished derivatives such as 57 (Figure 5), with a water-solubility of $\sim 3 \mathrm{mM}$ [89].

\subsection{4. meso-Imidazolium Porphyrins}

The synthesis of porphyrins carrying $N$-alkylated meso-imidazolyl functionalities represents another strategy for the preparation of cationic porphyrins [99]. Lindsey and co-workers prepared porphyrins with one or two meso-imidazolyl groups by starting from imidazole-functionalized dipyrromethane precursors $[100,101]$. Mono-imidazolyl porphyrin 58 was alkylated with various alkylating reagents. The resulting imidazolium porphyrins were studied for their use in photodynamic therapy. The zwitterionic imidazolium sulfonate porphyrin $60 \mathrm{Zn}$, for example, is the product obtained when 1,4-butane sultone was used as the alkylating reagent (Scheme 15) [100]. 


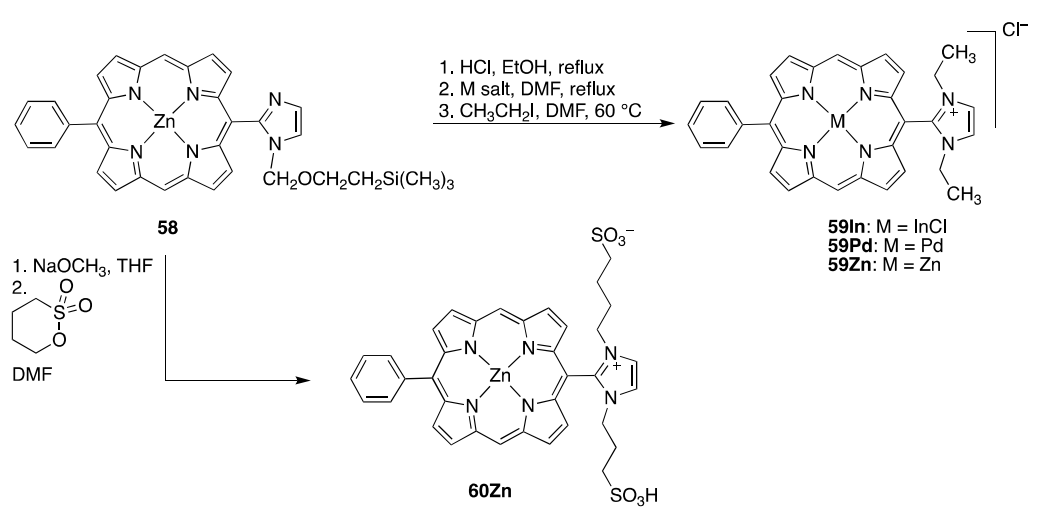

Scheme 15. meso-Imidazolium porphyrins, as described by the groups of Lindsey and Hamblin [100,101].

\section{Water-Soluble Porphyrins Bearing Anionic Substituents}

\subsection{Porphyrins with Carboxylate Functional Groups}

Many naturally occurring porphyrins contain acetic acid or propionic acid side chains [102]. With increasing number of acid side chains, their solubility in aqueous solution increases, with the uroporphyrins being freely soluble, particularly in solutions of basic pH (Scheme 16) [102].

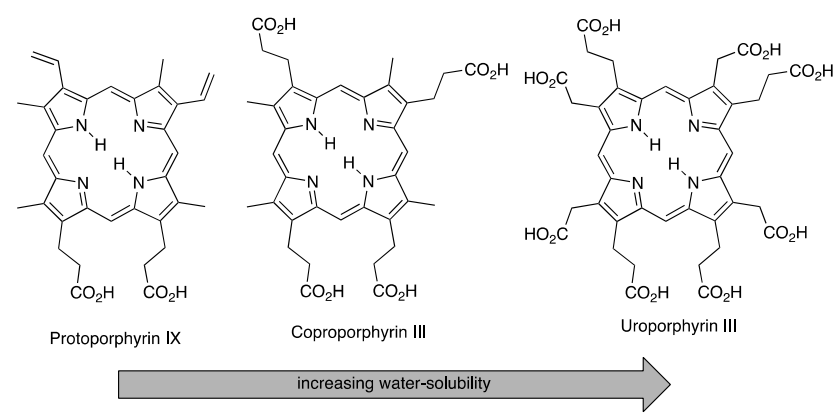

Scheme 16. Increasing water-solubility of the naturally occurring porphyrins with increasing number of carboxylic acid functionalities.

This suggests that the introduction of carboxylic acid functional groups to the periphery of porphyrins might be an effective way of furnishing water-soluble derivatives. This is, in fact, also observed. To simplify the purification of the porphyrins, the carboxylate groups are often masked throughout the synthesis as esters and are revealed by saponification in the final step.

meso-Tetrakis(4-carboxyphenyl)porphyrin, and its ester, are well known, and readily synthe-sized by condensation of the corresponding aldehydes with pyrrole [103-105]. They are also commercially available [58]. Carboxylate groups may also be introduced to the porphyrin by starting with more elaborate building blocks containing esters. Classic carboxylated meso-aryl porphyrins, such as meso-tetrakis(4-carboxyphenyl)porphyrin, have been prepared by Adler synthesis with ester-substituted benzaldehydes followed by saponification of the esters [40]. Tetracarboxylated palladium porphyrin 62 was prepared thusly, whereby the carboxylate moieties were revealed by standard ester saponification conditions after the palladium insertion step (Scheme 17) [106].

An introduction of esters to the $\beta$-positions of a porphyrin from ester-substituted building blocks is also possible, as illustrated by the synthesis of carboxylated benzoporphyrins starting from an ester-functionalized isoindole (Scheme 18) [107]. A retro-Diels-Alder reaction of 63 with concomitant saponification of the methyl esters afforded octacarboxylate 64. Protonation provided the octaacid 
65 that also precipitated under these conditions. The water-solubility of the sodium salt 64 was determined to be $0.111 \mathrm{M}$ [107].

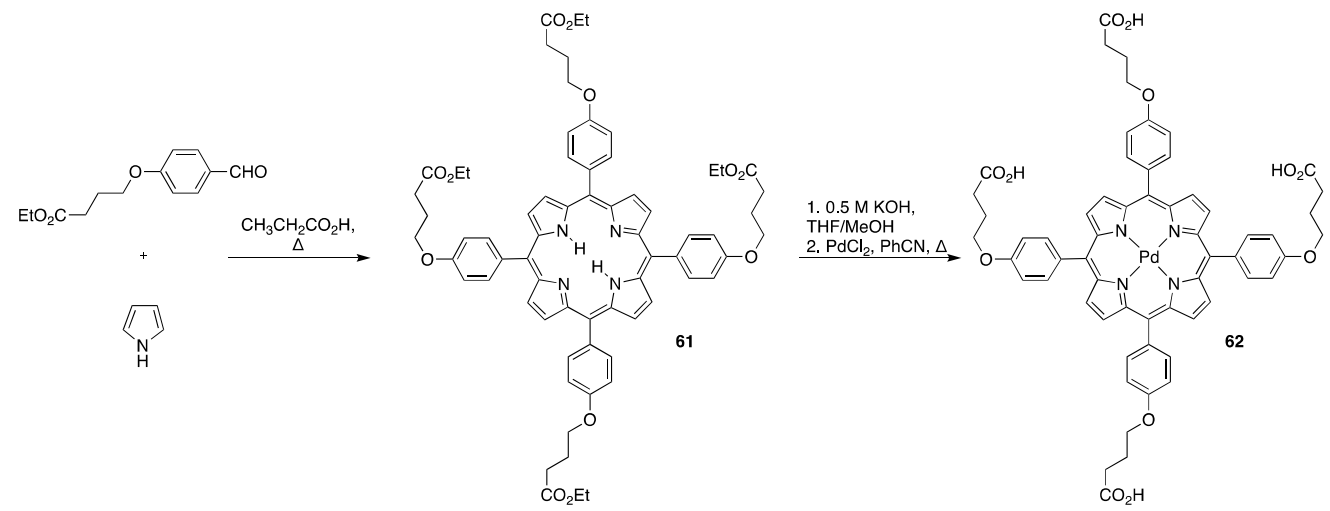

Scheme 17. Carboxylated meso-aryl porphyrins, as described by the group of Skondra [106].

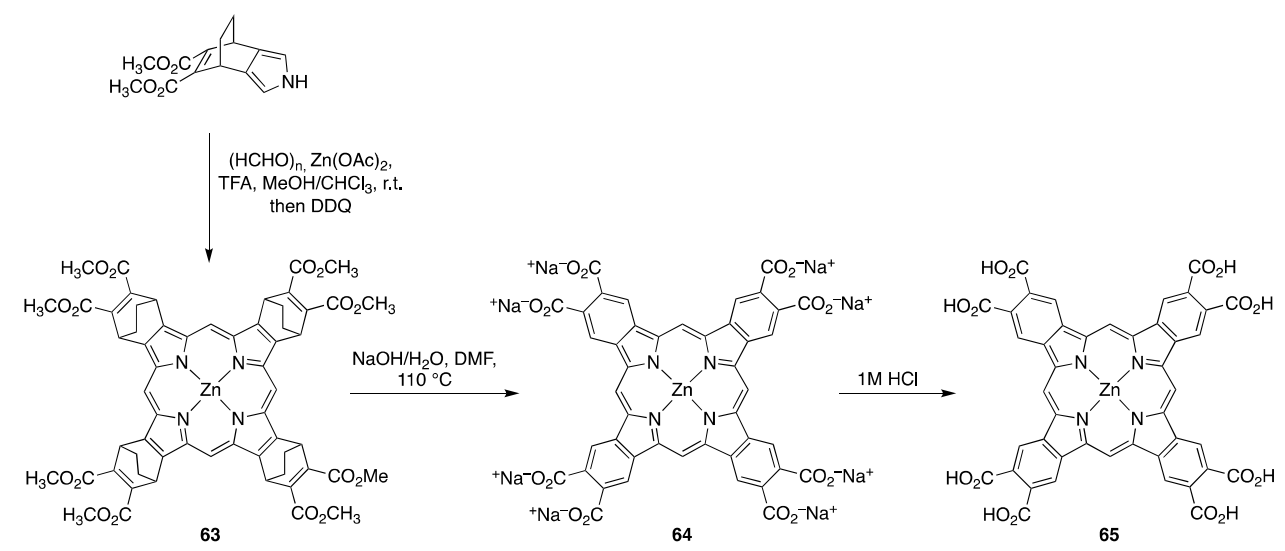

Scheme 18. Carboxylated benzoporphyrins, as described by the group of Sugimoto [107].
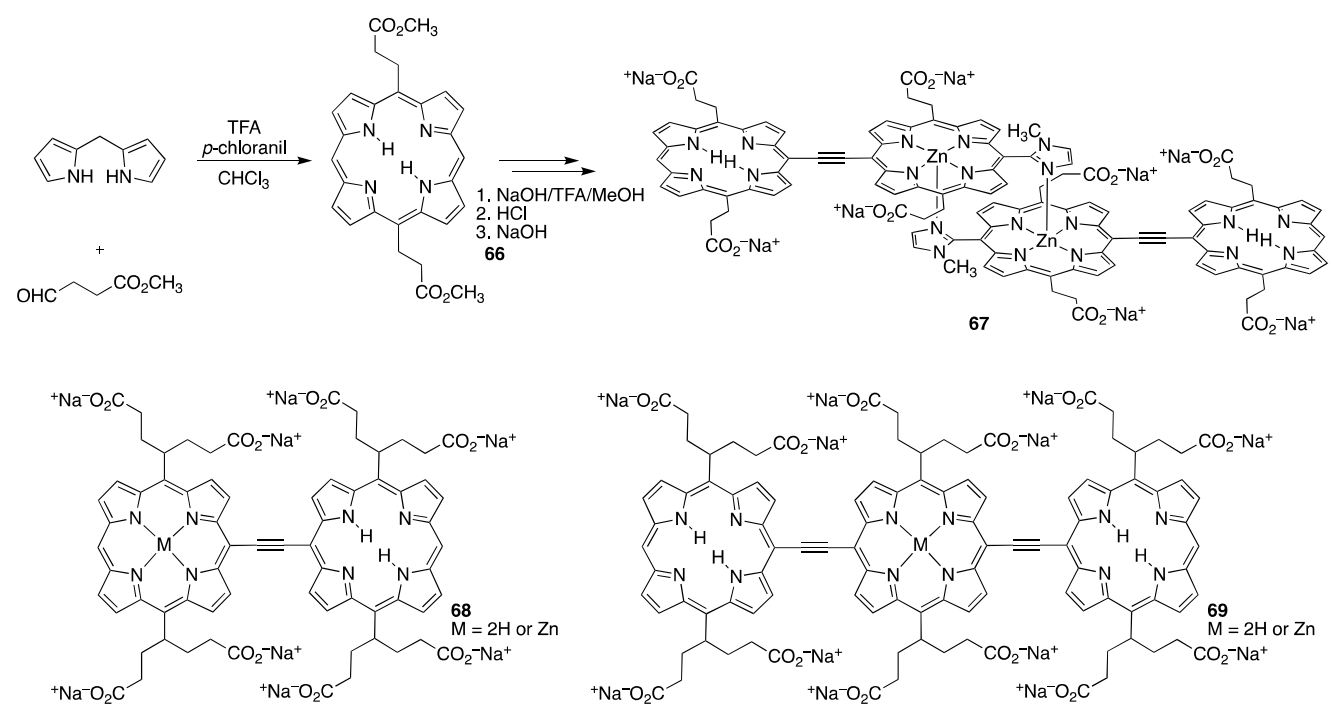

Scheme 19. Porphyrin dimers and trimers bearing carboxylate groups in the meso-positions, as described by the group of Kobuke [108,109].

Water-soluble acetylene-linked bis(imidazolylporphyrins) were prepared from starting materials bearing protected acid functionalities. Thus, ester-functionalized aldehyde and dipyrromethane were 
condensed and oxidized to synthesize porphyrin 66 bearing ester-terminated alkyl chains in the meso-positions. The ester moieties were carried through the entire synthesis of the porphyrin dimer and the carboxylates were only deprotected in the last step (Scheme 19) [108]. Using this strategy, bulky bis(carboxylethyl)methyl substituents could also be introduced to the meso-positions early in the synthesis to furnish dimers of type 68 and trimers of type 69, which showed less aggregation in water [109].

Lindsey and co-workers prepared carboxylated trans-AB porphyrins using a $2+2$ dipyrromethane condensation strategy, using dipyrromethane 70 carrying a protected 2,4,6-triester-subsituted meso-phenyl group (Scheme 20) [110]. The condensation of $\mathbf{7 0}$ and counterpart $\mathbf{7 1}$ in the presence of zinc afforded the zinc-porphyrin triester $\mathbf{7 2}$, which could be saponified to afford the tricarboxylic acid 73a. Along an analogous route, trans-AB porphyrins $73 \mathrm{~b}$ and $73 \mathrm{c}$ bearing bioconjugatable groups at the meso-position opposite the solubilizing groups were prepared.
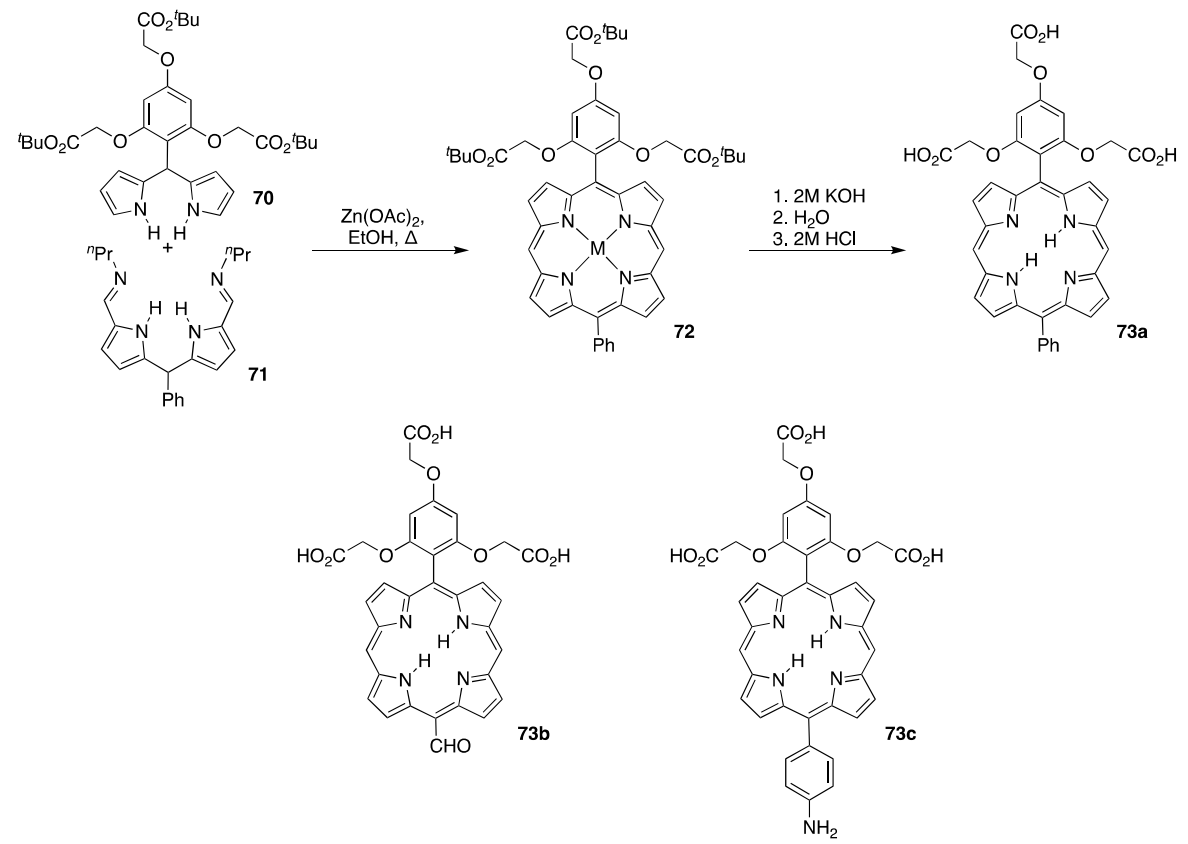

Scheme 20. Carboxylated trans-AB porphyrins, as described by the group of Lindsey [110].

To maximize the number of carboxylic acid groups introduced, carboxylic acid ester-terminated dendritic components can be utilized, often bound to the porphyrin through amide linkages. For instance, treatment of tetrarylporphyrin acid chloride $\mathbf{7 4}$ with dimethyl iminodiacetate or its second generation dendrimer analogue, followed by saponification of the esters, afforded the polyacid porphyrins $\mathbf{7 5 a}$ or $\mathbf{7 5 b}$, respectively (Scheme 21) [111]. They were purified by precipitation and filtration.

1,4,7,10-Tetraazacyclododecane-1,4,7,10-tetraacetic acid (DOTA) groups were also introduced to porphyrins through amide linkers on one or more meso-aryl groups of a porphyrin. These compounds were used as multimodal heterometallic complexes for MRI/PET imaging applications [112,113].

meso-Tetrakis(4-hydroxyphenyl)porphyrin (76) is a versatile starting material for the synthesis of hydrophilic derivatives since the $p$-phenolic oxygens can react with a variety of solubilizing groups. $\mathrm{A}_{4}$-Porphyrin $\mathbf{7 6}$ is synthesized through the Adler procedure, generally as its 4-methoxy derivative, that can be purified and handled easily. It is subsequently deprotected using $\mathrm{BBr}_{3}$ [14] (see also below, Schemes 23 and 47).

Using tetraphenol 76, Chen and co-workers also synthesized porphyrins bearing dendritic carboxylate groups, albeit their synthesis was less convergent than that of Mukhtar and co-workers [114], since the dendrimer generations were built up on the porphyrin core. Thus, $\mathbf{7 6}$ was converted to polyamine-derivatized porphyrin 77 in three steps. Reaction of the amines in $\mathbf{7 7}$ with 
bromoacetic acid ethyl ester provided the protected porphyrin $\mathbf{7 8}$, followed by hydrolysis with TFA to give the free acid 79 (Scheme 22) [114] that was isolated by precipitation (addition of a MeOH solution of 79 to $\mathrm{Et}_{2} \mathrm{O}$ ).
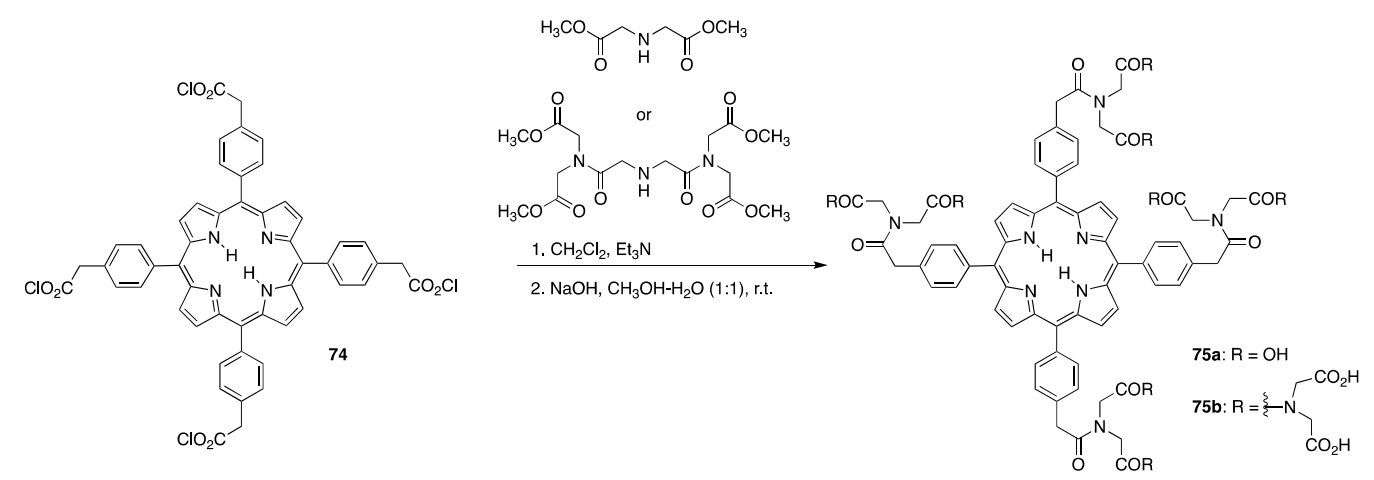

Scheme 21. Dendritic carboxylated porphyrins, as described by the group of Mukhtar [111].

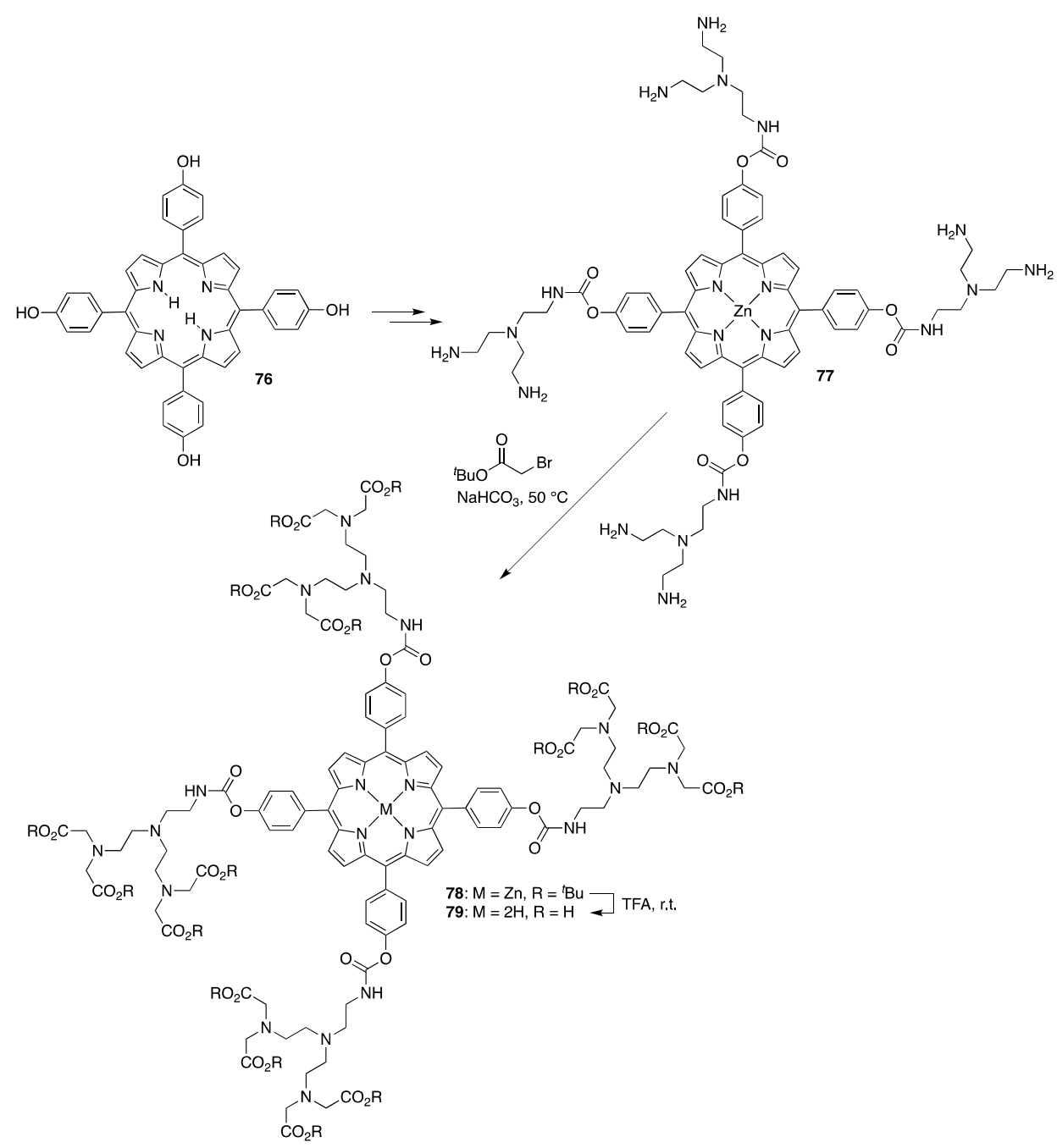

Scheme 22. Dendritic polycarboxylated porphyrins, as described by the group of Chen [114].

Alkylation strategies have also been employed for the introduction of carboxylates. For instance, various carboxylated core-modified porphyrins were prepared by $O$-alkylation of the phenolic oxygens of a meso-4-hydroxyphenyl-substituted core-modified dithiaporphyrin. Like their aza-analogues, 
the requisite core-modified porphyrins were synthesized with a methyl-ether protecting group in the $p$-position of one or more phenyl groups and deprotected using the standard $\mathrm{BBr}_{3}$ method. The phenolic oxygens were then alkylated with ethyl bromoacetate. Saponification of the installed esters furnished the dithiaporphyrin $\mathbf{8 1}$ bearing carboxylic acid functional groups (Scheme 23) [115].
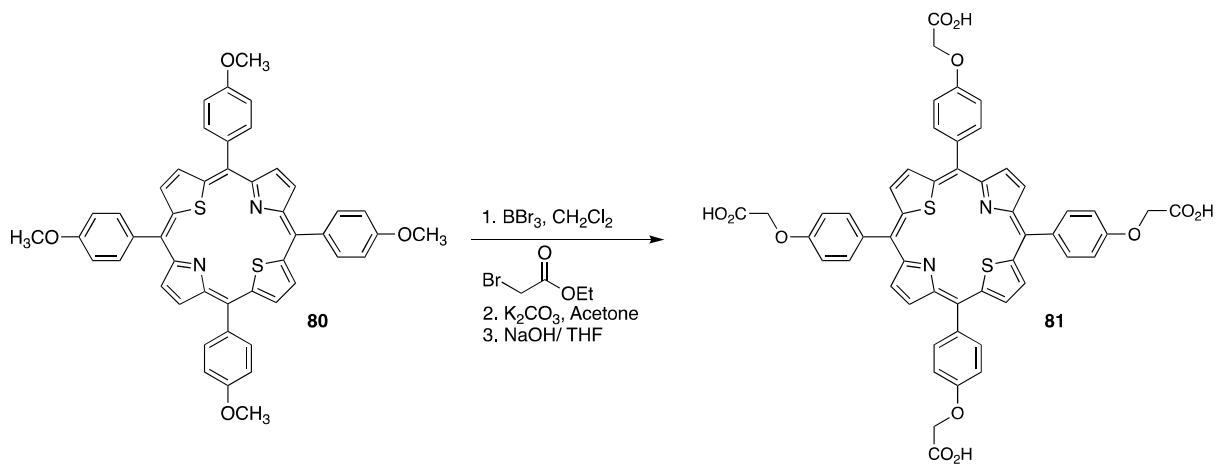

Scheme 23. Core-modified carboxylated porphyrin, as described by the group of Detty [115].

Diethylenetriamine- $N, N, N^{\prime \prime}, N^{\prime \prime}$-tetraacetate (DTTA) groups were also introduced to meso positions of a porphyrin by alkylation of meso-tetrakis(bromomethylphenyl)porphyrin [116]. The DTTA groups were introduced as protected $t$-butyl esters and deprotected using standard conditions. The water-soluble products were purified by sequential cation and anion exchange chromatography.

Prato and co-workers also used an alkylation strategy to synthesize octacarboxylated porphyrin 84, starting from a tetra(bromomethyl)-substituted porphyrin. Alkylation of porphyrin 82 with diethyl malonate afforded the tetramalonic ester-derivatized porphyrin $\mathbf{8 3}$, which was saponified to free the eight carboxylate moieties (Scheme 24) [97]. Octacarboxylate 84 precipitated under the saponification conditions and was isolated by filtration to afford the pure product.
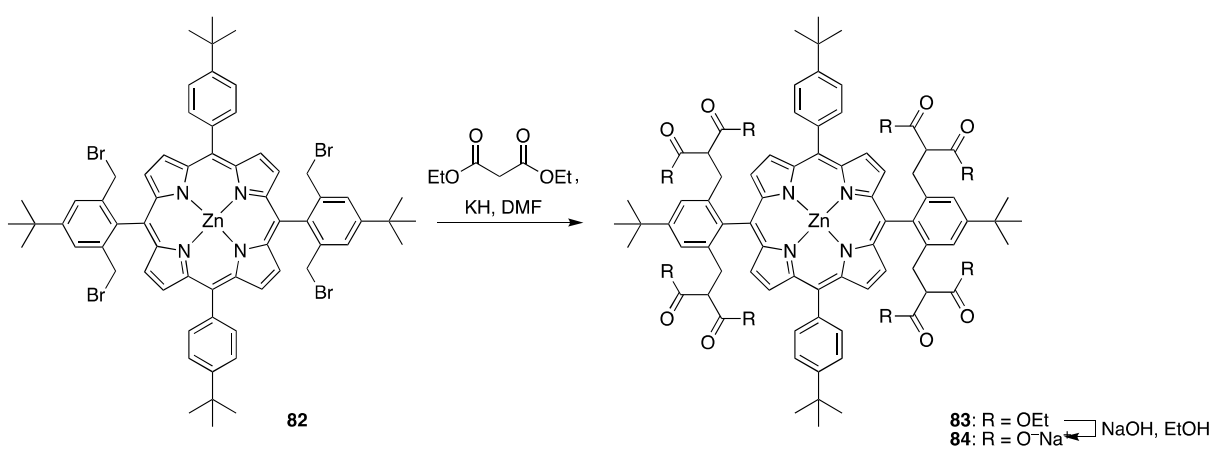

Scheme 24. Octacarboxylated porphyrin $\mathbf{8 4}$, as described by the group of Prato [97].

Carboxyphenyl substituents can also be directly introduced to the meso-positions of synthetic chlorins and bacteriochlorins by Suzuki coupling of suitable meso-bromo-substituted porphyrins with boronic esters derived from benzoic acid. Using the same Suzuki coupling approach that was used to introduce pyridyl substituents to the meso-position (cf. Scheme 12), chlorins 85, 86 and the bacteriochlorin 87 (Figure 6) were prepared [91]. The carboxylate functionality was introduced in the free acid form, eliminating the need for the utilization of protecting groups.

As well starting from meso-brominated precursors, the group of Anderson used a Sonogashira coupling strategy to functionalize the meso-positions of a PEGylated porphyrin dimer with carboxylate groups. meso-Dibromoporphyrin dimer 49 was coupled with 5-ethynyl-1,3-benzenedicarboxylic acid to form the tetracarboxylated water-soluble porphyrin dimer 88 (Scheme 25) [70]. Again, it is noteworthy that the acid functionality was introduced in unprotected form. 


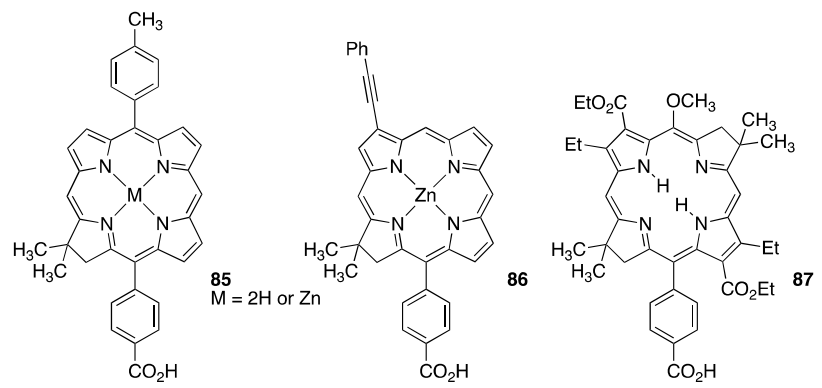

Figure 6. Molecular structures of meso-carboxyphenyl-substituted chlorins 85 and 86, and bacteriochlorin 87 .
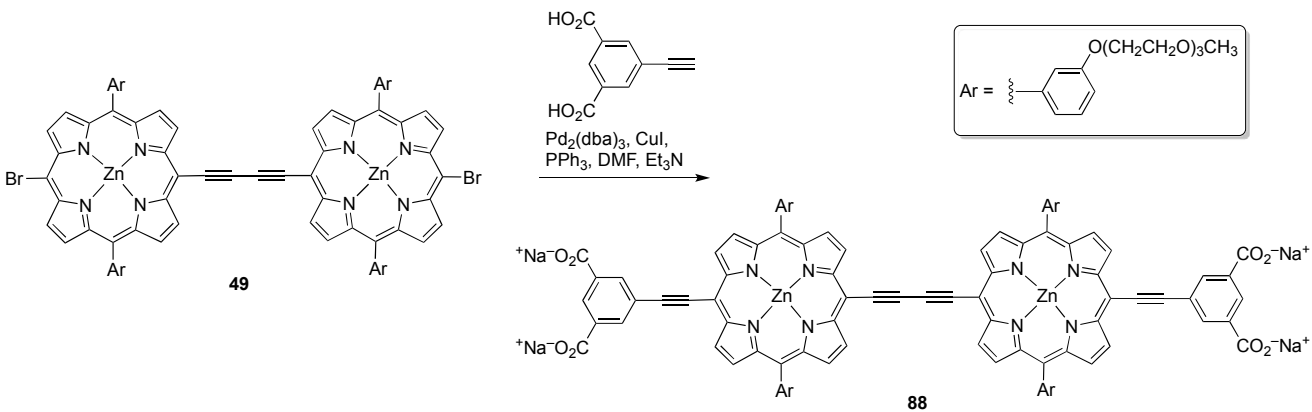

Scheme 25. Carboxylated bis-acetylene linked porphyrin dimers, as described by the group of Anderson [70]. dba = dibenzylacetone.

Functionalization of the $\beta$-position of bacteriochlorins with carboxyphenyl groups was also achieved by Suzuki coupling, albeit this method required the use of protected boronic ester carboxylates [117]. Thus, $\beta$-dibromoporphyrin 89 was functionalized using the boronic ester of the $t$-butyl ester-protected 3,5-carboxyphenyl substituents (Scheme 26). The protecting groups were removed at the last step of the synthesis by acid treatment. Furthermore, the option for bioconjugation was demonstrated in these systems by Suzuki coupling of a meso-bromobacteriochlorin, generated by regioselective bromination of the parent bacteriochlorin, to produce hydrophilic tetracarboxyl-bacteriochlorin 94 [117].

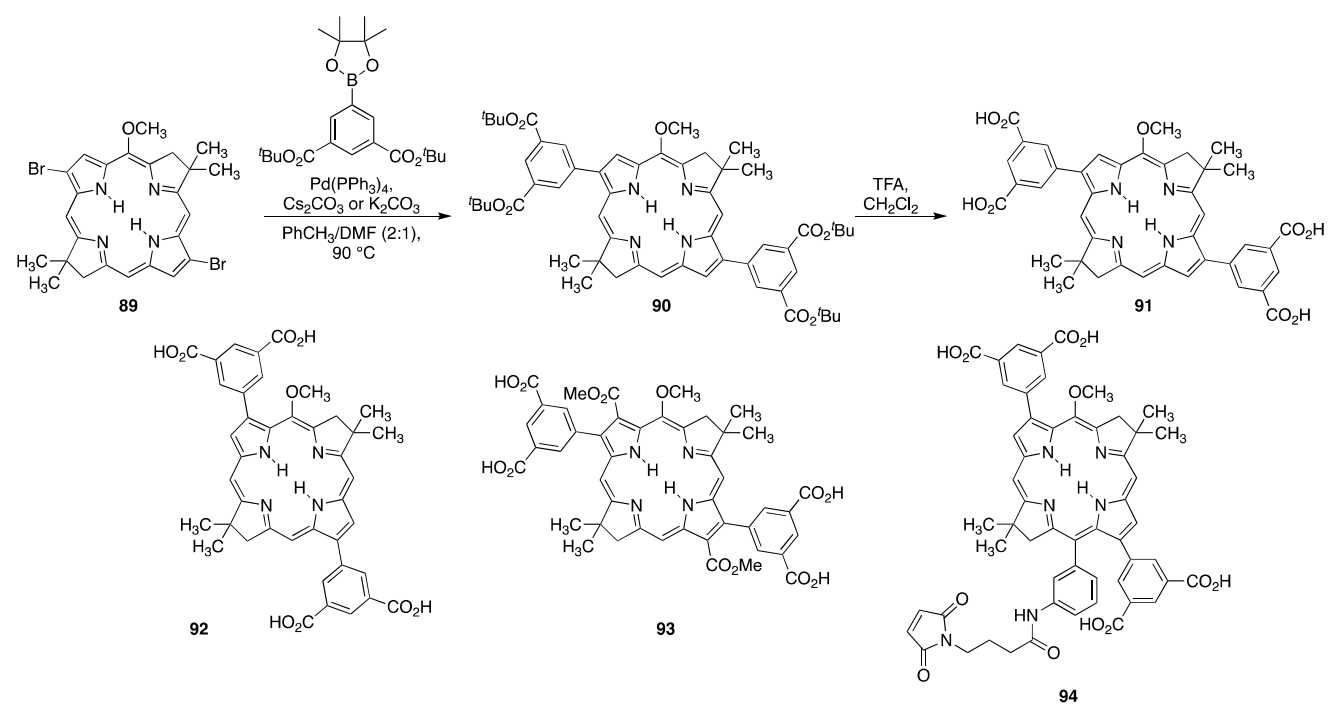

Scheme 26. Tetracarboxybacteriochlorins, as described by the group of Lindsey [117]. 


\subsection{Sulfonated Porphyrins}

Sulfonation of meso-tetraphenylporphyrin proceeds regioselectively at the para-positions of the meso-phenyl rings [118]. This reaction led to the earliest examples of water-soluble meso-tetraaryl-porphyrins [40]. A number of sulfonated $\mathrm{A}_{4}$ porphyrins were prepared by direct sulfonation methods [40], and are commercially available [58]. However, this solubilization strategy has drawbacks, not the least of which are the harsh reaction conditions (conc. $\mathrm{H}_{2} \mathrm{SO}_{4}, \Delta$ ) required for the sulfonation step, and the difficulty in purifying the target compound. On the other hand, sulfonation readily leads to the solubilization of porphyrins in aqueous media. Interestingly, the porphyrin is protonated during the sulfonation step and is thus protected by the dicationic charge from getting sulfonated at the $\beta$-positions along an electrophilic aromatic substitution pathway, in contrast with the regioselective $\beta$-sulfonation of the less basic corroles using chlorosulfonic acid [119-121].

One particular challenge faced by using sulfonation procedures is the incorporation of other functional groups since they may be incompatible with the harsh sulfonation conditions. The sulfonation step is often employed directly after porphyrin formation, then subsequent modification of the porphyrin is performed. The drawback of this strategy is the difficulty in handling and purification of the sulfonated porphyrins.

Despite these disadvantages, the traditional direct sulfonation method was employed by Pillai and co-workers to regioselectively introduce sulfonate groups to the meso-p-phenyl positions of $N$-confused porphyrins (Scheme 27) [122]. Sulfonation of $\mathrm{N}$-confused porphyrin 95 by treatment with $\mathrm{H}_{2} \mathrm{SO}_{4}$ at elevated temperature over several hours afforded the tetrasulfonated porphyrin $\mathbf{9 6}$ that was tested as a photosensitizer for PDT [122]. The product was purified by precipitation and continuous Soxhlet extraction with $\mathrm{MeOH}$. No further functionalizations of this porphyrin derivative were reported.

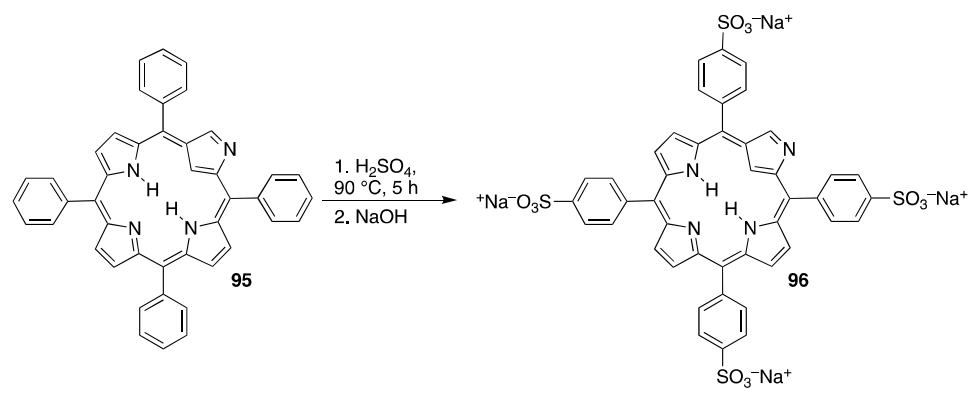

Scheme 27. Sulfonated N-confused porphyrin, as described by the group of Pillai [122].

Likewise, asymmetric meso-aryl porphyrins were also subjected to sulfonation reactions. For instance, $\mathrm{A}_{3} \mathrm{~B}$ porphyrin meso-trisphenyl-4-pyridylporphyrin, made by mixed aldehyde condensation, could be trisulfonated using oleum at $80^{\circ} \mathrm{C}$ [123]. The pure product was obtained by precipitation and centrifugation after neutralization of the acid. The pyridyl moiety could then be functionalized with a platinum complex for study as a tumor targeting photosensitizer. The group of Lippard prepared the $\mathrm{A}_{3} \mathrm{~B}$ porphyrin meso-trisphenyl-(2,6-nitrophenyl)porphyrin 97 (Scheme 28). Reduction of the nitro group afforded the 2,6-diaminophenyl porphyrin $\mathbf{9 8}$ that was subjected to sulfonation. The water-soluble product 99 was purified and isolated by reverse phase chromatography (RP-18). The purified free amine could then be functionalized with DPA for its use as a $\mathrm{Zn}^{2+}$ chemosensor [124]. Furthermore, the manganese complex of $\mathbf{1 0 0}$ was prepared and used as a dual function contrast agent for the fluorescence imaging of $\mathrm{Zn}^{2}$ and MRI in biological contexts [124].

As the previous examples have shown, some functionalities tolerate the sulfonation conditions. Surprisingly, this is also the case for isoindoline nitroxide-functionalized $\mathrm{A}_{3} \mathrm{~B}$ porphyrin 101. All phenyl substituents could be sulfonated by treatment with $\mathrm{H}_{2} \mathrm{SO}_{4}$ with retention of the isoindoline nitroxide (Scheme 29), albeit the yield for the water-soluble final product 102 was low $(\sim 30 \%)$ [125]. 

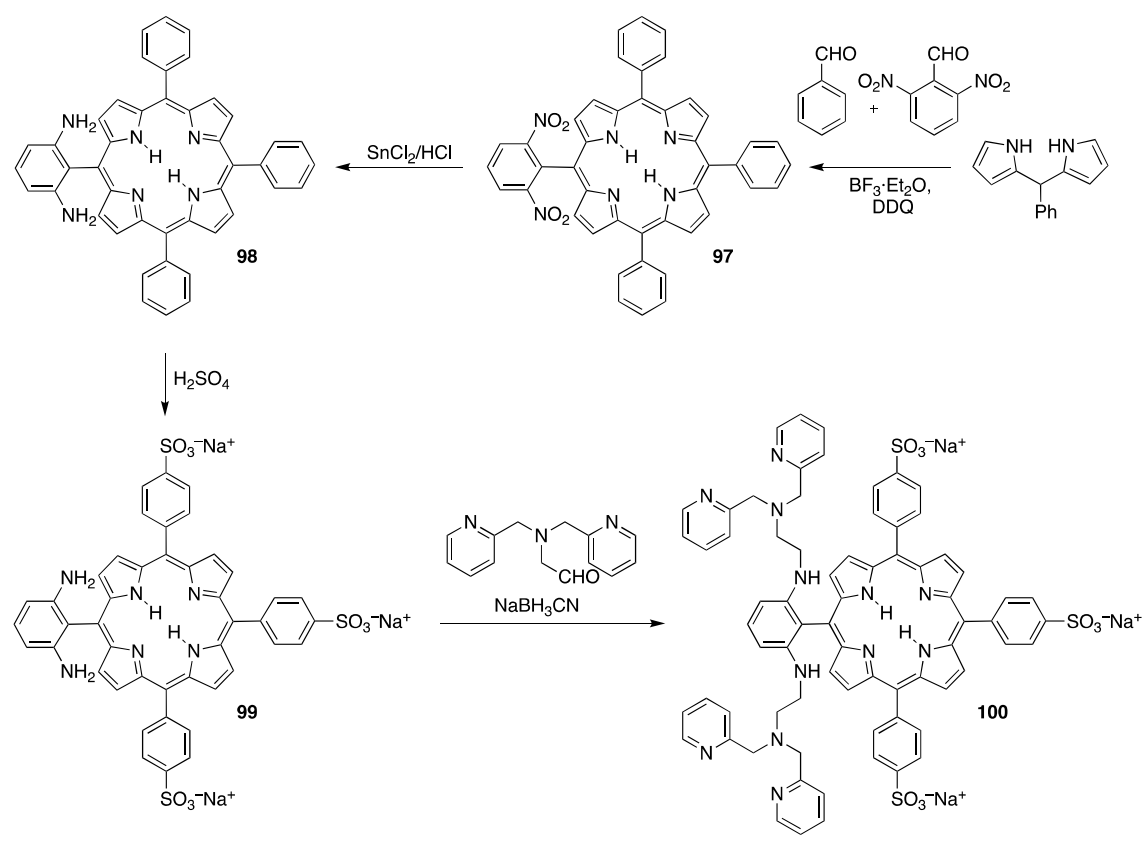

Scheme 28. Sulfonated $\mathrm{A}_{3} \mathrm{~B}$ porphyrin bearing DPA substituents for fluorescence sensing of $\mathrm{Zn}^{2+}$, as described by the group of Lippard [124].

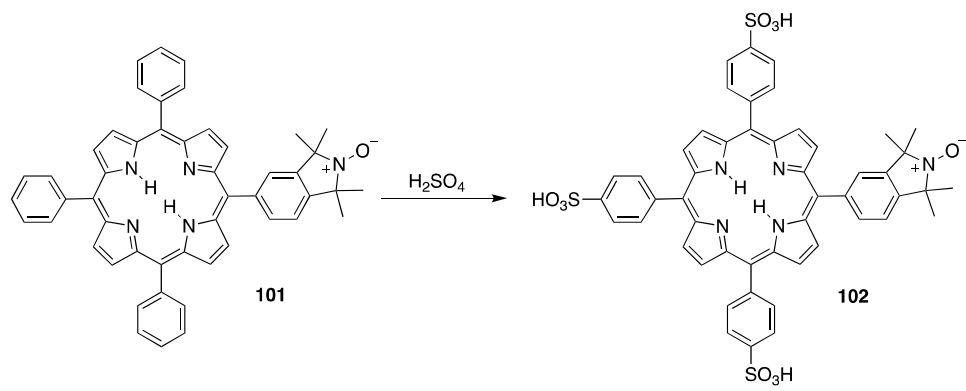

Scheme 29. Sulfonated isoindoline nitroxide-functionalized $A_{3} B$ porphyrin, as described by the group of Yang [125].

A chlorosulfonation method has been used for the introduction of sulfonic acid groups to a number of halogenated meso-aryl porphyrins by the group of Wyatt and co-workers (Scheme 30) [126]. Treatment of chlorinated porphyrin 103, for example, with chlorosulfonic acid afforded chlorosulfonation product 104 that was hydrolyzed by suspension in $\mathrm{H}_{2} \mathrm{O}$ to provide the corresponding sulfonic acid product 105. Alternatively, the chlorosulfonate could also be converted to sulfonamide derivatives by reaction with amines [126]. The corresponding chlorin and bacteriochlorin 106 and 107, respectively, were made by diimide reduction of the sulfonated porphyrin 105, and were tested as photosensitizers for the PDT of tumors (Scheme 30) [127].

The attachment of sulfonated groups to the $\beta$-positions of a tetrapyrrolic macrocycle is an alternative method toward the generation of hydrophilic sulfonated derivatives. This approach was applied to the generation of alkylsulfonated bacteriochlorins [128]. For example, sulfonated bacterio-chlorophyll derivatives were prepared by reaction of Pd-bacteriopheophorbide (108) with homo-taurine (Scheme 31) [128]. Treatment of either $\mathbf{1 0 9}$ or the sulfo-NHS ester $\mathbf{1 1 0}$ with a second equivalent of homotaurine also yielded the bis-sulfonated product 111 (with the trisulfonated compound arising from imine formation with the $\beta$-acetyl group as a minor product). Bacteriochlorin 112M could also prepared using a similar procedure using taurine as the nucleophile. All of the sulfonated derivatives were found to possess high solubility in water (up to $40 \mathrm{mg} / \mathrm{mL}$ ) [129]. 
The products were either purified by HPLC (MeOH/phosphate-buffer solvent systems) or by silica gel chromatography $\left(4: 1 \mathrm{CHCl}_{3}: \mathrm{MeOH}\right)$.

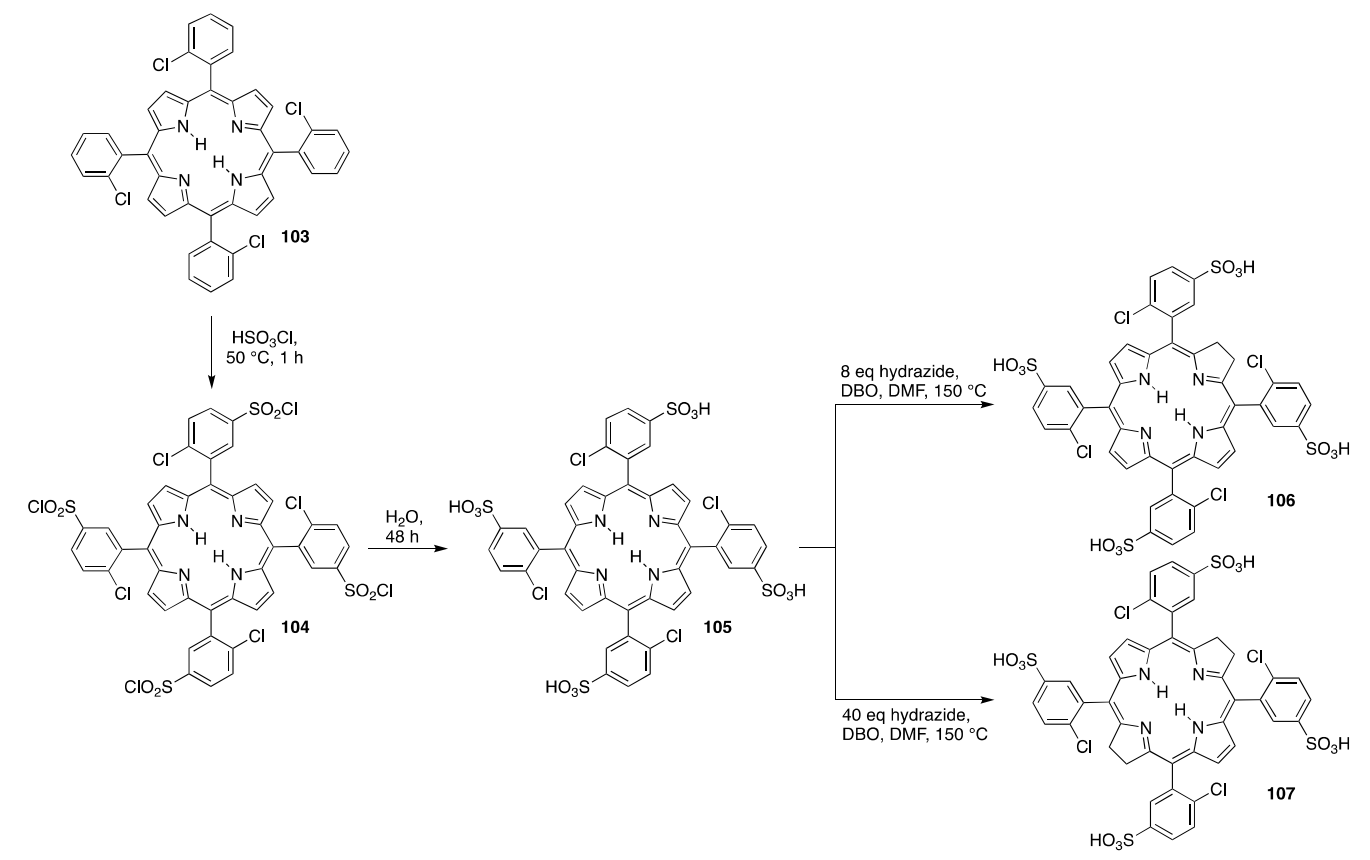

Scheme 30. Chlorosulfonated porphyrins and their hydrolysis and reduction products, as described by the group of Wyatt [126]. DBO = 1,4-diazobicyclo[2.2.2]octane.

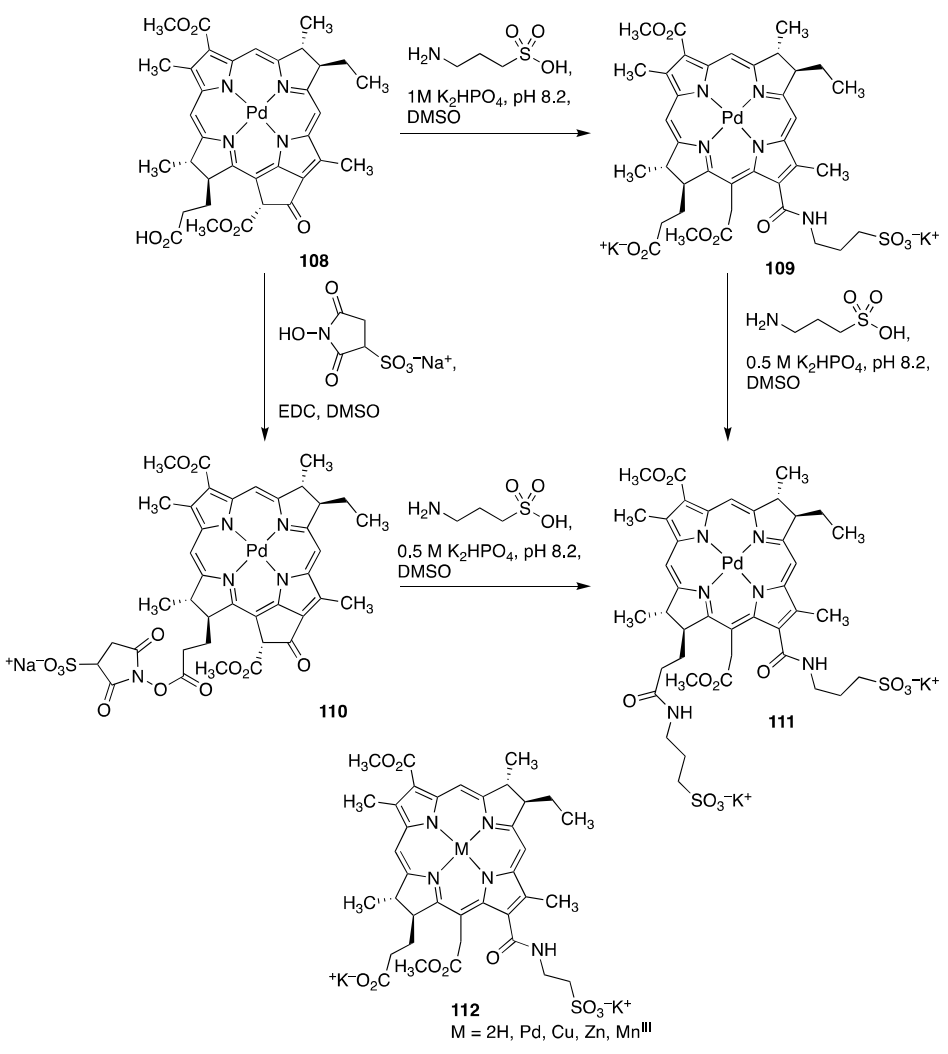

Scheme 31. Sulfonated Pd-bacteriopheophorbide, as described by the group of Scherz [129]. EDC = 1-ethyl-3-(3-dimethylaminopropyl)carbodiimide. 
Sulfonate functionalities may also be introduced at a late stage in the porphyrin synthesis by transition metal-mediated cross-coupling strategies. For instance, Anderson and co-workers introduced sulfonate groups to the meso-positions of a meso-brominated PEGylated conjugated porphyrin dimer using a Suzuki coupling with a sulfonated arylboronic acid, a strategy similar to the introduction of pyridine functionalities described above (cf. Scheme 13) [70]. The tetrasulfonated porphyrin dimer 113 (Figure 7) was purified using semi-preparative reverse-phase HPLC.

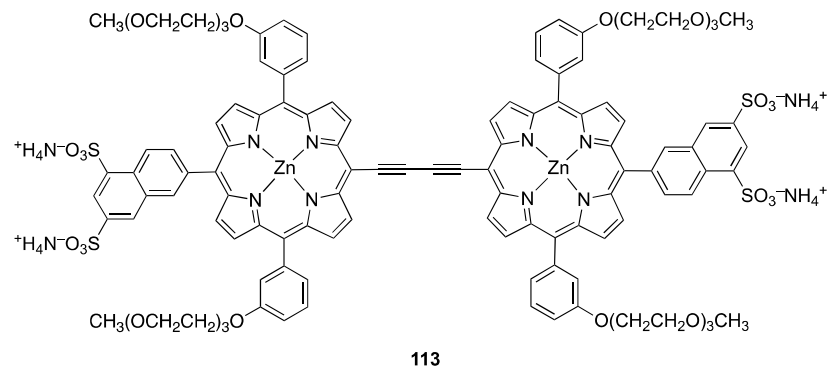

Figure 7. Molecular structure of sulfonated biporphyrin 113.

\subsection{Porphyrins with Phosphate/Phosphonate Functional Groups}

The introduction of alkylphosphonate functional groups to the periphery of a porphyrin is another strategy to impart hydrophilicity to porphyrins and hydroporphyrins. Phosphate groups have also been employed, but because of the increased hydrolytic lability of the phosphate group, only rarely.

Alkyl phosphonates have been introduced to the porphyrin by modification of a porphyrin or by the synthesis of the porphyrin macrocycle with protected phosphonate/phosphate or alcohol building blocks. Deprotection and subsequent modification of the porphyrin furnished the water-soluble phosphonated derivatives. One of the first examples of porphyrins bearing phosphonate groups was introduced by the group of Montforts [130]. They prepared water-soluble metalloporphyrins by phosphonation of the primary alkyl alcohols in deuteroporphyrin derivative 114M (Scheme 32) [130]. Their strategy involved the conversion of the alcohols in 114M to brominated derivative $115 \mathrm{M}$, followed by reaction with $\mathrm{P}\left(\mathrm{OSiMe}_{3}\right)_{3}$, and subsequent hydrolysis of the intermediate with $\mathrm{MeOH} / \mathrm{H}_{2} \mathrm{O}$ to afford phosphonate $\mathbf{1 1 6}$. The free phosphonate functional groups were used to attach these derivatives to electrode surfaces [130]. Using a similar strategy, diphosphonated chlorin derivatives rac-117 and rac-118 were also prepared (Scheme 32).

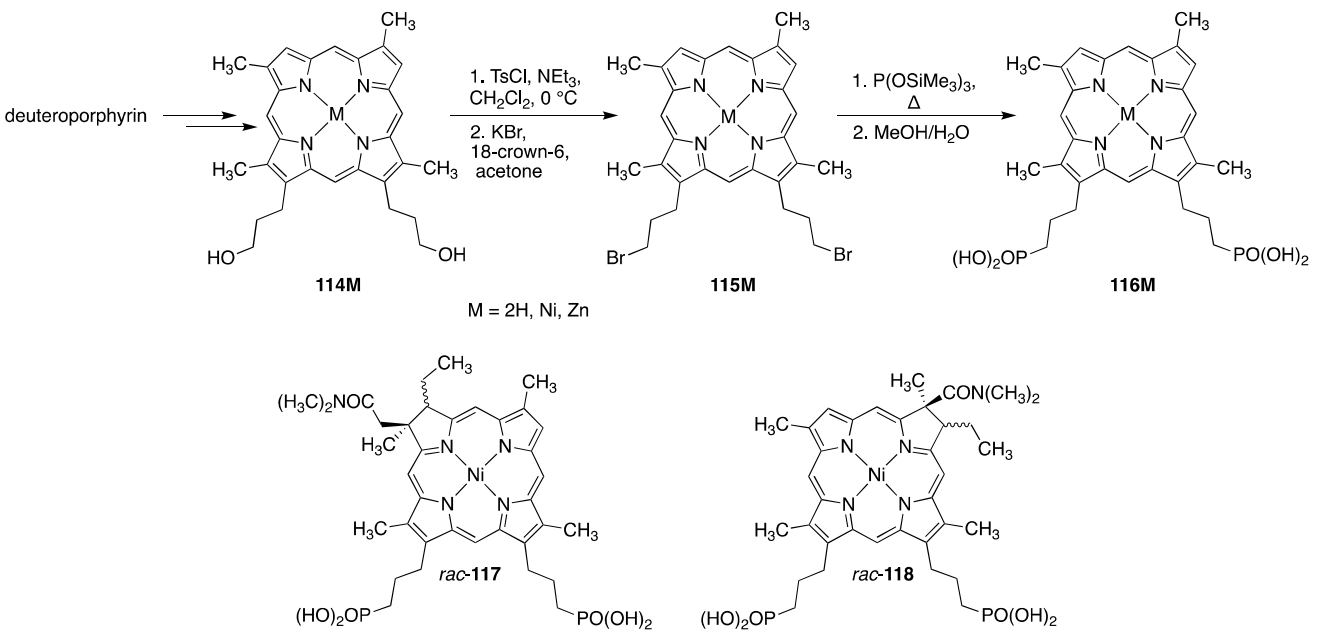

Scheme 32. Phosphonated $\beta$-alkyl porphyrin derivatives, as described the group of Montforts [130]. 
While the requisite alkyl alcohols for phosphonation in $\mathbf{1 1 4 M}$ were generated by functional group manipulation of the propionic acid side chains present in the natural product precursors, the requisite alcohols can also be introduced (in free or protected form) at the porphyrin synthesis stage. For instance, Lindsey and co-workers prepared trans-AB porphyrin $\mathbf{1 1 9}$ by using a dipyrromethane precursor bearing two $t$-butyldimethylsilyl-(TBDMS) protected hydroxyl groups (Scheme 33) [131]. After removal of the protecting groups, the hydroxyl groups could be derivatized in a similar manner as described by Montforts [130] to provide the protected phosphonate ester 120. An ester hydrolysis revealed the free phosphonate groups, conveying water-solubility. The corresponding zinc complexes were also prepared.

Along analogous pathways, trans-AB porphyrins bearing amino (121c), acetamido (121d), and iodoacetamido (121e) bioconjugatable tethers at the meso-phenyl position opposite the solubilizing group also became accessible (Scheme 33) [132]. This approach is suitable for the synthesis of phosphonated chlorins, synthesized by using dipyrromethane building block 123, bearing two protected alcohols (Scheme 34) [133]. After condensation of $\mathbf{1 2 2}$ and 123, the benzyl ether protecting groups in $\mathbf{1 2 4}$ were removed, and the alcohols were brominated and phosphonated. The phosphonate ester was then treated with TMS-Br to furnish the free phosphonates.

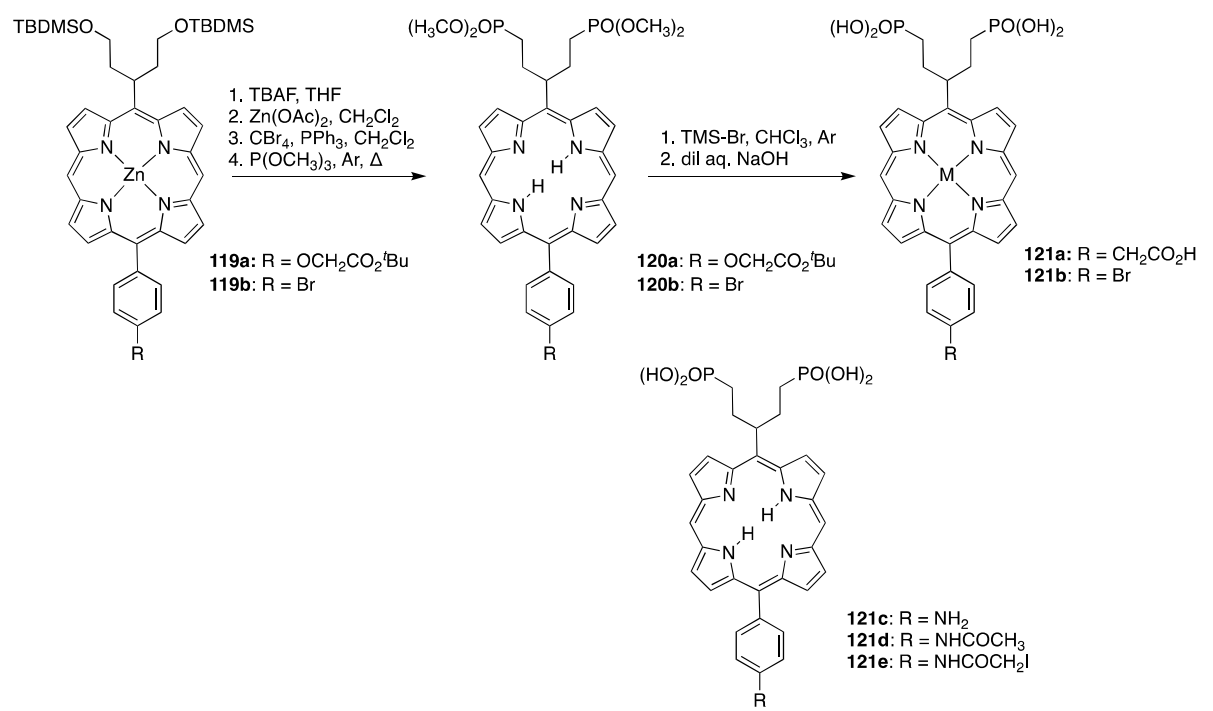

Scheme 33. trans-AB Porphyrins bearing swallowtail phosphonate motifs, as described by the group of Lindsey [131,132].
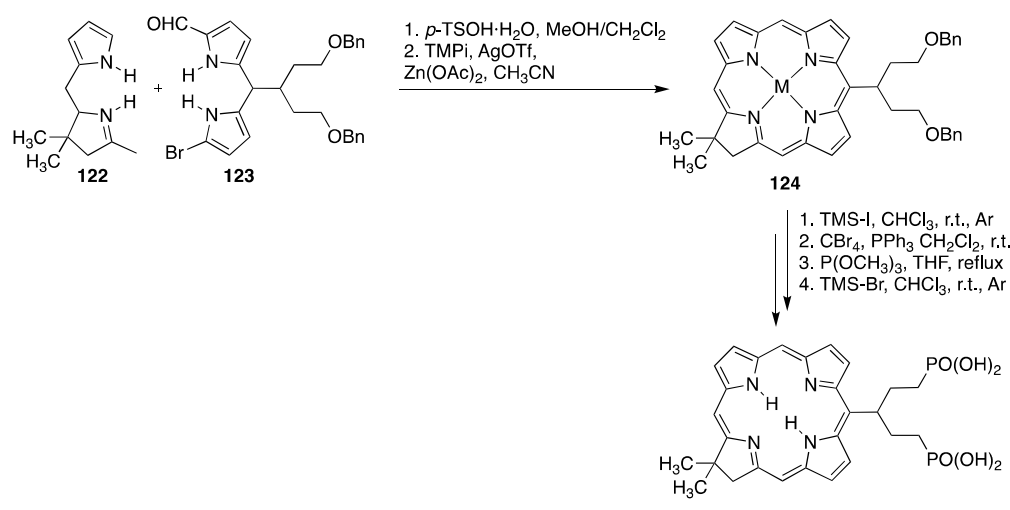

125

Scheme 34. Synthetic chlorins bearing phosphonate swallowtail motifs, as described by the group of Lindsey [133]. TMPi = 2,2,6,6-tetramethylpiperidine. 
Lindsey and co-workers also prepared trans-AB porphyrins incorporating phosphate groups, though in this instance they started with a dipyrromethane precursor already bearing phosphate esters (Scheme 35) [131]. Hydrolysis of the protected phosphate groups afforded the free phosphate groups.

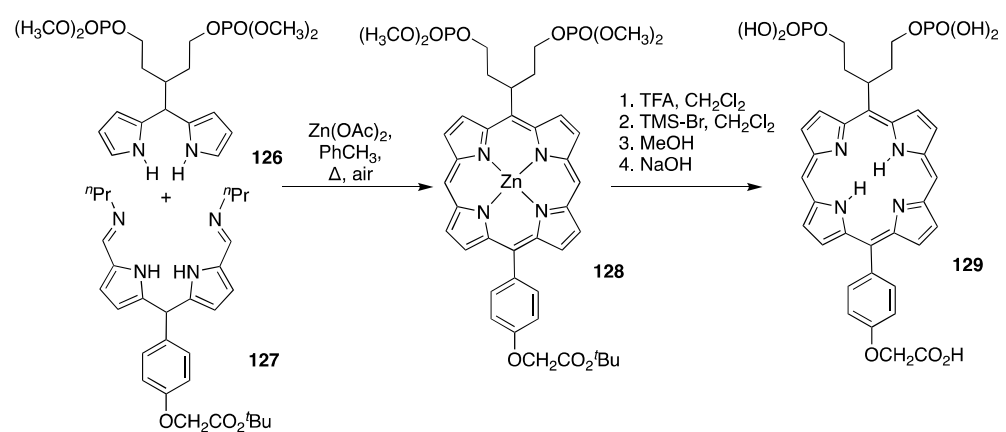

Scheme 35. Porphyrin bearing phosphate swallowtail motif, as described by the group of Lindsey [131].

Phosphonate groups can also be introduced to the porphyrin by starting with dipyrromethane precursors bearing protected phosphonate functional groups. Using this strategy, trans-AB porphyrin 130 (Figure 8) was synthesized by condensation using a dipyrromethane precursor carrying an 2,6-diphosphonated aryl ring that projects the solubilizing groups above and below the plane of the macrocycle target (cf. Scheme 35) [134]. Hydrolysis of the phosphonate esters and saponification affords the trans-AB porphyrin bearing both the phosphonate solubilization groups and a carboxylic acid bioconjugatable tether. Using a similar strategy as for chlorin 125, this 2,6-aryl-phosphonate motif was also incorporated into chlorin 131 [133]. Again, the Suzuki coupling strategy of $\beta$-dibromobacteriochlorins proved versatile enough to be applicable to the introduction of $\beta$-aryl-phosphonate groups (cf. Scheme 6) to afford, after hydrolysis of the phosphonate esters, water-soluble bacteriochlorin 132.
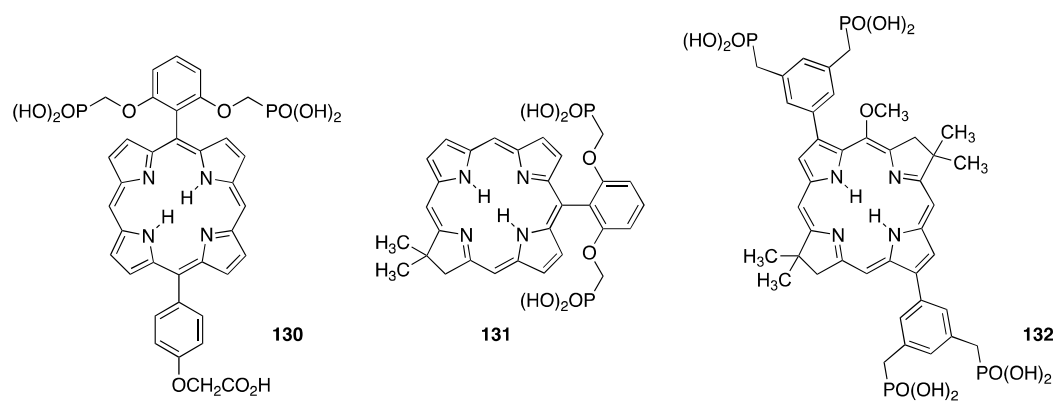

Figure 8. Molecular structures of phosphonated porphyrin 130, chlorin 131, and bacteriochlorin 132.

\section{Water-Soluble Porphyrins with Neutral Groups}

\subsection{PEGylated Porphyrins}

PEGylation has emerged as a strategy for the preparation of neutral water-soluble porphyrins and hydroporphyrins. It has many benefits over traditional means using ionic groups. For instance, PEGylation strategies are more flexible with respect to where in the synthetic sequence they are introduced. This is because the PEG functional group is not very reactive once installed. Unwanted reactivity to form oligomeric species is also suppressed by using heterobifunctional PEG chains, in which one end of the PEG chain often has a methyl cap. PEGylated porphyrins are also much more amenable to traditional aqueous work-up conditions, as they may partition favorably in organic solvents such as $\mathrm{CH}_{2} \mathrm{Cl}_{2}$ and EtOAc $[135,136]$. Often times PEGylated porphyrins can be purified by normal silica-gel chromatography using polar solvents [14,137-139]. 


\subsubsection{Porphyrinoid Macrocycle Total Synthesis Using PEGylated Building Blocks}

Despite these advantages, the multistep manipulation of porphyrins with PEG-groups present throughout the synthesis is relatively rare. For instance, Brunner and co-workers presented such an example. They synthesized the $\mathrm{A}_{3} \mathrm{~B}$ porphyrin 133 by mixed condensation of two arylaldehydes and pyrrole, with one of the aryl aldehydes carrying a PEG chain $(n=2,3$ or 17) (Scheme 36) [140]. The resulting $\mathrm{A}_{3} \mathrm{~B}$ PEGylated porphyrins 133a-133c were purified using ordinary silica gel chromatography $\left(\mathrm{CH}_{2} \mathrm{Cl}_{2} / \mathrm{MeOH}\right.$ mixtures). The PEGylated porphyrins were also amenable to further modification at the malonic ester functional group to generate platinum-porphyrin conjugates.

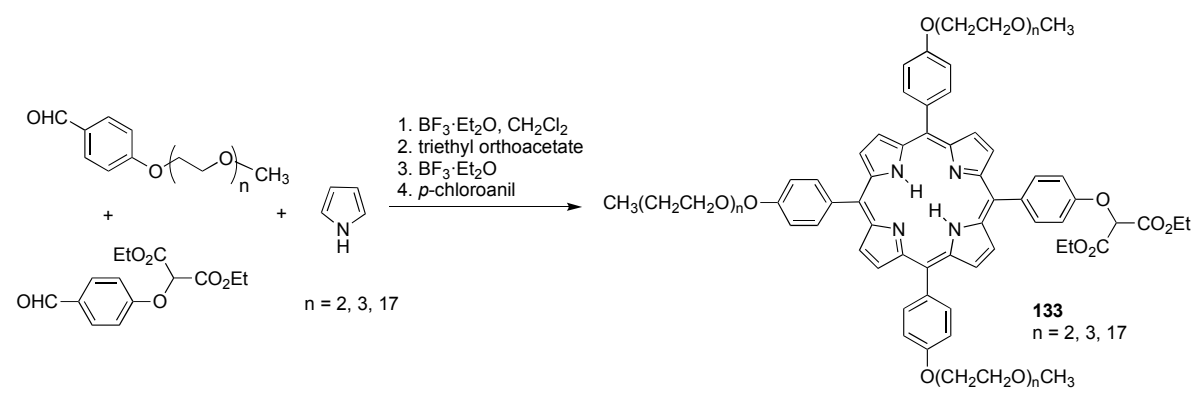

Scheme 36. $\mathrm{A}_{3} \mathrm{~B}$ porphyrin carrying three short PEG chains, as described by the group of Brunner [140].

Another example for the early introduction of PEGylated building blocks was reported by the group of Anderson [70]. Using a PEGylated benzaldehyde, porphyrin 26 bearing two methyl-capped tetraethylene glycol (TEG) groups on opposite meso-phenylgroups was prepared. Leaving the PEG chains intact, it was converted to the bis-acetylene linked porphyrin dimer 134. Porphyrin dimer 134 was found not to be sufficiently soluble in aqueous media for biological application. Therefore, these materials were further derivatized with additional solubilizing groups, all while the PEG functional groups remained intact (Scheme 37) [70].

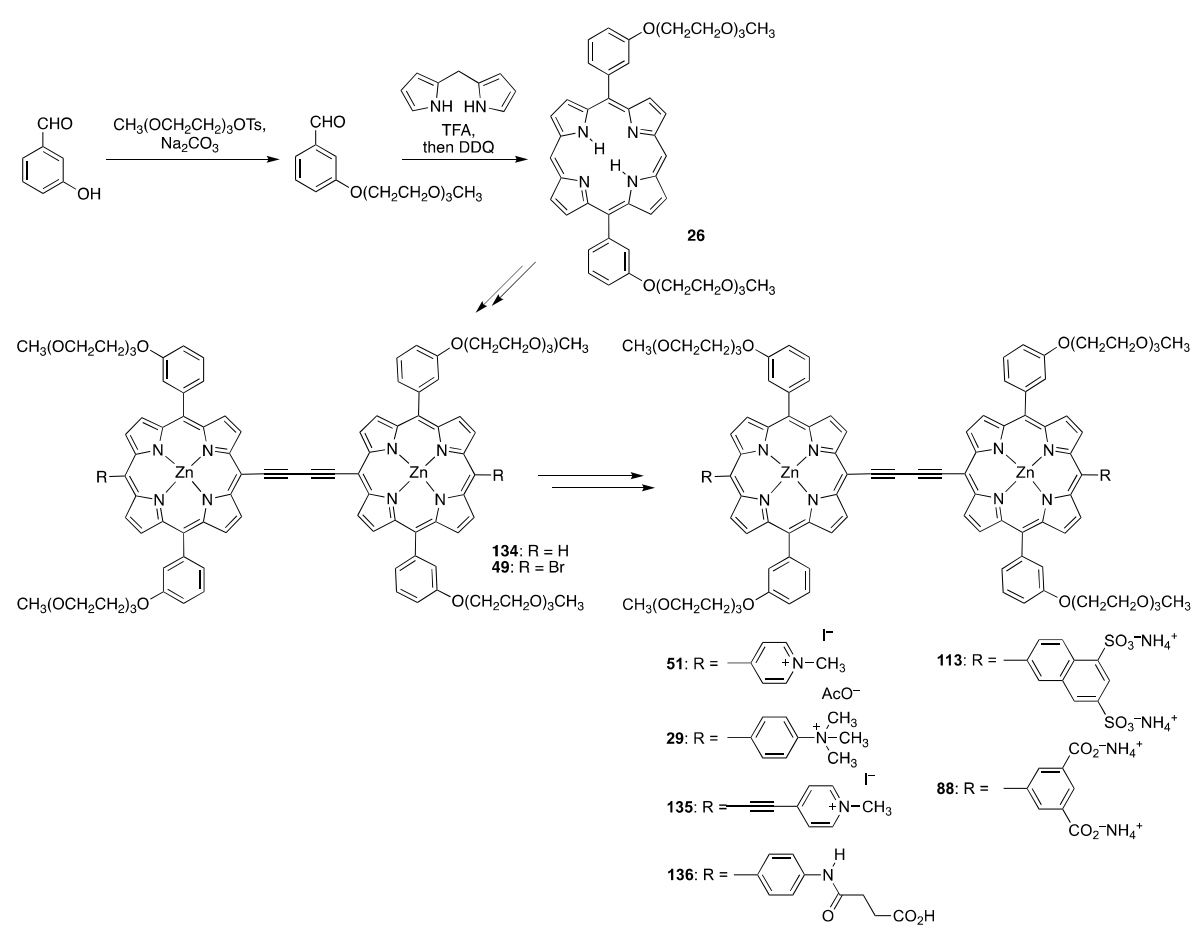

Scheme 37. Hydrophilic bis-acetylene linked porphyrin dimers carrying PEG chains and various other solubilizing motifs, as described by the group of Anderson [70]. 
Starting from the meso-dibromo dimer 49, cationic (pyridinium; cf. Scheme 13), anionic (sulfonate) and carboxlyate (cf. Scheme 25) groups were introduced using either Suzuki or Sonogashira coupling strategies. The Senge arylation method was also used to introduce ammonium and pyridyl solubilizing

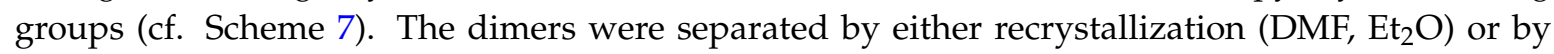
semi-preparative reverse phase HPLC. Due to insufficient solubility of the compounds in regular reverse-phase HPLC solvents (such as $\mathrm{CH}_{3} \mathrm{CN}, \mathrm{MeOH}$, water), DMF, DMSO, or THF were used. Also due to solubility issues, the authors could not measure $\log \mathrm{P}$ values for these compounds in octanol:water. However, they did compare the relative polarity of some derivatives by means of their retention times under reverse-phase HPLC conditions (Table 1).

Table 1. Comparison of the retention times of hydrophilic porphyrin dimers shown in Scheme 37 [70].

\begin{tabular}{cc}
\hline Porphyrin Dimer & Retention Time/min ${ }^{\mathbf{a}}$ \\
\hline 51 & 6.2 \\
29 & 6.8 \\
135 & 7.6 \\
136 & 15.6 \\
88 & 18.0
\end{tabular}

a HPLC Conditions: $\mathrm{C}_{8}$ column $(5 \mu \mathrm{m}, 3.9 \mathrm{~mm} \times 150 \mathrm{~mm}), 1 \mathrm{~mL} / \mathrm{min}$ flow rate; solvent $\mathrm{A}: 1 \%$ aqueous acetic acid; solvent B: THF, linear gradient.

PEG-substituted dipyrromethanes also found use in the early introduction of solubilizing groups. The group of Lindsey was able to synthesize chlorins from a PEGylated dipyrromethane precursor (Scheme 38) [136]. This strategy also incorporated a bioconjugatable tether at another meso-position, the precursor of which was also introduced at the dipyrromethane stage.

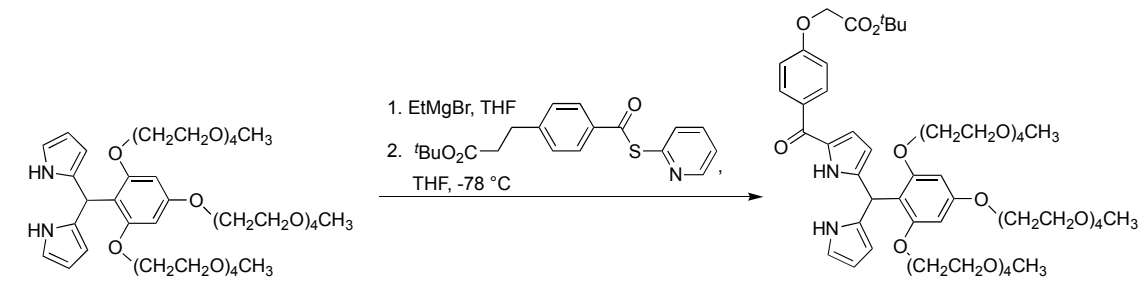

137

138

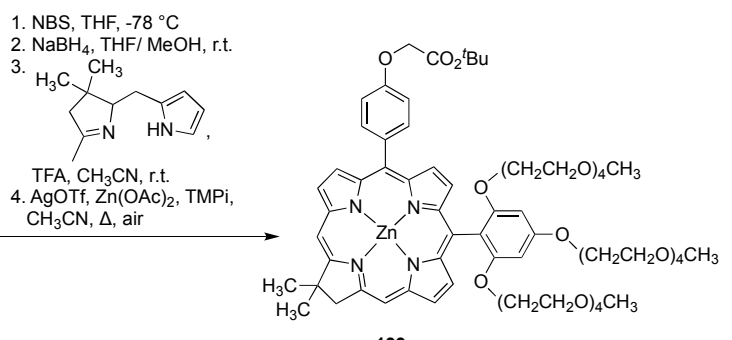

139

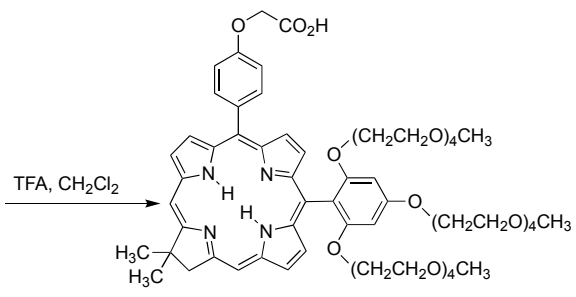

140

Scheme 38. PEGylated synthetic chlorins using PEGylated building blocks, as described by the group of Lindsey [136]. TMPi = 2,2,6,6-tetramethylpiperidine.

\subsubsection{PEGylation of meso-aryl Porphyrins}

A number of meso-tetraarylporphyrins bearing PEG groups have been synthesized by PEGylation of porphyrins incorporating suitable linker functionalities on the aryl groups. These porphyrins are usually prepared via Adler or Lindsey methods and the PEG groups can be linked by various methods including etherification, amidation or esterification reactions. Particularly popular linking groups for the PEGylation of porphyrins are meso-phenol substituents. PEGylation of various 
meso-tetrahydroxyphenyl porphyrin derivatives with a suitably functionalized PEG precursor yields water-soluble porphyrins, with activation of the PEG group often required.

For example, meso-tetrakis(3-hydroxyphenyl)chlorin (141) was rendered water-soluble by introducing PEG groups through two different etherification strategies. Tetraphenolporphyrin $\mathbf{1 4 1}$ was treated with $p$-nitrophenylcarbonate- or cyanuric chloride-activated methoxypolyethyleneglycol to afford the water-soluble PEGylated porphyrins 142 or 143, respectively (Scheme 39) [141].
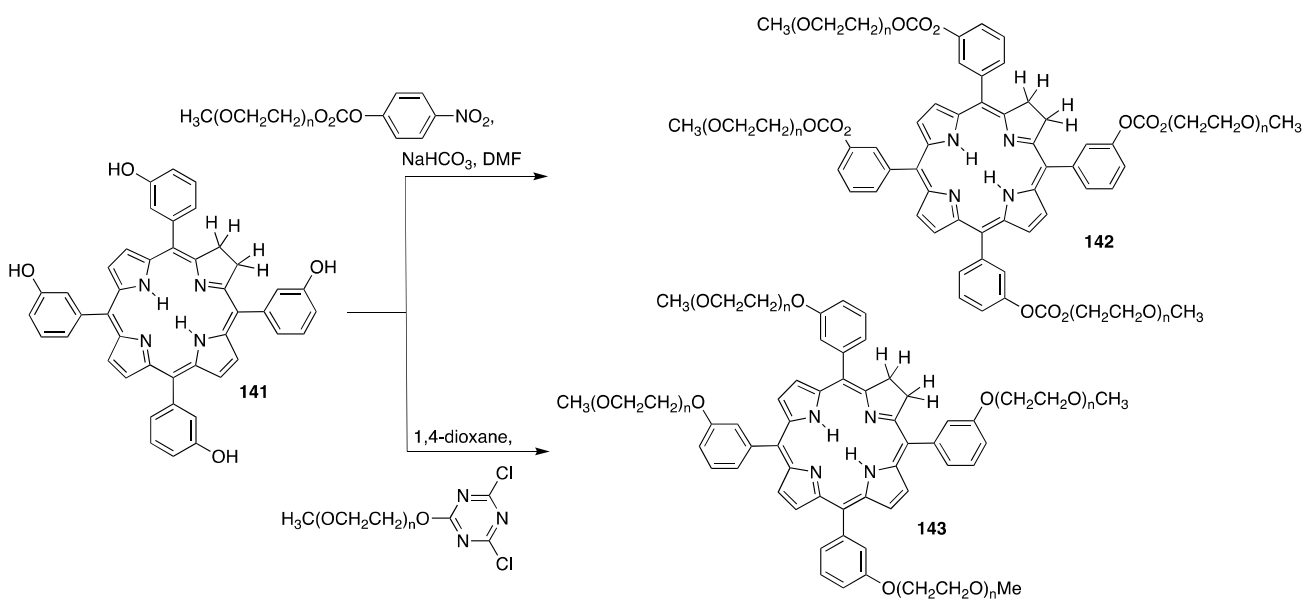

Scheme 39. PEGylated derivatives of meso-tetrakis(3-hydroxyphenyl)chlorin, as described by the group of Sinn [141].

meso-Tetrakis(4-hydroxyphenyl)porphyrin (76) can also be alkylated using various activated PEGs. For instance, this procedure has been employed to alkylate $\mathbf{7 6}$ by treatment with PEG-mesylates to form 144. (Scheme 40) [137].

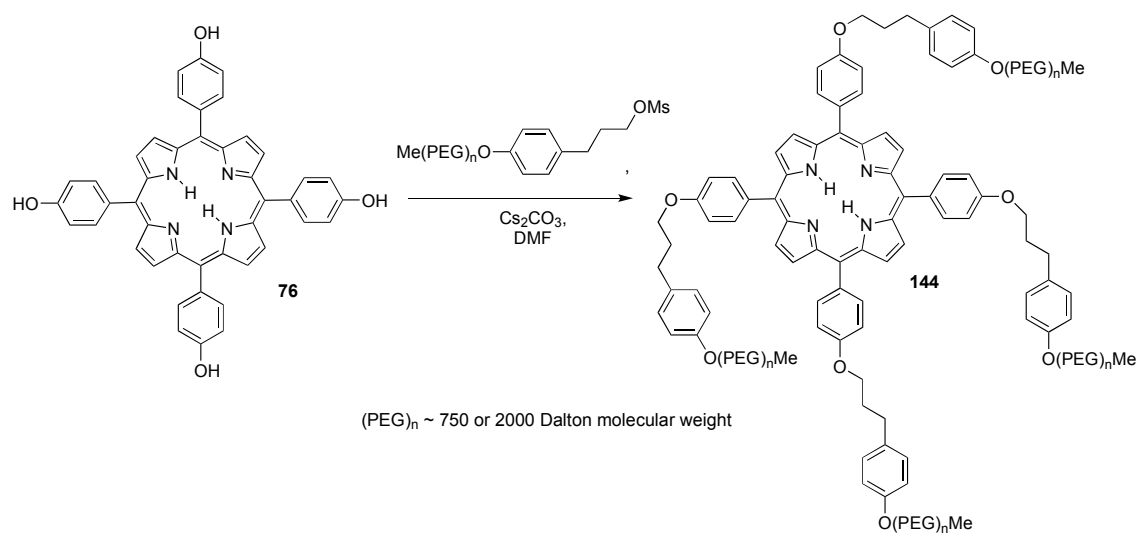

Scheme 40. PEGylated derivatives of meso-tetra(4-hydroxyphenyl)porphyrin, as described by the group of Pozzi [137].

Under similar conditions, single PEG chains or PEG-dendrimers (Scheme 41) [142] can also be introduced into asymmetric meso-hydroxyphenylporphyrins [143,144]. Vitalini and co-workers prepared PEGylated derivatives of $\mathbf{7 6}$ by alkylation of the phenolic oxygens with a chlorinated PEG [145]. The PEG-functionalized porphyrins could be purified by adding a solution of the compound in $\mathrm{CH}_{2} \mathrm{Cl}_{2}$ to a cold solution of $\mathrm{Et}_{2} \mathrm{O}$ to induce precipitation (for larger PEGs) $[137,143]$; porphyrins bearing smaller PEG-chains could also be purified by column chromatography $\left(\mathrm{CH}_{2} \mathrm{Cl}_{2}\right.$-acetone-MeOH or $\mathrm{CH}_{2} \mathrm{Cl}_{2} / \mathrm{EtOH}$ mixtures) $[137,142]$. 


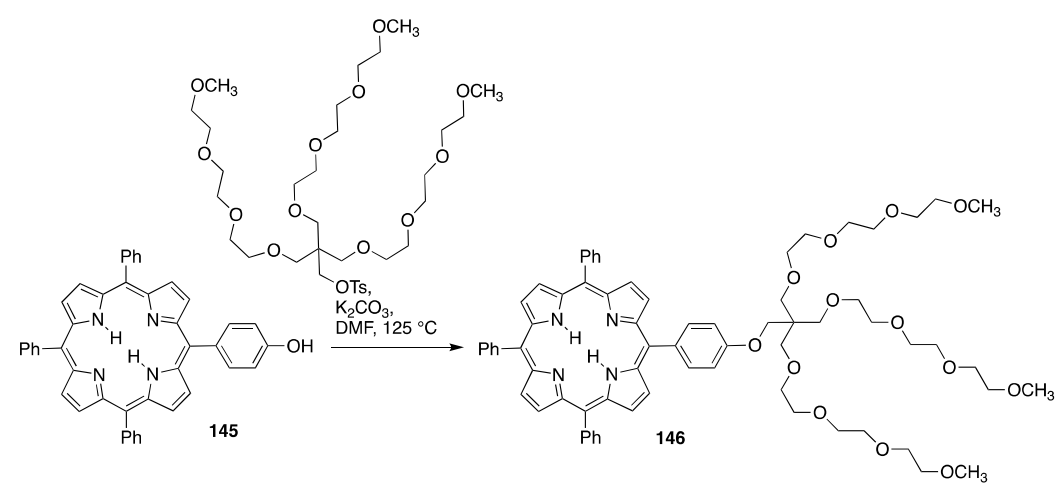

Scheme 41. Amphiphilic porphyrin with a PEG-dendrimer, as described by the group of Dumoulin [142].

PEGylation of meso-arylporphyrins was also achieved by inversion of the Williamson ether synthesis reaction partners, i.e., involving a halogenated porphyrin precursor and PEGs bearing a free alcohol. An example is the PEGylation of tetra( $p$-bromomethylphenyl)porphyrin (147) with a methyl-capped PEG alcohol $\left(\mathrm{M}_{\mathrm{n}}=550\right)$ that afforded the tetra-PEGylated porphyrin $\mathbf{1 4 8}$ as the main product, along with partially PEGylated porphyrins (Scheme 42). The porphyrin starting material was prepared by Lindsey porphyrin synthesis from 4-(bromomethyl)benzaldehyde and pyrrole [146]. The PEGylated products were amenable to aqueous work-up (extraction with $\mathrm{CH}_{2} \mathrm{Cl}_{2}$ ) and were purified by HPLC.

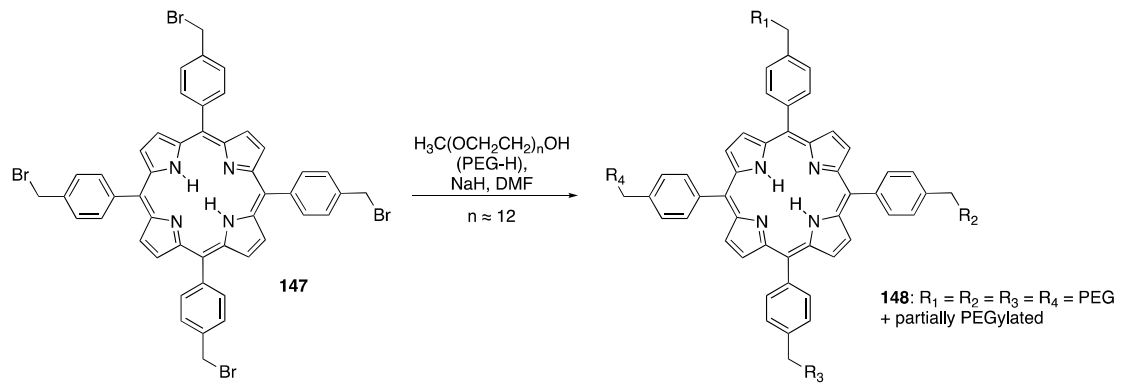

Scheme 42. PEGylated meso-aryl porphyrins by benzylation of a PEG with tetra( $p$-bromomethylphenyl)porphyrin, as described by the group of Lee [146].

meso-Aryl porphyrins bearing peripheral carboxylic acid functional groups can be PEGylated by amide formation using an amine-terminated PEG. For instance, Scolaro and co-workers prepared PEGylated derivatives of meso-tetrakis(4-carboxyphenyl)porphyrin (149) by treatment with Jeffamine M-600 ( $n=7-9)$ (Scheme 43) [147].

Also starting from tetraacid 149, Lovell and co-workers reacted it with a variety of homobi-functional PEG-diamines (average Mw ranging from $150 \mathrm{Da}$ to $10 \mathrm{kDa}$ ) to synthesize a PEG-linked porphyrin mesh 151 (Figure 9) [148]. This reaction illustrates the complex cross-linked structure formed when using PEGs capable of reacting at both ends. The porphyrin-PEG-mesh was purified by dialysis, followed by addition of citric acid to precipitate unreacted porphyrin.

PEGylated porphyrins and hydroporphyrins with amide linkages can also be prepared starting with aminophenyl porphyrins. For instance, Peng et al. functionalized a chlorin with a poly-( $\varepsilon$-caprolactone)-polyethyleneglycol) diblock copolymer [149]. Introduction of the PEG-polymer was achieved by treatment of meso-tetrakis(4-aminophenyl)chlorin with the acid chloride of the diblock copolymer. The polymer-functionalized porphyrin was purified by precipitation with $\mathrm{Et}_{2} \mathrm{O}$, followed by a dialysis step in acetone. Vicente and co-workers prepared water-soluble porphyrin-peptide 
conjugates with a PEG linker on one meso-aryl group starting from an $\mathrm{AB}_{3}$ porphyrin 152 bearing one $p$-aminophenyl group.

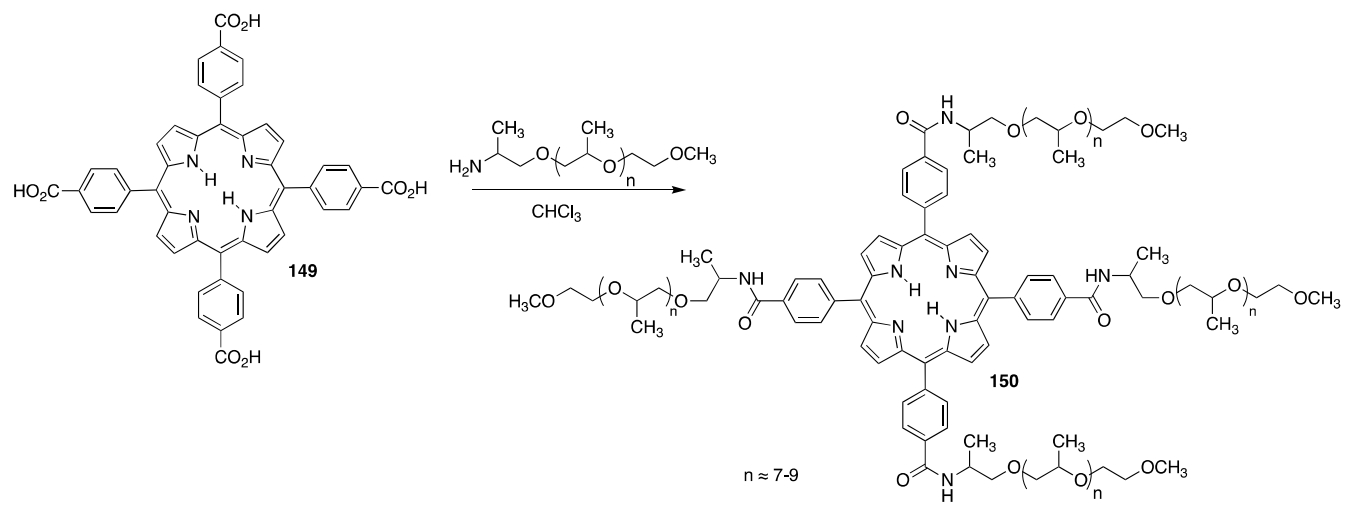

Scheme 43. PEGylated porphyrins derived from meso-tetrakis(4-carboxyphenyl)porphyrin using a PEG-amine, as described by the group of Scolaro [147].

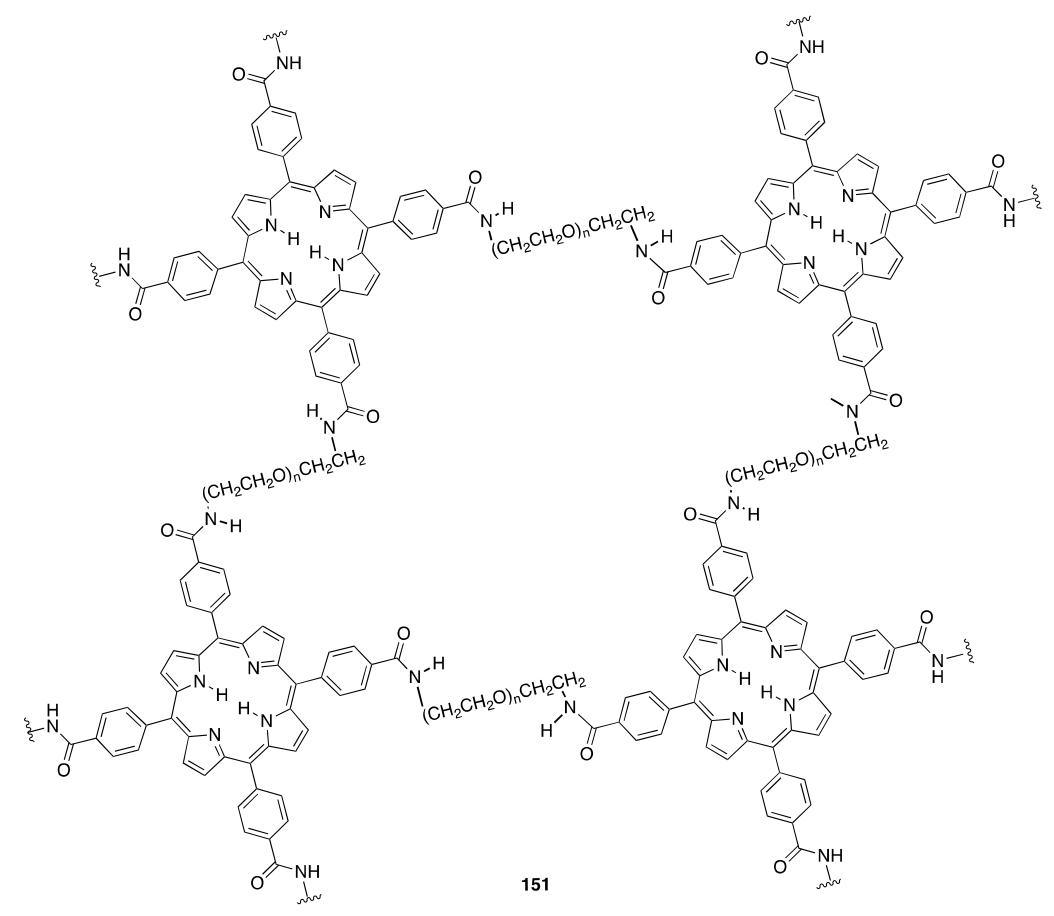

Figure 9. Partial molecular structures of PEG-linked porphyrin mesh 151.

The amine functionality in $\mathbf{1 5 2}$ was reacted with diglycolic anhydride, followed by amide-coupling using a PEG-amine and Boc-deprotection (Scheme 44). A peptidyl resin can be coupled to the hydroxybenzotriazole (HOBt) ester of the porphyrin 154 [150]. More hydrophilic PEGylated $\mathrm{A}_{3} \mathrm{~B}$ porphyrins bearing three carboxyphenyl groups were also prepared in a similar manner [150]. Oligo-ethylene glycol amide-linkages have also been utilized as hydrophilic spacers in instances that require designed structures on the periphery of a hydrophilic porphyrin. Using this strategy, Alessio and co-workers have prepared ruthenium-porphyrin conjugates with oligoethylene glycol spacers [151]. This methodology has also been used to develop Rhenium (I)-porphyrin conjugates in a similar manner [152]. 

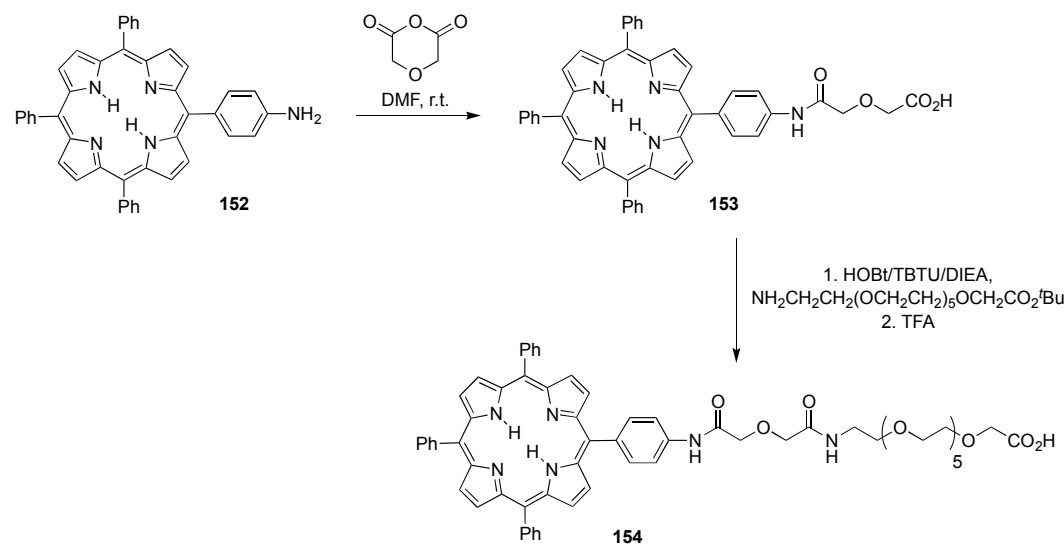

Scheme 44. PEGylated $\mathrm{AB}_{3}$ porphyrin with carboxylic acid bioconjugation handle, as described by the group of Vicente [150]. HOBt $=1$-hydroxybenzotriazole, TBTU $=O$-(benzotriazol1-yl) $N, N, N^{\prime}, N^{\prime}-$ tetramethyluronium tetrafluoroborate, DIEA $=N, N$-diisopropylethylamine.

Lastly, PEGylation of meso-hydroxyphenylporphyrins can be achieved utilizing ester linkages. Thus, Diederich and co-workers prepared dendritic porphyrin 156 by esterification of porphyrin tetraol 155 with a carboxylic acid-functionalized dendron under Mitsunobu conditions (Scheme 45) [153].

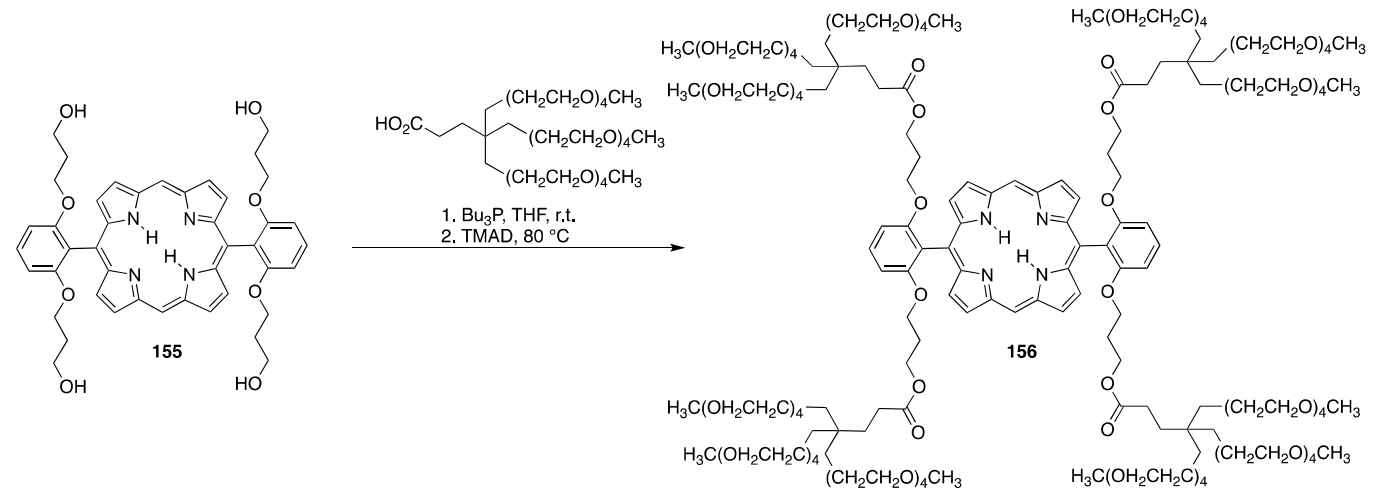

Scheme 45. Porphyrin-PEG dendrimer conjugates, as described by the group of Diederich [153]. TMAD $=N, N, N^{\prime}, N^{\prime}$-tetramethylazodicarboxamide.

The extension of the reactive alcohol site from the phenolic position using an alkyl chain was employed to accommodate the bulky PEG-dendrimer substituents. The resulting porphyrin-dendrimers were purified by preparative gel permeation chromatography and were soluble in phosphate buffer at $\mathrm{pH}$ 7. Alternatively, the PEGylation of a meso-hydroxphenyl $\mathrm{A}_{2} \mathrm{~B}_{2}$ porphyrin by DCC/DMAP-mediated esterification with a PEG-carboxylic acid (1000 Da) was reported (Scheme 46) [154].

$\pi$-Extended porphyrin derivatives may also be subjected to the same PEGylation strategies as seen for regular porphyrins. For instance, PEGylation of the phenolic oxygens in quinoline-annulated porphyrin 160 was reported by Luciano et al. (Scheme 47) [14] using a similar O-alkylation method as described for regular porphyrins (Scheme 40).

Precursor porphyrin 159 was prepared from meso-tetrakis(4-methoxyphenyl)porphyrin. $\mathrm{A} \mathrm{BBr}_{3}$-mediated deprotection was employed to deprotect the phenolic oxygens as the penultimate step of the synthesis. The phenol could then be PEGylated using either a short $(n=4)$ or long chain (avg. MW 550, $n \approx 12$ ) PEG-mesylate [14]. The short PEG chain derivative 161a was found to be only slightly soluble in water. However, the derivative bearing long PEGs (161b) was soluble in PBS to 
form $\sim 30 \mathrm{mM}$ solutions and were used as photoacoustic imaging contrast agents for in vivo imaging of tumors in a mouse model [14].
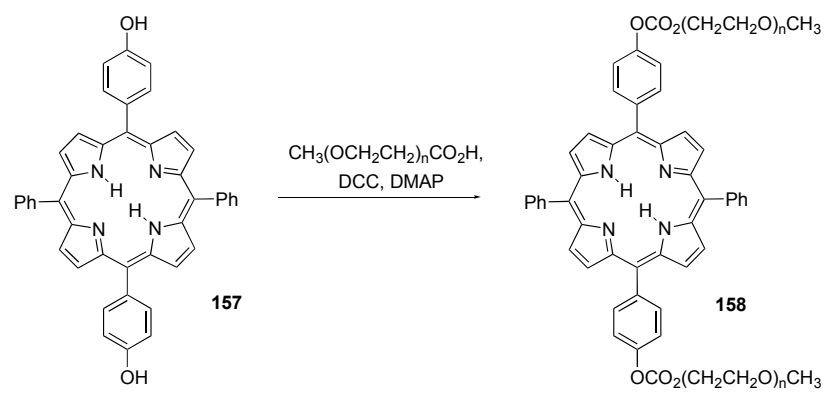

Scheme 46. PEGylated $\mathrm{A}_{2} \mathrm{~B}_{2}$ porphyrin, as described by the group of Nawaz [154]. DCC = dicyclo-hexylcarbodiimide, DMAP = 4-dimethylaminopyridine.

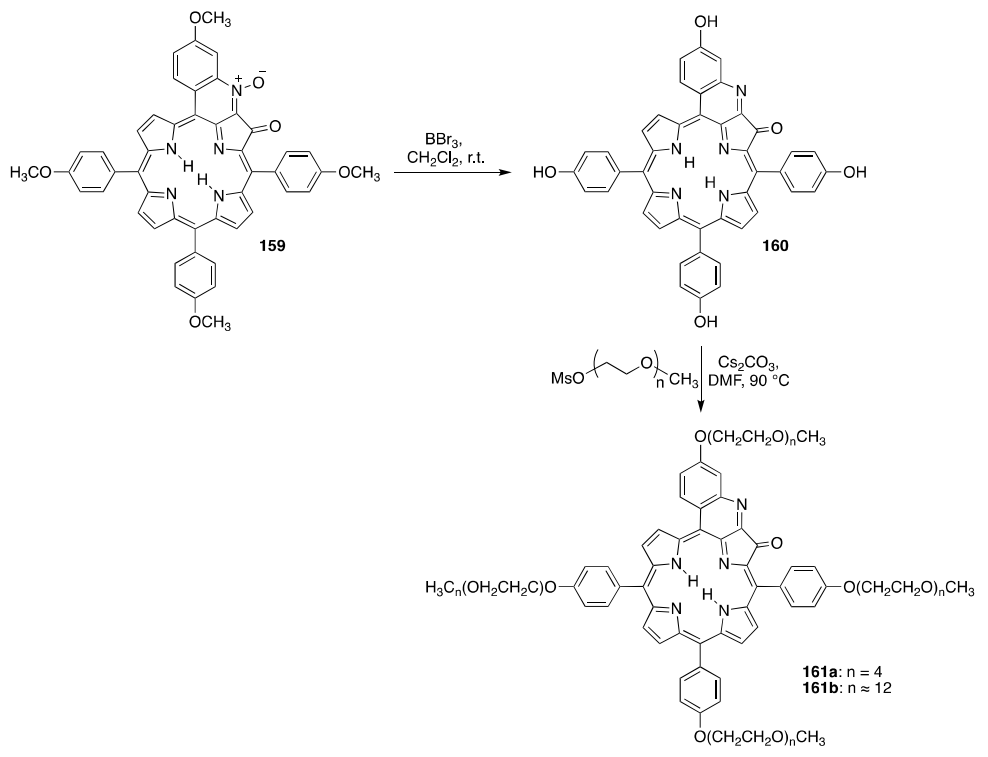

Scheme 47. PEGylated quinoline-annulated porphyrins, as described by the group of Brückner [14].

Brückner and co-workers were able to take advantage of the well-known $\mathrm{S}_{\mathrm{N}} \mathrm{Ar}$ reactivity of meso-pentafluorophenylporphyrins toward nucleophiles at the $p$-F positions to introduce PEG groups to pyrrole-modified porphyrins (PMPs) at a late stage of the synthetic sequence toward meso-arylmetalloporpholactones $[138,139,155]$ (Scheme 48). This allowed the preparation of a variety of PEGylated porpholactone metal complexes (163M) that were used as optical high $\mathrm{pH}$ or cyanide sensors in water [139]. The PEGylated derivatives were purified by silica gel chromatography $\left(\mathrm{CH}_{2} \mathrm{Cl}_{2} / 5 \% \mathrm{MeOH}\right)$. Similarly, thiol-functionalized sugars were introduced into meso-pentafluorophenylporphyrins using the $\mathrm{S}_{\mathrm{N}} \mathrm{Ar}$ reaction, also resulting in their solubilization in aqueous solutions [156].

Building on previous efforts for the solubilization of antimony porphyrins by axial ligand exchange with alcohols (cf. Scheme 11), Yasuda and co-workers prepared hydrophilic PEGylated phosphorus porphyrins, such as tetraphenylporphyrin derivative 164 (Figure 10) by introduction of short PEGs as axial ligands. Incorporation of the axial-PEGs furnished highly water-soluble derivatives. Porphyrin 164, for example, has a water-solubility of $17.3 \mathrm{mM}$ [90]. 


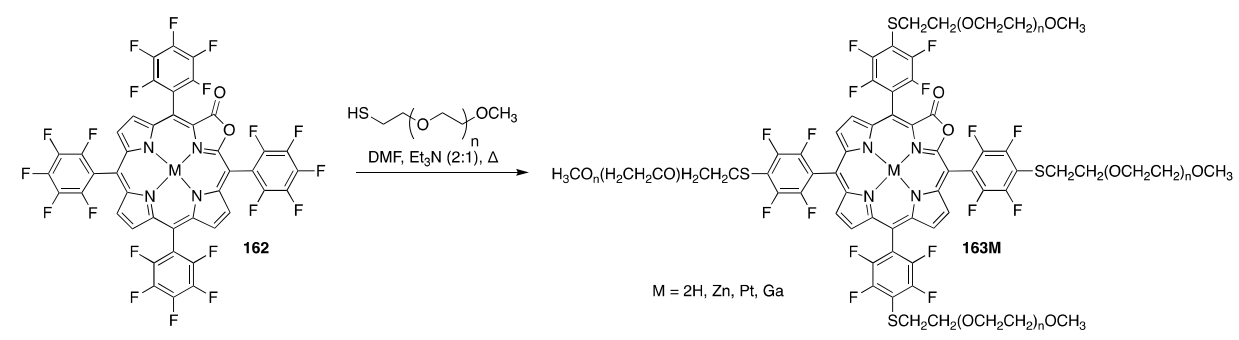

Scheme 48. PEGylated porpholactone derived from meso-tetrakis(pentafluorophenyl)porphyrin derivatives, as described by the group of Brückner [139].

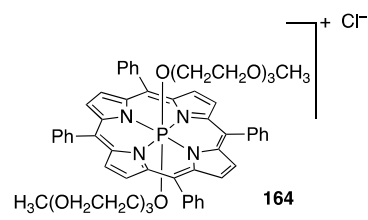

Figure 10. Molecular structure of axially-PEGylated phosphorus porphyrin 164.

\subsubsection{Porphyrins PEGylated at Their $\beta$-Positions}

A number of PEGylated $\beta$-alkyl-porphyrins and -chlorins were prepared. Representative of these are a number of PEGylated chlorin e6 derivatives, prepared firstly by Hamblin et al. [157]. The PEGylation increased tumor targeting of the photosensitizer. Mono-(165a), di-(165b), and tri-(165c) PEGylated derivatives of chlorin e6 were also prepared in which the PEG groups were introduced by esterification at one to three of its carboxylic acids using a short methyl-capped PEG (Scheme 49) [158]. Longer reaction times were needed to increase the yield of the tri-PEGylated product $165 \mathrm{c}$. The authors also measured the solubility of the compounds to be $1.8 \pm 1.3 \mathrm{mM}$ for $11,2.3 \pm 1.0 \mathrm{mM}$ for $165 \mathrm{a}$, $3.3 \pm 0.9 \mathrm{mM}$ for $\mathbf{1 6 5 b}$, and $3.9 \pm 0.8 \mathrm{mM}$ for $165 \mathrm{c}$ in $1 \%(v / v)$ DMSO/water, indicating the increased aqueous solubility with the increase of the number of PEG chains. Products $165 \mathrm{a}$ and $165 \mathrm{~b}$ are single isomers, indicating a sterics-controlled regioselectivity of the sequential PEGylation.

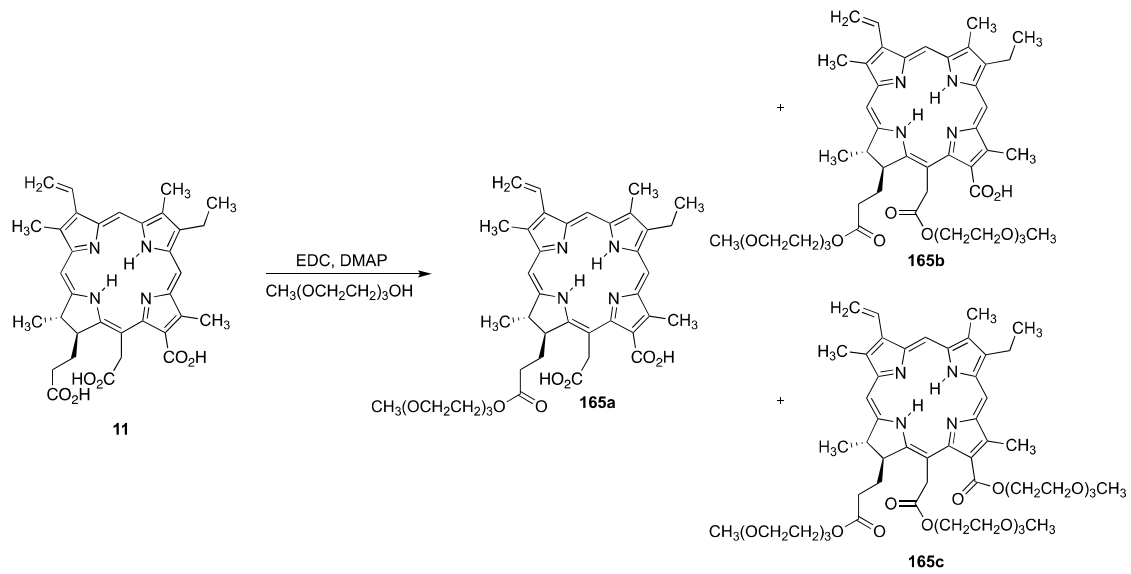

Scheme 49. PEGylated derivatives of chlorin e6, as described by the group of Greer [158]. EDC = 1-ethyl3-(3-dimethylaminopropyl)carbodiimide, DMAP = 4-dimethylaminopyridine.

The propionic side chains in protoporphyrin 166 could also be functionalized with PEG-chains through amide linkages, whereby a short diamine established the requisite amine linkage sites. Amine intermediate 167 was then reacted with succinimidyl-PEG 5000 to afford the water-soluble PEGylated protoporphyrin derivative 168 (Scheme 50), and its zinc complex [159,160]. 


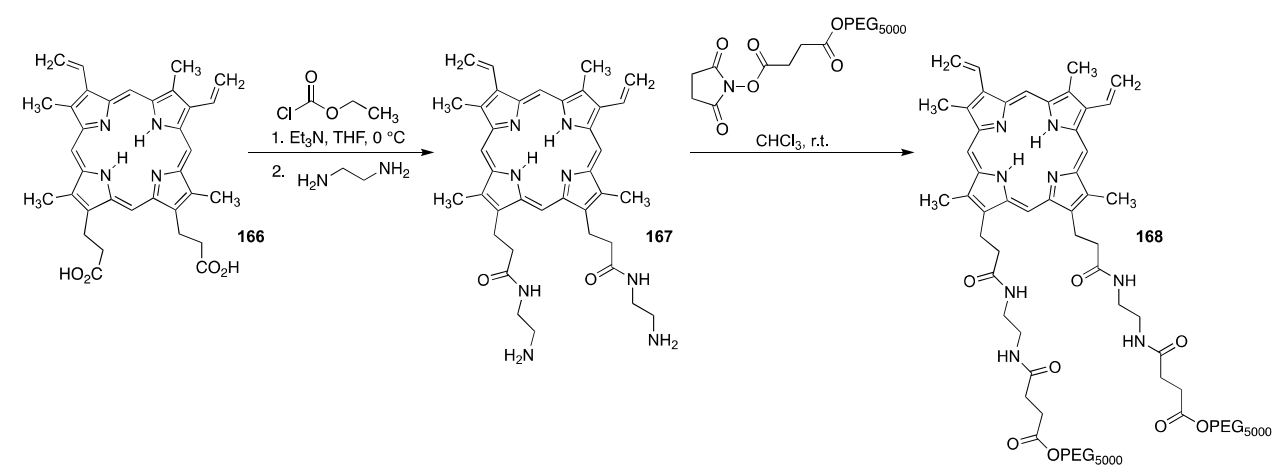

Scheme 50. PEGylated protoporphyrin and its zinc complex, as described by the group of Maeda [159].

Other PEGylated porphyrins were prepared using ether linkages. For example, brominated hematoporphyrin derivative 169 was converted to the corresponding PEGylated compounds 170a-170f by treatment with a stoichiometric excess of a methyl-capped PEG (Scheme 51) [161,162]. Concomitantly, the propionic acid side chains were also derivatized with PEG chains. After hydrolysis of the propionic ester side chains, platinum-conjugates were prepared and evaluated for their antitumor phototoxicty and cytotoxicity $[161,162]$. The PEGylated derivatives were amenable to aqueous work-up and purified by alumina chromatography.

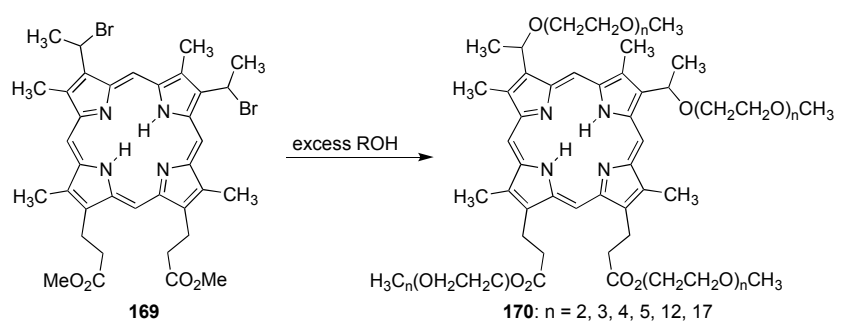

Scheme 51. PEGylated hematoporphyrin, as described by Brunner and Sohn [161,162].

Etherification conditions were also applied to cycloimide-bacteriochlorin alcohol derivative 171 (Scheme 52) [163]. Activation of the hydroxyethyl substituent on the bacteriochlorin 171 with trifluoroacetic anhydride, followed by treatment with hydroxyl-terminated short PEGs and diols of varying length gave the corresponding derivatives 172a-172d. The products were insoluble in water, but aqueous solutions were prepared with the help of $10 \%$ Cremophore $\mathrm{EL}^{\circledR}$, a PEGylated castor oil formulation vehicle.
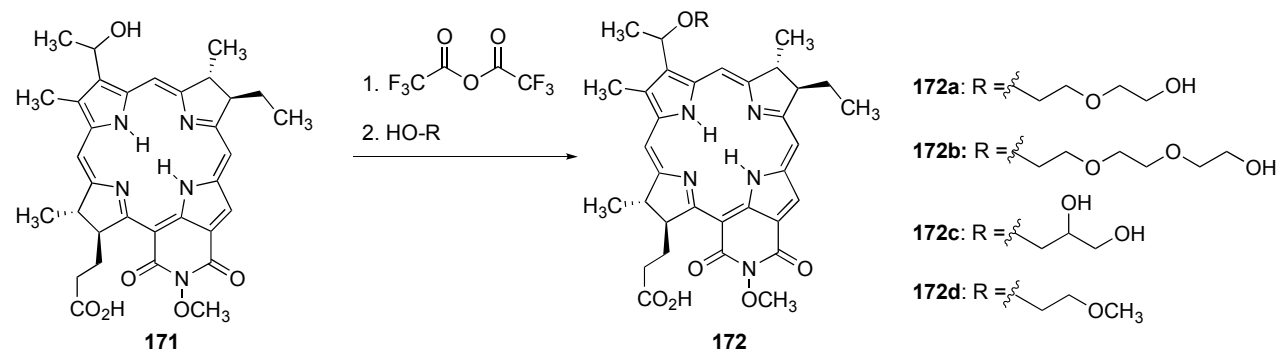

Scheme 52. Hydrophilic bacteriochlorin cycloimides, as described by the group of Feofanov [163].

The meso-Suzuki coupling method developed by Lindsey and co-workers and utilized for the introduction of a variety of solubilization groups to hydroporphyrins (cf. Schemes 5, 12 and 26) was also utilized for the introduction of PEG groups to bacteriochlorin 173 (Scheme 53) [164]. 
Bacterio-chlorin 173 was prepared by Suzuki coupling of the corresponding meso-bromobacteriochlorin with an aryl-boronic ester bearing two unprotected aldehyde functional groups. The aldehyde functionalities were PEGylated by reductive amination with an amine-terminated PEG to afford the water-soluble PEGylated bacteriochlorin 174.
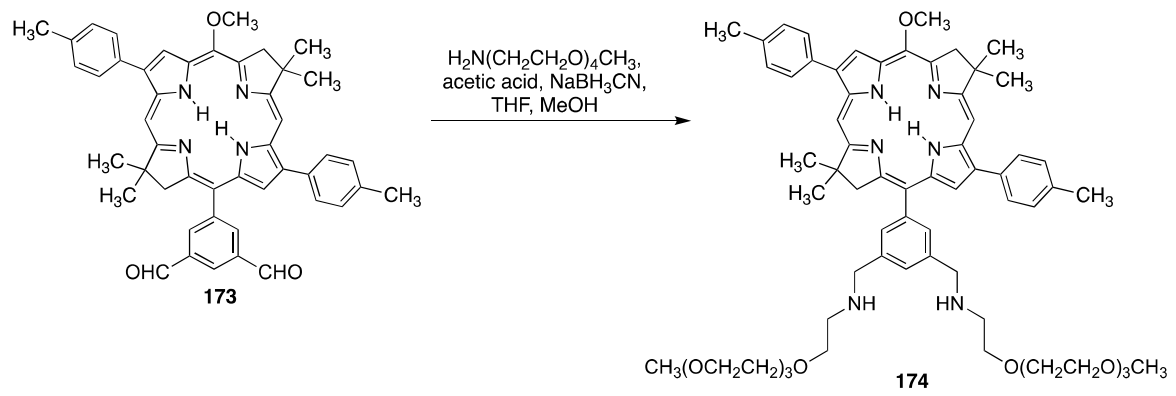

Scheme 53. PEGylated bacteriochlorins formed by reductive amination, as described by the group of Lindsey [164].

Another representative example for the introduction of PEG groups via Suzuki coupling of dibromobacteriochlorin 19 with a Boc-protected amine-derivatized boronic ester, followed by Boc-deprotection under standard conditions, afforded diaryl bacteriochlorin 175 carrying two amine groups. The amines were PEGylated by amide formation with a PEG-NHS ester to afford bacteriochlorin 176 (Scheme 54) [135]. Derivatives bearing bioconjugatable tethers (177) and (178) were also prepared using a regioselective meso-bromination strategy, followed by similar coupling sequences [135].

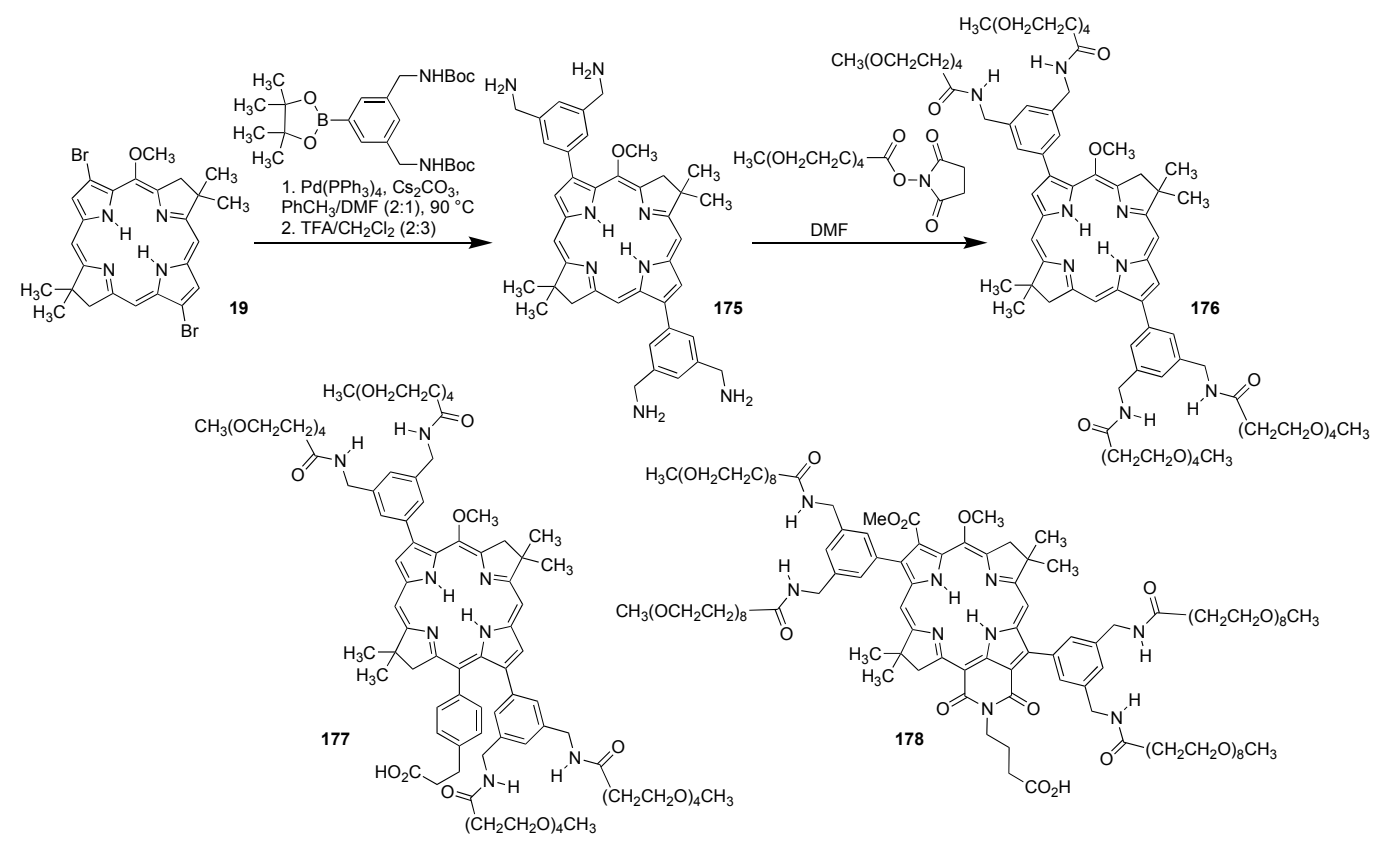

Scheme 54. $\beta$-Substituted PEGylated synthetic bacteriochlorins via Suzuki coupling, as described by the group of Lindsey [135].

Due to the versatility of the 3,13-dibromobacteriochlorin building block 19, various solubilization motifs could be introduced to this scaffold. Thus, ammonium (compounds 22 and 23, Figure 11), carboxylate (compound 92, Figure 11), phosphonate (compound 132, Figure 11) and PEG (compound 
176, Figure 11) solubilizing motifs were introduced by coupling with suitable arylboronic esters as shown in Scheme 54.
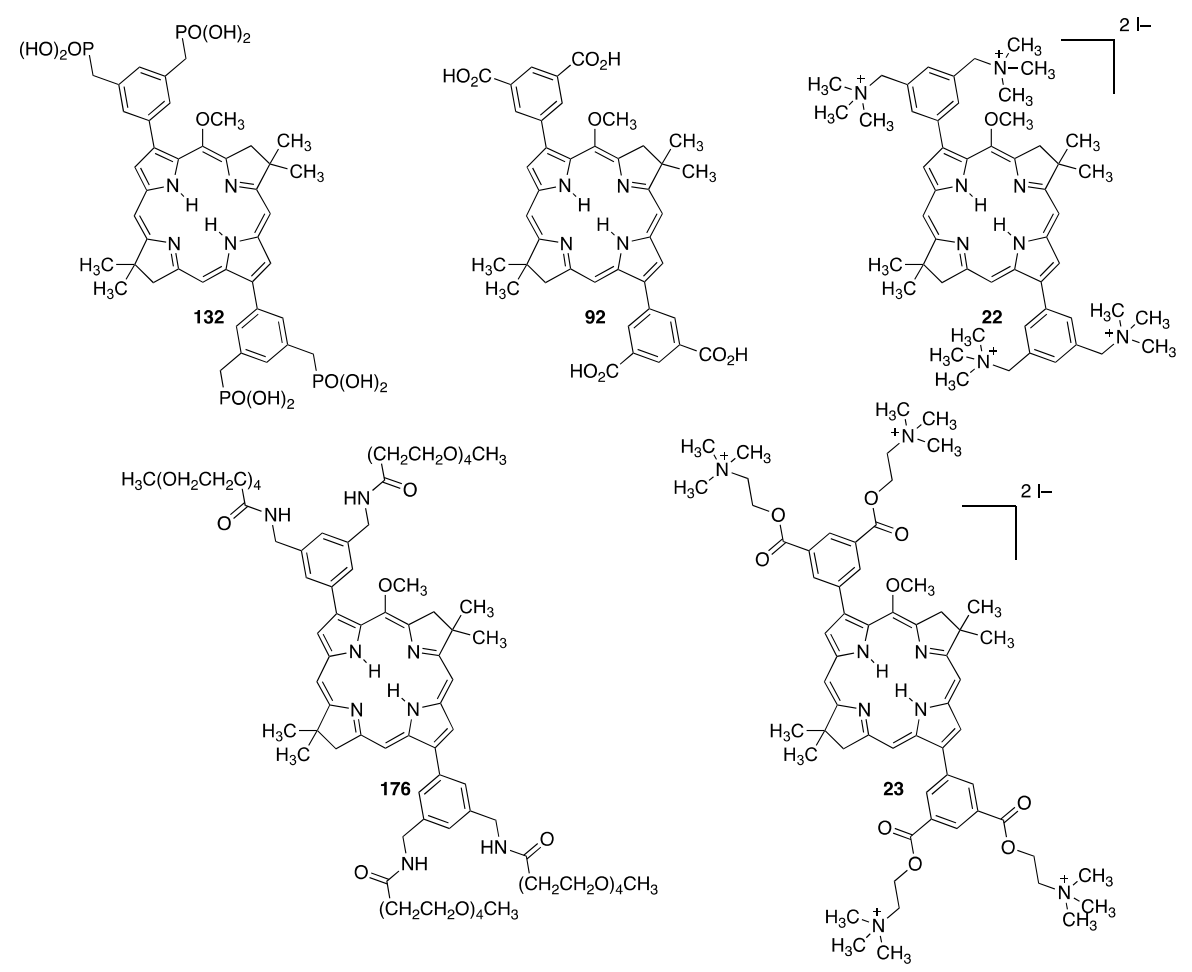

Figure 11. Molecular structures of a variety of examples of water-soluble bacteriochlorins derived by Suzuki coupling (Scheme 54).

The products were compared by Lindsey and co-workers according to several notable parameters [65] (Table 2). The method of purification of the water-soluble adducts, the solubility of the compounds (as measured by the change in UV-vis absorption spectra over a 1000-fold concentration range), the full width at half-maximum (FWHM) of the longest wavelength of absorption and emission, and the stability of the chromophores in the light and dark.Overall, it was found that either the cationic ammonium or neutral-PEGylated species were the most promising derivatives because of their facile purification (precipitation), their amenability to further bioconjugation reactions, and good dark and light stabilities. The PEGylated derivatives were also shown to display very little aggregation, as demonstrated by the sharp absorbance and emission peaks in their optical spectra over a 1000-fold concentration range.

With the PEGylated derivatives appearing to be among the most promising motifs for solubilization, Lindsey and co-workers set out to prepare a series of PEGylated chlorins and bacteriochlorins (with options for bioconjugation) using a range of synthetic methodologies [135,136]. One such example for the direct, late-stage PEGylation of chlorin derivatives was the azide-alkyne Huisgen-cycloaddition (click) reaction between an alkyne-substituted porphyrin or chlorin and an azide-terminated PEG.

This strategy was employed to perform a direct PEGylation of trans-AB porphyrin 179 (Scheme 55) to afford the PEGylated porphyrin 180 [165]. Along analogous routes, synthetic chlorins 181 and 182 were prepared from alkyne-substituted meso-aryl groups and subsequent reactions with PEG-azides [136]. In addition, an aldol condensation method was developed to directly introduce an aryl group bearing three PEG chains to the $\beta$-positions of a $\beta$-diacetyl-substituted chlorin 183. Reaction of $\mathbf{1 8 3}$ with a PEG-substituted aryl aldehyde formed the porphyrin-chalcone $\mathbf{1 8 4}$ (Scheme 56) [136]. The absorption spectrum of the PEGylated chlorin-chalcone $\mathbf{1 8 4}$ was broadened in pure water, indicating its aggregation. 
Table 2. Comparison of relevant properties concerning hydrophilicity of a series of structurally similar synthetic bacteriochlorins, as described by the group of Lindsey [65].

\begin{tabular}{|c|c|c|c|c|c|}
\hline Compounds & Purification Method ${ }^{a}$ & Water-Solubility $^{b}$ & $\begin{array}{l}\text { FWHM (abs, } \\
\text { fl) }(\mathrm{nm})^{\mathrm{c}}\end{array}$ & $\begin{array}{l}\text { Stability in } \\
\text { Light }(\%) d\end{array}$ & $\begin{array}{l}\text { Stability in } \\
\text { Dark (\%) }^{\mathrm{e}}\end{array}$ \\
\hline 132 & reverse phase chromatography & $0.46 \mu \mathrm{M}-460 \mu \mathrm{M}$ & 26,30 & 85 & $>95$ \\
\hline 92 & $\begin{array}{c}\text { ppt, washing with } \\
\text { hexanes/MeOH (49:1) }\end{array}$ & $0.32 \mu \mathrm{M}-320 \mu \mathrm{M}$ & 26,26 & 96 & $>95$ \\
\hline 22 & ppt, washing with $\mathrm{Et}_{2} \mathrm{O} / \mathrm{THF}(1: 1)$ & $0.24 \mu \mathrm{M}-240 \mu \mathrm{M}$ & 26,26 & 82 & $>95$ \\
\hline 23 & ppt.,washing with $\mathrm{Et}_{2} \mathrm{O} / \mathrm{THF}(1: 1)$ & $0.18 \mu \mathrm{M}-180 \mu \mathrm{M}$ & 40,26 & 96 & $>95$ \\
\hline 176 & $\begin{array}{c}\text { ppt, washing with } \\
\text { hexanes } / \mathrm{CH}_{2} \mathrm{Cl}_{2}(19: 1)\end{array}$ & $0.43 \mu \mathrm{M}-430 \mu \mathrm{M}$ & 22,23 & 95 & $>95$ \\
\hline
\end{tabular}

${ }^{a}$ For the final step of the synthesis; ${ }^{b}$ measured in aqueous media (PBs except 176, water) by the absorption upon reciprocal change in concentration and path length; ${ }^{c} 1 \mu \mathrm{M}$ in PBS. FWHM $=$ full width at half maximum of the longest wavelength band of absorption or emission, an indicator of aggregation; ${ }^{\mathrm{d}}$ The $\%$ remaining of a $1 \mu \mathrm{M}$ solution in PBS after several hours of absorption and fluorescence studies. ${ }^{\mathrm{e}}$ The $\%$ remaining of a, $1 \mu \mathrm{M}$ solution in PBS allowed to stand in the dark at $4{ }^{\circ} \mathrm{C}$ for $48 \mathrm{~h}$ (as determined by absorption intensity of $\mathrm{Q}_{\mathrm{y}}$ band.

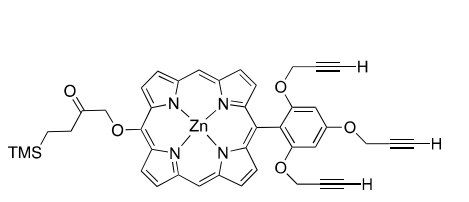

179

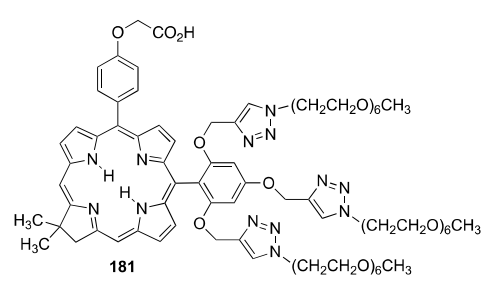

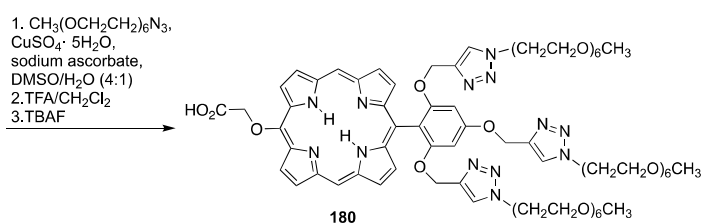

180

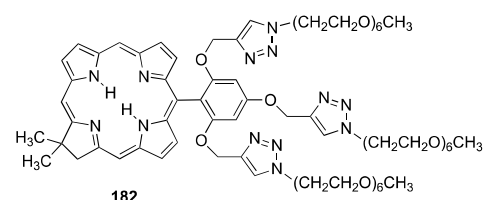

182

Scheme 55. PEGylated porphyrins and chlorins prepared through click chemistry, as described by the group of Lindsey [136].

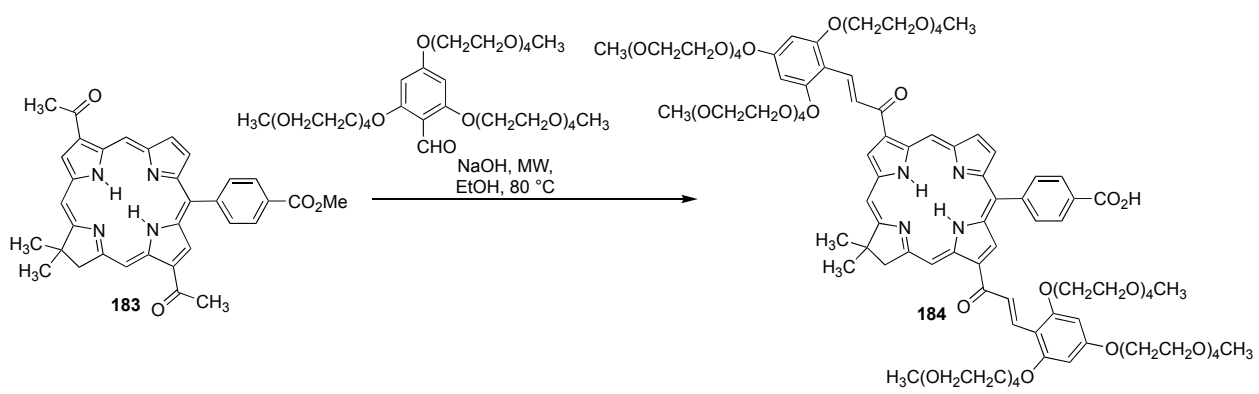

Scheme 56. PEGylated chlorins prepared by Aldol-condensation of $\beta$-diacetyl chlorin, as described by the group of Lindsey [136].

Lindsey and co-workers also used an amide coupling of an alkyl-amine substituted bacteriochlorin with a PEG-NHS ester to produce PEGylated bacteriochlorin 186 (Scheme 57) [135]. The $\beta$-functionalized bacteriochlorin 185 was prepared by Sonogashira coupling and subsequent reduction of the alkynes. Boc-deprotection was followed by saponificiation to furnish the amine and acid-derivatized intermediate, which was reacted with a PEG-NHS ester to provide the PEGylated bacteriochlorin 186. The carboxylic acid functionality on this chromophore is available for bioconjugation. 

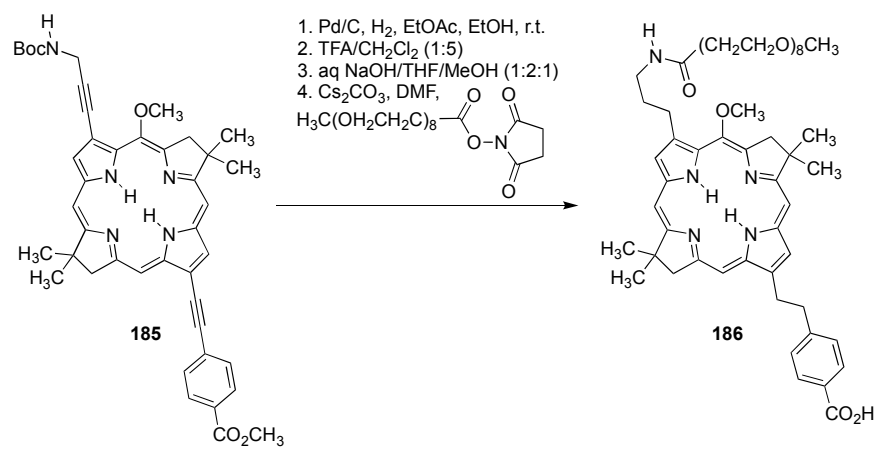

Scheme 57. PEGylated bacteriochlorins bearing a bioconjugatable tether prepared by amide coupling, as described by the group of Lindsey [135].

\section{Summary and Outlook}

In summary, significant progress has been made in the past decades toward the preparation of water-soluble porphyrins and hydroporphyrins. A wide range of options are available for their solubilization in aqueous media. Cationic, anionic or neutral groups may be introduced in regio- and chemoselective fashion. Their number and positioning has major influences on the solubility of the derivatized porphyrin, whereby swallowtail approaches stand out as seemingly particularly effective in mediating water-solubility with a moderate concomitant increase in molecular weight. All solubilizing functionalities can be introduced at early stages of the synthesis of the target compound-generally in protected form - or at late stages. The late-state introduction of the solubilizing motif(s) reduces the number of difficult chromatographic steps needed in the synthetic sequence; and these polar moieties and/or their water-solubility generally complicate their isolation and purification. Irrespective of the timing of the introduction of the solubilizing groups, multiple linking strategies are available. As far as flexibility and ease of implementation, PEGylation strategies stand out because they generate neutral chromophores of good solubility, the PEG chains are chemically stable, the versatility of the linking moieties that can be used to link PEG chains to the chromophore, and the facility of the work-up conditions once the PEG chains are established. A combined approach using both ionic and PEG groups may also have its merits in cases where the introduction of short PEGs was not enough to solubilize the macrocycle.

Even though the toolbox for the synthetic chemist to affect water-solubility is already extensive, the continued development of solubilizing strategies that are mild, selective, and introduce chemically robust solubilization motifs to porphyrins is vital to the field for these versatile chromophores to realize their full potential in the many technical and biomedical applications that take place in aqueous media.

Acknowledgments: This work was supported by the US National Science Foundation through grant CHE-1465133 and the University of Connecticut.

Author Contributions: M.L. and C.B. wrote the paper to equal parts.

Conflicts of Interest: The authors declare no conflict of interest.

\section{References and Note}

1. Huang, H.; Song, W.; Rieffel, J.; Lovell, J.F. Emerging applications of porphyrins in photomedicine. Front. Phys. 2015, 3, 23. [CrossRef] [PubMed]

2. Sternberg, E.D.; Dolphin, D.; Brückner, C. Porphyrin-based photosensitizers for use in photodynamic therapy. Tetrahedron 1998, 54, 4151-4202. [CrossRef]

3. Dolmans, D.E.J.G.J.; Fukumura, D.; Jain, R.K. Photodynamic therapy for cancer. Nat. Rev. Cancer 2003, 3, 380-387. [CrossRef] [PubMed] 
4. Brandis, A.S.; Salomon, Y.; Scherz, A. Bacteriochlorophyll sensitizers in photodynamic therapy. In Chlorophylls and Bacteriochlorophylls; Grimm, B., Porra, R.J., Rüdinger, W., Scheer, H., Eds.; Springer: Dordrecht, The Netherlands, 2006; pp. 485-494.

5. Ethirajan, M.; Chen, Y.; Joshi, P.; Pandey, R.K. The role of porphyrin chemistry in tumor imaging and photodynamic therapy. Chem. Soc. Rev. 2011, 40, 340-362. [CrossRef] [PubMed]

6. Donnelly, R.F.; McCarron, P.A.; Tunney, M.M. Antifungal photodynamic therapy. Microbiol. Res. 2008, 163, 1-12. [CrossRef] [PubMed]

7. Wainwright, M. Photoantimicrobials—So what's stopping us? Photodiagn. Photodyn. Ther. 2009, 6, 167-169. [CrossRef] [PubMed]

8. Pandey, R.K.; James, N.; Chen, Y.; Dobhal, M.P. Cyanine dye-based compounds for tumor imaging with and without photodynamic therapy. Top. Heterocycl. Chem. 2008, 14, 41-74.

9. Weissleder, R.; Pittet, M.J. Imaging in the era of molecular oncology. Nature 2008, 452, 580-589. [CrossRef] [PubMed]

10. Kim, C.; Favazza, C.; Wang, L.V. In vivo photoacoustic tomography of chemicals: High-resolution functional and molecular optical imaging at new depths. Chem. Rev. 2010, 110, 2756-2782. [CrossRef] [PubMed]

11. Luo, S.; Zhang, E.; Su, Y.; Cheng, T.; Shi, C. A review of NIR dyes in cancer targeting and imaging. Biomaterials 2011, 32, 7127-7138. [CrossRef] [PubMed]

12. Wang, L.V.; Hu, S. Photoacoustic tomography: In vivo imaging from organelles to organs. Science 2012, 335, 1458-1462. [CrossRef] [PubMed]

13. Weber, J.; Beard, P.C.; Bohndiek, S.E. Contrast agents for molecular photoacoustic imaging. Nat. Methods 2016, 13, 639-650. [CrossRef] [PubMed]

14. Luciano, M.; Erfanzadeh, M.; Zhou, F.; Zhu, H.; Bornhütter, T.; Röder, B.; Zhu, Q.; Brückner, C. In vivo photoacoustic tumor tomography using a quinoline-annulated porphyrin as NIR molecular contrast agent. Org. Biomol. Chem. 2017, 15, 972-983. [CrossRef] [PubMed]

15. Stender, A.S.; Marchuk, K.; Liu, C.; Sander, S.; Meyer, M.W.; Smith, E.A.; Neupane, B.; Wang, G.; Li, J.; Cheng, J.-X.; et al. Single cell optical imaging and spectroscopy. Chem. Rev. 2013, 113, 2469-2527. [CrossRef] [PubMed]

16. Jiang, J.; Taniguchi, M.; Lindsey, J.S. Near-infrared tunable bacteriochlorins equipped for bioorthogonal labeling. New J. Chem. 2015, 39, 4534-4550. [CrossRef]

17. Spencer, J.A.; Ferraro, F.; Roussakis, E.; Klein, A.; Wu, J.; Runnels, J.M.; Zaher, W.; Mortensen, L.J.; Alt, C.; Turcotte, R.; et al. Direct measurement of local oxygen concentration in the bone marrow of live animals. Nature 2014, 508, 269-273. [CrossRef] [PubMed]

18. Lemon, C.M.; Karnas, E.; Han, X.; Bruns, O.T.; Kempa, T.J.; Fukumura, D.; Bawendi, M.G.; Jain, R.K.; Duda, D.G.; Nocera, D.G. Micelle-encapsulated quantum dot-porphyrin assemblies as in vivo two-photon oxygen sensors. J. Am. Chem. Soc. 2015, 137, 9832-9842. [CrossRef] [PubMed]

19. Drain, C.M.; Varotto, A.; Radivojevic, I. Self-organized porphyrinic materials. Chem. Rev. 2009, 109, 1630-1658. [CrossRef] [PubMed]

20. Jurow, M.; Schuckman, A.E.; Batteas, J.D.; Drain, C.M. Porphyrins as molecular electronic components of functional devices. Coord. Chem. Rev. 2010, 254, 2297-2310. [CrossRef] [PubMed]

21. Tanaka, T.; Osuka, A. Conjugated porphyrin arrays: Synthesis, properties and applications for functional materials. Chem. Soc. Rev. 2015, 44, 943-969. [CrossRef] [PubMed]

22. Barona-Castano, J.C.; Carmona-Vargas, C.C.; Brocksom, T.J.; de Oliveira, K.T. Porphyrins as catalysts in scalable organic reactions. Molecules 2016, 21, 310. [CrossRef] [PubMed]

23. Rybicka-Jasińska, K.; Ciszewski, Ł.W.; Gryko, D. Photocatalytic reaction of diazo compounds with aldehydes. Adv. Synth. Catal. 2016, 358, 1671-1678. [CrossRef]

24. Rybicka-Jasińska, K.; Shan, W.; Zawada, K.; Kadish, K.M.; Gryko, D. Porphyrins as photoredox catalysts: Experimental and theoretical studies. J. Am. Chem. Soc. 2016, 138, 15451-15458. [CrossRef] [PubMed]

25. Panda, M.K.; Ladomenou, K.; Coutsolelos, A.G. Porphyrins in bio-inspired transformations: Light-harvesting to solar cell. Coord. Chem. Rev. 2012, 256, 2601-2627. [CrossRef]

26. Urbani, M.; Grätzel, M.; Nazeeruddin, M.K.; Torres, T. Meso-Substituted porphyrins for dye-sensitized solar cells. Chem. Rev. 2014, 114, 12330-12396. [CrossRef] [PubMed]

27. Kärkäs, M.D.; Verho, O.; Johnston, E.V.; Åkermark, B. Artificial photosynthesis: Molecular systems for catalytic water oxidation. Chem. Rev. 2014, 114, 11863-12001. [CrossRef] [PubMed] 
28. Hedley, G.J.; Ruseckas, A.; Samuel, I.D.W. Light harvesting for organic photovoltaics. Chem. Rev. 2017, 117, 796-837. [CrossRef] [PubMed]

29. Smith, K.M. Development of porphyrin syntheses. New J. Chem. 2016, 40, 5644-5649. [CrossRef]

30. Hiroto, S.; Miyake, Y.; Shinokubo, H. Synthesis and functionalization of porphyrins through organometallic methodologies. Chem. Rev. 2017, 117, 2910-3043. [CrossRef] [PubMed]

31. Montforts, F.-P.; Gerlach, B.; Höper, F. Discovery and synthesis of less common natural hydroporphyrins. Chem. Rev. 1994, 94, 327-347. [CrossRef]

32. Brückner, C.; Samankumara, L.; Ogikubo, J. Syntheses of bacteriochlorins and isobacteriochlorins. In Handbook of Porphyrin Science; Kadish, K.M., Smith, K.M., Guilard, R., Eds.; World Scientific: River Edge, NJ, USA, 2012; Volume 17, pp. 1-112.

33. Lindsey, J.S. De novo synthesis of gem-dialkyl chlorophyll analogues for probing and emulating our green world. Chem. Rev. 2015, 115, 6534-6620. [CrossRef] [PubMed]

34. Taniguchi, M.; Lindsey, J.S. Synthetic chlorins, possible surrogates for chlorophylls, prepared by derivatization of porphyrins. Chem. Rev. 2017, 117, 344-535. [CrossRef] [PubMed]

35. Arnold, L.; Müllen, K. Modifying the porphyrin core-A chemist's jigsaw. J. Porphyr. Phthalocyanines 2011, 15, 757-779. [CrossRef]

36. Brückner, C.; Akhigbe, J.; Samankumara, L. Syntheses and structures of porphyrin analogues containing non-pyrrolic heterocycles. In Handbook of Porphyrin Science; Kadish, K.M., Smith, K.M., Guilard, R., Eds.; World Scientific: River Edge, NJ, USA, 2014; Volume 31, pp. 1-276.

37. Szyszko, B.; Latos-Grazynski, L. Core chemistry and skeletal rearrangements of porphyrinoids and metalloporphyrinoids. Chem. Soc. Rev. 2015, 44, 3588-3616. [CrossRef] [PubMed]

38. Brückner, $\mathrm{C}$. The breaking and mending of meso-tetraarylporphyrins: Transmuting the pyrrolic building blocks. Acc. Chem. Res. 2016, 49, 1080-1092. [CrossRef] [PubMed]

39. Costa, L.D.; Costa, J.I.; Tome, A.C. Porphyrin macrocycle modification: Pyrrole ring-contracted or -expanded porphyrinoids. Molecules 2016, 21, 320. [CrossRef] [PubMed]

40. Hambright, P. Chemistry of water-soluble porphyrins. In The Porphyrin Handbook; Kadish, K.M., Smith, K.M., Guilard, R., Eds.; Academic Press: San Diego, CA, USA, 2000; Volume 3, pp. 129-210.

41. Pisarek, S.; Maximova, K.; Gryko, D. Strategies toward the synthesis of amphiphilic porphyrins. Tetrahedron 2014, 70, 6685-6715. [CrossRef]

42. Singh, S.; Aggarwal, A.; Bhupathiraju, N.V.; Arianna, G.; Tiwari, K.; Drain, C.M. Glycosylated porphyrins, phthalocyanines, and other porphyrinoids for diagnostics and therapeutics. Chem. Rev. 2015, 115, 10261-10306. [CrossRef] [PubMed]

43. Moylan, C.; Scanlan, E.M.; Senge, M.O. Chemical synthesis and medicinal applications of glycoporphyrins. Curr. Med. Chem. 2015, 22, 2238-2348. [CrossRef] [PubMed]

44. Králová, J.; Kejík, Z.; Bříza, T.; Poučková, P.; Král, A.; Martásek, P.; Král, V. Porphyrin-cyclodextrin conjugates as a nanosystem for versatile drug delivery and multimodal cancer therapy. J. Med. Chem. 2010, 53, 128-138. [CrossRef] [PubMed]

45. Gotardo, M.C.A.F.; Sacco, H.C.; Filho, J.C.S.; Ferreira, A.G.; Tedesco, A.C.; Assis, M.D. A novel crowned porphyrin derived from meso-tetrakis(pentafluorophenyl)porphyrin. J. Porphyr. Phthalocyanines 2003, 7, 399-404. [CrossRef]

46. Welch, C.; Archibald, S.J.; Boyle, R.W. Reductive amination-A convenient method for generating diverse, mono-functionalised 5,10,15,20-tetraphenylporphyrins. Synthesis 2009, 551-556. [CrossRef]

47. McCarthy, J.R.; Perez, M.J.; Brückner, C.; Weissleder, R. A polymeric nanoparticle preparation that eradicates tumors. Nano Lett. 2005, 5, 2552-2556. [CrossRef] [PubMed]

48. Paproski, R.J.; Forbrich, A.; Huynh, E.; Chen, J.; Lewis, J.D.; Zheng, G.; Zemp, R.J. Porphyrin nanodroplets: Sub-micrometer ultrasound and photoacoustic contrast imaging agents. Small 2016, 12, 371-380. [CrossRef] [PubMed]

49. Da Silveira, J.M.; da Silva, A.R.; Senge, M.O.; Jorge, R.A. Effects of preparation conditions of poly(lactide-co-glycolide) nanoparticles loaded with amphiphilic porphyrins and their photoactivities. J. Nanosci. Nanotechnol. 2014, 14, 6274-6286. [CrossRef] [PubMed]

50. Chouikrat, R.; Seve, A.; Vanderesse, R.; Benachour, H.; Barberi-Heyob, M.; Richeter, S.; Raehm, L.; Durand, J.O.; Verelst, M.; Frochot, C. Non-polymeric nanoparticles for photodynamic therapy applications: Recent developments. Curr. Med. Chem. 2012, 19, 781-792. [CrossRef] [PubMed] 
51. Paszko, E.; Senge, M.O. Immunoliposomes. Curr. Med. Chem. 2012, 19, 5239-5277. [CrossRef] [PubMed]

52. Huynh, E.; Lovell, J.F.; Helfield, B.L.; Jeon, M.; Kim, C.; Goertz, D.E.; Wilson, B.C.; Zheng, G. Porphyrin shell microbubbles with intrinsic ultrasound and photoacoustic properties. J. Am. Chem. Soc. 2012, 134, 16464-16467. [CrossRef] [PubMed]

53. Lovell, J.F.; Jin, C.S.; Huynh, E.; Jin, H.; Kim, C.; Rubinstein, J.L.; Chan, W.C.W.; Cao, W.; Wang, L.V.; Zheng, G. Porphysome nanovesicles generated by porphyrin bilayers for use as multimodal biophotonic contrast agents. Nat. Mater. 2011, 10, 324-332. [CrossRef] [PubMed]

54. Hambright, P.; Fleischer, E.B. The acid-base equilibria, kinetics of copper ion incorporation, and acid-catalyzed zinc ion displacement from the water-soluble porphyrin $\alpha, \beta, \gamma$, $\delta$-tetra(4- $N$ methylpyridyl)-porphine. Inorg. Chem. 1970, 9, 1757-1761. [CrossRef]

55. Wheelhouse, R.T.; Sun, D.; Han, H.; Han, F.X.; Hurley, L.H. Cationic porphyrins as telomerase inhibitors: The interaction of tetra-(N-methyl-4-pyridyl)porphine with quadruplex DNA. J. Am. Chem. Soc. 1998, 120, 3261-3262. [CrossRef]

56. McMillin, D.R.; Shelton, A.H.; Bejune, S.A.; Fanwick, P.E.; Wall, R.K. Understanding binding interactions of cationic porphyrins with $\beta$-form DNA. Coord. Chem. Rev. 2005, 249, 1451-1459. [CrossRef]

57. Merchat, M.; Bertolini, G.; Giacomini, P.; Villaneuva, A.; Jori, G. Meso-Substituted cationic porphyrins as efficient photosensitizers of gram-positive and gram-negative bacteria. J. Photochem. Photobiol. B 1996, 32, 153-157. [CrossRef]

58. Commercial Suppliers of Porphyrins, for example: Frontier Scientific: Logan, UT, USA; Sigma-Aldrich: St. Louis, MO, USA; PorphyChem SAS: Dijon, France; Porphyrin Systems GbR: Appen, Germany.

59. Manono, J.; Marzilli, P.A.; Marzilli, L.G. New porphyrins bearing positively charged peripheral groups linked by a sulfonamide group to meso-tetraphenylporphyrin: Interactions with calf thymus DNA. Inorg. Chem. 2009, 48, 5636-5647. [CrossRef] [PubMed]

60. Lamarche, F.; Sol, V.; Huang, Y.-M.; Granet, R.; Guilloton, M.; Krausz, P. Synthesis and biological evaluation of polyamine-porphyrin conjugates as potential agents in photodynamic therapy (PDT). J. Porphyr. Phthalocyanines 2002, 6, 130-134. [CrossRef]

61. Drogat, N.; Gady, C.; Granet, R.; Sol, V. Design and synthesis of water-soluble polyaminated chlorins and bacteriochlorins-With near-infrared absorption. Dyes Pigments 2013, 98, 609-614. [CrossRef]

62. Taima, H.; Okubo, A.; Yoshioka, N.; Inoue, H. Synthesis of cationic water-soluble esters of chlorin e6. Tetrahedron Lett. 2005, 46, 4161-4164. [CrossRef]

63. Ruzié, C.; Krayer, M.; Balasubramanian, T.; Lindsey, J.S. Tailoring a bacteriochlorin building block with cationic, amphipathic, or lipophilic substituents. J. Org. Chem. 2008, 73, 5806-5820. [CrossRef] [PubMed]

64. Huang, L.; Huang, Y.Y.; Mroz, P.; Tegos, G.P.; Zhiyentayev, T.; Sharma, S.K.; Lu, Z.; Balasubramanian, T.; Krayer, M.; Ruzie, C.; et al. Stable synthetic cationic bacteriochlorins as selective antimicrobial photosensitizers. Antimicrob. Agents Chemother. 2010, 54, 3834-3841. [CrossRef] [PubMed]

65. Jiang, J.; Yang, E.; Reddy, K.R.; Niedzwiedzki, D.M.; Kirmaier, C.; Bocian, D.F.; Holten, D.; Lindsey, J.S. Synthetic bacteriochlorins bearing polar motifs (carboxylate, phosphonate, ammonium and a short PEG). Water-solubilization, bioconjugation, and photophysical properties. New J. Chem. 2015, 39, 5694-5714. [CrossRef]

66. Sharma, S.K.; Krayer, M.; Sperandio, F.F.; Huang, L.; Huang, Y.Y.; Holten, D.; Lindsey, J.S.; Hamblin, M.R. Synthesis and evaluation of cationic bacteriochlorin amphiphiles with effective in vitro photodynamic activity against cancer cells at low nanomolar concentration. J. Porphyr. Phthalocyanines 2013, 17, $73-85$. [CrossRef] [PubMed]

67. Thamyongkit, P.; Speckbacher, M.; Diers, J.R.; Kee, H.L.; Kirmaier, C.; Holten, D.; Bocian, D.F.; Lindsey, J.S. Swallowtail porphyrins: Synthesis, characterization and incorporation into porphyrin dyads. J. Org. Chem. 2004, 69, 3700-3710. [CrossRef] [PubMed]

68. Thamyongkit, P.; Lindsey, J.S. Synthesis of swallowtail-substituted multiporphyrin rods. J. Org. Chem. 2004, 69, 5796-5799. [CrossRef] [PubMed]

69. Reddy, K.R.; Lubian, E.; Pavan, M.P.; Kim, H.-J.; Yang, E.; Holten, D.; Lindsey, J.S. Synthetic bacteriochlorins with integral spiro-piperidine motifs. New J. Chem. 2013, 37, 1157-1173. [CrossRef]

70. Balaz, M.; Collins, H.A.; Dahlstedt, E.; Anderson, H.L. Synthesis of hydrophilic conjugated porphyrin dimers for one-photon and two-photon photodynamic therapy at NIR wavelengths. Org. Biomol. Chem. 2009, 7, 874-888. [CrossRef] [PubMed] 
71. Banfi, S.; Caruso, E.; Buccafurni, L.; Battini, V.; Zazzaron, S.; Barbieri, P.; Orlandi, V. Antibacterial activity of tetraaryl-porphyrin photosensitizers: An in vitro study on gram negative and gram positive bacteria. J. Photochem. Photobiol. B 2006, 85, 28-38. [CrossRef] [PubMed]

72. Tovmasyan, A.G.; Babayan, N.S.; Sahakyan, L.A.; Shahkhatuni, A.G.; Gasparyan, G.H.; Aroutiounian, R.M.; Ghazaryan, R.K. Synthesis and in vitro anticancer activity of water-soluble cationic pyridylporphyrins and their metallocomplexes. J. Porphyr. Phthalocyanines 2008, 12, 1100-1110. [CrossRef]

73. Diabate, P.D.; Laguerre, A.; Pirrotta, M.; Desbois, N.; Boudon, J.; Gros, C.P.; Monchaud, D. DNA structure-specific sensitization of a metalloporphyrin leads to an efficient in vitro quadruplex detection molecular tool. New J. Chem. 2016, 40, 5683-5689. [CrossRef]

74. Laguerre, A.; Chang, Y.; Pirrotta, M.; Desbois, N.; Gros, C.P.; Lesniewska, E.; Monchaud, D. Surface-promoted aggregation of amphiphilic quadruplex ligands drives their selectivity for alternative DNA structures. Org. Biomol. Chem. 2015, 13, 7034-7039. [CrossRef] [PubMed]

75. Ko, Y.J.; Yun, K.J.; Kang, M.S.; Park, J.; Lee, K.T.; Park, S.B.; Shin, J.H. Synthesis and in vitro photodynamic activities of water-soluble fluorinated tetrapyridylporphyrins as tumor photosensitizers. Bioorg. Med. Chem. Lett. 2007, 17, 2789-2794. [CrossRef] [PubMed]

76. Schmitt, F.; Govindaswamy, P.; Süss-Fink, G.; Ang, W.H.; Dyson, P.J.; Juillerat-Jeanneret, L.; Therrien, B. Ruthenium porphyrin compounds for photodynamic therapy of cancer. J. Med. Chem. 2008, 51, 1811-1816. [CrossRef] [PubMed]

77. Schmitt, F.; Govindaswamy, P.; Zava, O.; Süss-Fink, G.; Juillerat-Jeanneret, L.; Therrien, B. Combined arene ruthenium porphyrins as chemotherapeutics and photosensitizers for cancer therapy. J. Biol. Inorg. Chem. 2009, 14, 101-109. [CrossRef] [PubMed]

78. Hu, X.; Ogawa, K.; Kiwada, T.; Odani, A. Water-soluble metalloporphyrinates with excellent photo-induced anticancer activity resulting from high tumor accumulation. J. Inorg. Biochem. 2017, 170, 1-7. [CrossRef] [PubMed]

79. Gianferrara, T.; Serli, B.; Zangrando, E.; Iengo, E.; Alessio, E. Pyridylporphyrins peripherally coordinated to ruthenium-nitrosyls, including the water-soluble $\mathrm{Na}_{4}\left[\mathrm{Zn} \cdot 4^{\prime} \mathrm{TPyP}\left(\mathrm{RuCl}_{4}(\mathrm{NO})\right\}_{4}\right]$ : Synthesis and structural characterization. New J. Chem. 2005, 29, 895-903. [CrossRef]

80. Haeubl, M.; Reith, L.M.; Gruber, B.; Karner, U.; Müller, N.; Knör, G.; Schoefberger, W. DNA interactions and photocatalytic strand cleavage by artificial nucleases based on water-soluble gold(III) porphyrins. J. Biol. Inorg. Chem. 2009, 14, 1037-1052. [CrossRef] [PubMed]

81. Sutton, J.M.; Clarke, O.J.; Fernandez, N.; Boyle, R.W. Porphyrin, chlorin, and bacteriochlorin isothiocyanates: Useful reagents for the synthesis of photoactive bioconjugates. Bioconjug. Chem. 2002, 13, 249-263. [CrossRef] [PubMed]

82. Song, R.; Kim, Y.-S.; Lee, C.O.; Sohn, Y.S. Synthesis and antitumor activity of DNA binding cationic porphyrin-platinum(II) complexes. Tetrahedron Lett. 2003, 44, 1537-1540. [CrossRef]

83. Spagnul, C.; Alberto, R.; Gasser, G.; Ferrari, S.; Pierroz, V.; Bergamo, A.; Gianferrara, T.; Alessio, E. Novel water-soluble ${ }^{99 \mathrm{~m}} \mathrm{Tc}(\mathrm{I}) / \operatorname{Re}(\mathrm{I})$-porphyrin conjugates as potential multimodal agents for molecular imaging. J. Inorg. Biochem. 2013, 122, 57-65. [CrossRef] [PubMed]

84. Gianferrara, T.; Spagnul, C.; Alberto, R.; Gasser, G.; Ferrari, S.; Pierroz, V.; Bergamo, A.; Alessio, E. Towards matched pairs of porphyrin- $\mathrm{Re}^{\mathrm{I}} /{ }^{99} \mathrm{~m}_{\mathrm{Tc}}{ }^{\mathrm{I}}$ conjugates that combine photodynamic activity with fluorescence and radio imaging. ChemMedChem 2014, 9, 1231-1237. [CrossRef] [PubMed]

85. Mion, G.; Mari, C.; Da Ros, T.; Rubbiani, R.; Gasser, G.; Gianferrara, T. Towards the synthesis of new tumor targeting photosensitizers for photodynamic therapy and imaging applications. ChemistrySelect 2017, 2, 190-200. [CrossRef]

86. Feng, X.-X.; Zhang, J.-X.; Wu, Y.; Zhang, Q.; Liu, J.-C. Detailed profiling on DNA binding affinity, cytotoxicity and pathway of induced cell death of novel water-soluble $\mathrm{Cu}(\mathrm{II})$-based acylhydrazone porphyrin derivatives. Dyes Pigm. 2017, 136, 773-781. [CrossRef]

87. Entract, G.M.; Bryden, F.; Domarkas, J.; Savoie, H.; Allott, L.; Archibald, S.J.; Cawthorne, C.; Boyle, R.W. Development of PDT/PET theranostics: Synthesis and biological evaluation of an ${ }^{18}$ F-radiolabeled water-soluble porphyrin. Mol. Pharm. 2015, 12, 4414-4423. [CrossRef] [PubMed]

88. Tovmasyan, A.; Babayan, N.; Poghosyan, D.; Margaryan, K.; Harutyunyan, B.; Grigoryan, R.; Sarkisyan, N.; Spasojevic, I.; Mamyan, S.; Sahakyan, L.; et al. Novel amphiphilic cationic porphyrin and its Ag(II) complex as potential anticancer agents. J. Inorg. Biochem. 2014, 140, 94-103. [CrossRef] [PubMed] 
89. Matsumoto, J.; Suemoto, Y.; Kanemaru, H.; Takemori, K.; Shigehara, M.; Miyamoto, A.; Yokoi, H.; Yasuda, M. Alkyl substituent effect on photosensitized inactivation of Escherichia coli by pyridinium-bonded P-porphyrins. J. Photochem. Photobiol. B 2017, 168, 124-131. [CrossRef] [PubMed]

90. Matsumoto, J.; Shinbara, T.; Tanimura, S.-I.; Matsumoto, T.; Shiragami, T.; Yokoi, H.; Nosaka, Y.; Okazaki, S.; Hirakawa, K.; Yasuda, M. Water-soluble phosphorus porphyrins with high activity for visible light-assisted inactivation of Saccharomyces cerevisiae. Photochem. Photobiol. A 2011, 218, 178-184. [CrossRef]

91. Aravindu, K.; Mass, O.; Vairaprakash, P.; Springer, J.W.; Yang, E.; Niedzwiedzki, D.M.; Kirmaier, C.; Bocian, D.F.; Holten, D.; Lindsey, J.S. Amphiphilic chlorins and bacteriochlorins in micellar environments. Molecular design, de novo synthesis, and photophysical properties. Chem. Sci. 2013, 4, 3459-3477. [CrossRef]

92. Reeve, J.E.; Collins, H.A.; Mey, K.D.; Kohl, M.M.; Thorley, K.J.; Paulsen, O.; Clays, K.; Anderson, H.L. Amphiphilic porphyrins for second harmonic generation imaging. J. Am. Chem. Soc. 2009, 131, 2758-2759. [CrossRef] [PubMed]

93. Reeve, J.E.; Corbett, A.D.; Boczarow, I.; Kaluza, W.; Barford, W.; Bayley, H.; Wilson, T.; Anderson, H.L. Porphyrins for probing electrical potential across lipid bilayer membranes by second harmonic generation. Angew. Chem. Int. Ed. Engl. 2013, 52, 9044-9048. [CrossRef] [PubMed]

94. Gros, C.P.; Michelin, C.; Depotter, G.; Desbois, N.; Clays, K.; Cui, Y.; Zeng, L.; Fang, Y.; Ngo, H.M.; Lopez, C. Non-linear optical, electrochemical and spectroelectrochemical properties of amphiphilic inner salt porphyrinic systems. J. Porphyr. Phthalocyanines 2016, 20, 1002-1015. [CrossRef]

95. Manono, J.; Marzilli, P.A.; Fronczek, F.R.; Marzilli, L.G. New porphyrins bearing pyridyl peripheral groups linked by secondary or tertiary sulfonamide groups: Synthesis and structural characterization. Inorg. Chem. 2009, 48, 5626-5635. [CrossRef] [PubMed]

96. Perera, T.; Abhayawardhana, P.; Marzilli, P.A.; Fronczek, F.R.; Marzilli, L.G. Formation of a metal-to-nitrogen bond of normal length by a neutral sufonamide group within a tridentate ligand. A new approach to radiopharmaceutical bioconjugation. Inorg. Chem. 2013, 52, 2412-2421. [CrossRef] [PubMed]

97. Guldi, D.M.; Zilbermann, I.; Anderson, G.; Li, A.; Balbinot, D.; Jux, N.; Hatzimarinaki, M.; Hirsch, A.; Prato, M. Multicomponent redox gradients on photoactive electrode surfaces. Chem. Commun. 2004, 726-727. [CrossRef] [PubMed]

98. Matsumoto, J.; Kubo, T.; Shinbara, T.; Matsuda, N.; Shiragami, T.; Fujitsuka, M.; Majima, T.; Yasuda, M. Spectroscopic analysis of the interaction of human serum albumin with tricationic phosphorus porphyrins bearing axial pyridinio groups. Bull. Chem. Soc. Jpn. 2013, 86, 1240-1247. [CrossRef]

99. Milgrom, L.R.; Bone, S.; Bruce, D.W.; Macdonald, M.P. Evidence for solid-state proton conductivity and low-dimensional ordering in meso-tetrakis (2-imidazolyl)porphyrin. J. Mol. Electron. 1991, 7, 95-100.

100. Bhaumik, J.; Yao, Z.; Borbas, K.E.; Taniguchi, M.; Lindsey, J.S. Masked imidazolyl-dipyrromethanes in the synthesis of imidazole-substituted porphyrins. J. Org. Chem. 2006, 71, 8807-8817. [CrossRef] [PubMed]

101. Mroz, P.; Bhaumik, J.; Dogutan, D.K.; Aly, Z.; Kamal, Z.; Khalid, L.; Kee, H.L.; Bocian, D.F.; Holten, D.; Lindsey, J.S.; et al. Imidazole metalloporphyrins as photosensitizers for photodynamic therapy: Role of molecular charge, central metal and hydroxyl radical production. Cancer Lett. 2009, 282, 63-76. [CrossRef] [PubMed]

102. Fuhrhop, J.-H.; Smith, K.M. Laboratory Methods in Porphyrin and Metalloporphyrin Research; Elsevier: Amsterdam, The Netherlands, 1975.

103. Longo, F.R.; Finarelli, M.G.; Kim, J.B. The synthesis and some physical properties of $m s$-tetra (pentafluorophenyl)-porphin and ms-tetra (pentachlorophenyl) porphin. J. Heterocycl. Chem. 1969, 6, 927-931. [CrossRef]

104. Datta-Gupta, N.; Bardos, T. Synthetic porphyrins. I. Synthesis and spectra of some para-substituted meso-tetraphenylporphines. J. Heterocycl. Chem. 1966, 3, 495-502. [CrossRef]

105. Lindsey, J.S.; Schreiman, I.C.; Hsu, H.C.; Kearney, P.C.; Marguerettaz, A.M. Rothemund and Adler-Longo reactions revisited: Synthesis of tetraphenylporphyrins under equilibrium conditions. J. Org. Chem. 1987, 52, 827-836. [CrossRef]

106. Kostas, I.D.; Coutsolelos, A.G.; Charalambidis, G.; Skondra, A. The first use of porphyrins as catalysts in cross-coupling reactions: A water-soluble palladium complex with a porphyrin ligand as an efficient catalyst precursor for the Suzuki-Miyaura reaction in aqueous media under aerobic conditions. Tetrahedron Lett. 2007, 48, 6688-6691. [CrossRef] 
107. Murashima, T.; Tsujimoto, S.; Yamada, T.; Miyazawa, T.; Uno, H.; Ono, N.; Sugimoto, N. Synthesis of water-soluble porphyrin and the corresponding highly planar benzoporphyrin without meso-substituents. Tetrahedron Lett. 2005, 46, 113-116. [CrossRef]

108. Ogawa, K.; Hasegawa, H.; Inaba, Y.; Kobuke, Y.; Inouye, H.; Kanemitsu, Y.; Kohno, E.; Hirano, T.; Ogura, S.; Okura, I. Water-soluble bis(imidazolylporphyrin) self-assemblies with large two-photon absorption cross sections as potential agents for photodynamic therapy. J. Med. Chem. 2006, 49, 2276-2283. [CrossRef] [PubMed]

109. Inaba, Y.; Ogawa, K.; Kobuke, Y. Synthesis and properties of acetylene-linked bis- and tris- porphyrins toward two-photon photodynamic therapy. J. Porphyr. Phthalocyanines 2007, 11, 406-417. [CrossRef]

110. Muresan, A.Z.; Lindsey, J.S. Design and synthesis of water-soluble bioconjugatable trans-AB-porphyrins. Tetrahedron 2008, 64, 11440-11448. [CrossRef] [PubMed]

111. Subbarayan, M.; Shetty, S.J.; Srivastava, T.S.; Noronha, O.P.D.; Samuel, A.M.; Mukhtar, H. Water-soluble 99m Tc-labeled dendritic novel porphyrins tumor imaging and diagnosis. Biochem. Biophys. Res. Commun. 2001, 281, 32-36. [CrossRef] [PubMed]

112. Eggenspiller, A.; Michelin, C.; Desbois, N.; Richard, P.; Barbe, J.-M.; Denat, F.; Licona, C.; Gaiddon, C.; Sayeh, A.; Choquet, P.; et al. Design of porphyrin-DOTA-like scaffolds as all-in-one multimodal heterometallic complexes for medical imaging. Eur. J. Org. Chem. 2013, 2013, 6629-6643. [CrossRef]

113. Gros, C.P.; Eggenspiller, A.; Nonat, A.; Barbe, J.-M.; Denat, F. New potential bimodal imaging contrast agents based on DOTA-like and porphyrin macrocycles. MedChem Comm 2011, 2, 119-125. [CrossRef]

114. Luo, J.; Chen, L.-F.; Hu, P.; Chen, Z.-N. Tetranuclear gadolinium(III) porphyrin complex as a theranostic agent for multimodal imaging and photodynamic therapy. Inorg. Chem. 2014, 53, 4184-4191. [CrossRef] [PubMed]

115. You, Y.; Gibson, S.L.; Hilf, R.; Davies, S.R.; Oseroff, A.R.; Roy, I.; Ohulchanskyy, T.Y.; Bergey, E.J.; Detty, M.R. Water-soluble, core-modified porphyrins. 3. Synthesis, photophysical properties, and in vitro studies of photosensitization, uptake, and localization with carboxylic acid-substituted derivatives. J. Med. Chem. 2003, 46, 3734-3747. [CrossRef] [PubMed]

116. Sour, A.; Jenni, S.; Ortí-Suárez, A.; Schmitt, J.; Heitz, V.; Bolze, F.; Loureiro de Sousa, P.; Po, C.; Bonnet, C.S.; Pallier, A.; et al. Four gadolinium(III) complexes appended to a porphyrin: A water-soluble molecular theranostic agent with remarkable relaxivity suited for mri tracking of the photosensitizer. Inorg. Chem. 2016, 55, 4545-4554. [CrossRef] [PubMed]

117. Jiang, J.; Vairaprakash, P.; Reddy, K.R.; Sahin, T.; Pavan, M.P.; Lubian, E.; Lindsey, J.S. Hydrophilic tetracarboxy bacteriochlorins for photonics applications. Org. Biomol. Chem. 2014, 12, 86-103. [CrossRef] [PubMed]

118. Srivastava, T.S.; Tsutsui, M. Preparation and purification of tetrasodium meso-tetra( $p$-sulfophenyl)porphine. An easy procedure. J. Org. Chem. 1973, 38, 2103. [CrossRef]

119. Mahammed, A.; Goldberg, I.; Gross, Z. Highly selective chlorosulfonation of tris(pentafluorophenyl)corrole as a synthetic tool for the preparation of amphiphilic corroles and metal complexes of planar chirality. Org. Lett. 2001, 3, 3443-3446. [CrossRef] [PubMed]

120. Saltsman, I.; Mahammed, A.; Goldberg, I.; Tkachenko, E.; Botoshansky, M.; Gross, Z. Selective substitution of corroles: Nitration, hydroformylation, and chlorosulfonation. J. Am. Chem. Soc. 2002, 124, 7411-7420. [CrossRef] [PubMed]

121. Vestfrid, J.; Kothari, R.; Kostenko, A.; Goldberg, I.; Tumanskii, B.; Gross, Z. Intriguing physical and chemical properties of phosphorus corroles. Inorg. Chem. 2016, 55, 6061-6067. [CrossRef] [PubMed]

122. Thomas, A.P.; Saneesh Babu, P.S.; Asha Nair, S.; Ramakrishnan, S.; Ramaiah, D.; Chandrashekar, T.K.; Srinivasan, A.; Radhakrishna Pillai, M. Meso-Tetrakis( $p$-sulfonatophenyl)-N-confused porphyrin tetrasodium salt: A potential sensitizer for photodynamic therapy. J. Med. Chem. 2012, 55, 5110-5120. [CrossRef] [PubMed]

123. Song, R.; Kim, Y.-S.; Sohn, Y.S. Synthesis and selective tumor targetting properties of water soluble porphyrin-Pt(II) conjugates. J. Inorg. Biochem. 2002, 83, 83-88. [CrossRef]

124. Zhang, X.A.; Lovejoy, K.S.; Jasanoff, A.; Lippard, S.J. Water-soluble porphyrins as a dual-function molecular imaging platform for MRI and fluorescence zinc sensing. Proc. Natl. Acad. Sci. USA 2007, 104, 10780-10785. [CrossRef] [PubMed] 
125. Liu, F.; Zou, T.J.; Tan, Z.L.; Chen, S.; Wu, Z.H.; Yan, G.P.; Zhang, Q.; Liang, S.C.; Yang, J. Isoindoline nitroxide-labeled porphyrins as potential fluorescence-suppressed spin probes. Org. Biomol. Chem. 2017, 15, 1245-1253. [CrossRef] [PubMed]

126. Monteiro, C.J.P.; Pereira, M.M.; Pinto, S.M.A.; Simões, A.V.C.; Sá, G.F.F.; Arnaut, L.G.; Formosinho, S.J.; Simões, S.; Wyatt, M.F. Synthesis of amphiphilic sulfonamide halogenated porphyrins: MALDI-TOFMS characterization and evaluation of 1-octanol/water partition coefficients. Tetrahedron 2008, 64, 5132-5138. [CrossRef]

127. Dabrowski, J.M.; Arnaut, L.G.; Pereira, M.M.; Monteiro, C.J.; Urbanska, K.; Simoes, S.; Stochel, G. New halogenated water-soluble chlorin and bacteriochlorin as photostable PDT sensitizers: Synthesis, spectroscopy, photophysics, and in vitro photosensitizing efficacy. ChemMedChem 2010, 5, 1770-1780. [CrossRef] [PubMed]

128. Brandis, A.; Mazor, O.; Neumark, E.; Rosenbach-Belkin, V.; Salomon, Y.; Scherz, A. Novel water-soluble bacteriochlorophyll derivatives for vascular-targeted photodynamic therapy: Synthesis, solubility, phototoxicity and the effect of serum proteins. Photochem. Photobiol. 2005, 81, 983-993. [CrossRef] [PubMed]

129. Mazor, O.; Brandis, A.; Plaks, V.; Neumark, E.; Rosenbach-Belkin, V.; Salomon, Y.; Scherz, A. WSTI 1, a novel water-soluble bacteriochlorophyll derivative; cellular uptake, pharmacokinetics, biodistribution and vascular-targeted photodynamic activity using melanoma tumors as a model. Photochem. Photobiol. 2005, 81, 342-351. [CrossRef] [PubMed]

130. Wedel, M.; Walter, A.; Montforts, F.-P. Synthesis of metalloporphyrins and metallochlorins for immobilization on electrode surfaces. Eur. J. Org. Chem. 2001, 2001, 1681-1687. [CrossRef]

131. Borbas, K.E.; Mroz, P.; Hamblin, M.R.; Lindsey, J.S. Bioconjugatable porphyrins bearing a compact swallowtail motif for water solubility. Bioconjug. Chem. 2006, 17, 638-653. [CrossRef] [PubMed]

132. Borbas, K.E.; Kee, H.L.; Holten, D.; Lindsey, J.S. A compact water-soluble porphyrin bearing an iodoacetamido bioconjugatable site. Org. Biomol. Chem. 2008, 6, 187-194. [CrossRef] [PubMed]

133. Borbas, K.E.; Chandrashaker, V.; Muthiah, C.; Kee, H.L.; Holten, D.; Lindsey, J.S. Design, synthesis, and photophysical characterization of water-soluble chlorins. J. Org. Chem. 2008, 73, 3145-3158. [CrossRef] [PubMed]

134. Sahin, T.; Vairaprakash, P.; Borbas, K.E.; Balasubramanian, T.; Lindsey, J.S. Hydrophilic bioconjugatable trans-AB-porphyrins and peptide conjugates. J. Porphyr. Pthalocyanines 2015, 19, 663-678. [CrossRef]

135. Zhang, N.; Jiang, J.; Liu, M.; Taniguchi, M.; Mandal, A.K.; Evans-Storms, R.B.; Pitner, J.B.; Bocian, D.F.; Holten, D.; Lindsey, J.S. Bioconjugatable, PEGylated hydroporphyrins for photochemistry and photomedicine. Narrow-band, near-infrared-emitting bacteriochlorins. New J. Chem. 2016, 40, 7750-7767. [CrossRef] [PubMed]

136. Liu, M.; Chen, C.-Y.; Mandal, A.K.; Chandrashaker, V.; Evans-Storms, R.B.; Pitner, J.B.; Bocian, D.F.; Holten, D.; Lindsey, J.S. Bioconjugatable, pegylated hydroporphyrins for photochemistry and photomedicine. Narrow-band, red-emitting chlorins. New J. Chem. 2016, 40, 7721-7740. [CrossRef] [PubMed]

137. Benaglia, M.; Danelli, T.; Fabris, F.; Sperandio, D.; Pozzi, G. Poly(ethylene glycol)-supported tetrahydroxy-phenyl porphyrin: A convenient, recyclable catalyst for photooxidation reactions. Org. Lett. 2002, 4, 4229-4232. [CrossRef] [PubMed]

138. Worlinsky, J.L.; Halepas, S.; Ghandehari, M.; Khalil, G.; Brückner, C. High pH sensing with water-soluble porpholactone derivatives and their incorporation into a Nafion ${ }^{\circledR}$ optode membrane. Analyst 2015, 140, 190-196. [CrossRef] [PubMed]

139. Worlinsky, J.L.; Halepas, S.; Brückner, C. PEGylated meso-arylporpholactone metal complexes as optical cyanide sensors in water. Org. Biomol. Chem. 2014, 12, 3991-4001. [CrossRef] [PubMed]

140. Lottner, C.; Bart, K.-C.; Bernhardt, G.; Brunner, H. Soluble tetraarylporphyrin-platinum conjugates as cytotoxic and phototoxic antitumor agents. J. Med. Chem. 2002, 45, 2079-2089. [CrossRef] [PubMed]

141. Reuther, T.; Kübler, A.C.; Zillmann, U.; Flechtenmacher, C.; Sinn, H. Comparison of the in vivo efficiency of photofrin II-, $m$ THPC-, $m$ THPC-PEG- and $m$ THPCnPEG-mediated PDT in a human xenografted head and neck carcinoma. Lasers Surg. Med. 2001, 29, 314-322. [CrossRef] [PubMed]

142. Topkaya, D.; Lafont, D.; Poyer, F.; Garcia, G.; Albrieux, F.; Maillard, P.; Bretonnière, Y.; Dumoulin, F. Design of an amphiphilic porphyrin exhibiting high in vitro photocytotoxicity. New J. Chem. 2016, 40, 2044-2050. [CrossRef] 
143. Zhang, J.-L.; Che, C.-M. Soluble polymer-supported ruthenium porphyrin catalysts for epoxidation, cyclopropanation, and aziridination of alkenes. Org. Lett. 2002, 4, 1911-1914. [CrossRef] [PubMed]

144. Nawalany, K.; Kozik, B.; Kepczynski, M.; Zapotoczny, S.; Kumorek, M.; Nowakowska, M.; Jachimska, B. Properties of polyethylene glycol supported tetraarylporphyrin in aqueous solution and its interaction with liposomal membranes. J. Phys. Chem. B 2008, 112, 12231-12239. [CrossRef] [PubMed]

145. Mineo, P.; Scamporrino, E.; Vitalini, D. Synthesis and characterization of uncharged water-soluble star polymers containing a porphyrin core. Macromol. Rapid Commun. 2002, 23, 681-687. [CrossRef]

146. Kim, W.J.; Kang, M.S.; Kim, H.K.; Kim, Y.; Chang, T.; Ohulchanskyy, T.Y.; Prasad, P.N.; Lee, K.-S. Water-soluble porphyrin-polyethylene glycol conjugates with enhanced cellular uptake for photodynamic therapy. J. Nanosci. Nanotechnol. 2009, 9, 7130-7135. [CrossRef] [PubMed]

147. Castriciano, M.A.; Romeo, A.; Angelini, N.; Micali, N.; Longo, A.; Mazzaglia, A.; Scolaro, L.M. Structural features of meso-tetrakis(4-carboxyphenyl)porphyrin interacting with amino-terminated poly(propylene oxide). Macromolecules 2006, 39, 5489-5496. [CrossRef]

148. Lovell, J.F.; Roxin, A.; Ng, K.K.; Qi, Q.; McMullen, J.D.; DaCosta, R.S.; Zheng, G. Porphyrin-cross-linked hydrogel for fluorescence-guided monitoring and surgical resection. Biomacromolecules 2011, 12, 3115-3118. [CrossRef] [PubMed]

149. Peng, C.-L.; Shieh, M.-J.; Tsai, M.-H.; Chang, C.-C.; Lai, P.-S. Self-assembled star-shaped chlorin-core poly( $\varepsilon$-caprolactone)-poly(ethylene glycol) diblock copolymer micelles for dual chemo-photodynamic therapies. Biomaterials 2008, 29, 3599-3608. [CrossRef] [PubMed]

150. Sibrian-Vazquez, M.; Jensen, T.J.; Hammer, R.P.; Vicente, M.G.H. Peptide-mediated cell transport of water soluble porphyrin conjugates. J. Med. Chem. 2006, 49, 1364-1372. [CrossRef] [PubMed]

151. Gianferrara, T.; Bergamo, A.; Bratsos, I.; Milani, B.; Spagnul, C.; Sava, G.; Alessio, E. Ruthenium-porphyrin conjugates with cytotoxic and phototoxic antitumor activity. J. Med. Chem. 2010, 53, 4678-4690. [CrossRef] [PubMed]

152. Mion, G.; Gianferrara, T.; Bergamo, A.; Gasser, G.; Pierroz, V.; Rubbiani, R.; Vilar, R.; Leczkowska, A.; Alessio, E. Phototoxic activity and DNA interactions of water-soluble porphyrins and their rhenium(I) conjugates. ChemMedChem 2015, 10, 1901-1914. [CrossRef] [PubMed]

153. Zingg, A.; Felber, B.; Gramlich, V.; Fu, L.; Collman, J.P.; Diederich, F. Dendritic iron(II) porphyrins as models for hemoglobin and myoglobin: Specific stabilization of $\mathrm{O}_{2}$ complexes in dendrimers with H-bond-donor centers. Helv. Chim. Acta 2002, 85, 333-351. [CrossRef]

154. Akhtar, M.A.; Riaz, S.; Hayat, A.; Nasir, M.; Muhammad, N.; Rahim, A.; Nawaz, M.H. Poly(ethylene oxide) tethered trans-porphyrin: Synthesis, self-assembly with fullerene $\left(\mathrm{C}_{60}\right)$ and DNA binding studies. J. Mol. Liq. 2017, 225, 235-239. [CrossRef]

155. Ogikubo, J.; Worlinsky, J.L.; Fu, Y.-J.; Brückner, C. A two-step, one-pot route to swap the pyrroline moiety in meso-tetraaryldihydroxy-chlorins with an O/N-substituted oxazoline. Tetrahedron Lett. 2013, 54, 1707-1710. [CrossRef]

156. Ahmed, S.; Davoust, E.; Savoie, H.; Boa, A.N.; Boyle, R.W. Thioglycosylated cationic porphyrins-Convenient synthesis and photodynamic activity in vitro. Tetrahedron Lett. 2004, 45, 6045-6047. [CrossRef]

157. Hamblin, M.R.; Miller, J.L.; Rizvi, I.; Ortel, B.; Maytin, E.V.; Hasan, T. PEGylation of a chlorin e6 polymer conjugate increases tumor targeting of photosensitizer. Cancer Res. 2001, 61, 7155-7162. [PubMed]

158. Kimani, S.; Ghosh, G.; Ghogare, A.; Rudshteyn, B.; Bartusik, D.; Hasan, T.; Greer, A. Synthesis and characterization of mono-, di-, and tri-poly(ethylene glycol) chlorin e6 conjugates for the photokilling of human ovarian cancer cells. J. Org. Chem. 2012, 77, 10638-10647. [CrossRef] [PubMed]

159. Sahoo, S.K.; Sawa, T.; Fang, J.; Tanaka, S.; Miyamoto, Y.; Akaike, T.; Maeda, H. Pegylated zinc protoporphyrin: A water-soluble heme oxygenase inhibitor with tumor-targeting capacity. Bioconjug. Chem. 2002, 13, 1031-1038. [CrossRef] [PubMed]

160. Regehly, M.; Greish, K.; Rancan, F.; Maeda, H.; Böhm, F.; Röder, B. Water-soluble polymer conjugates of ZnPP for photodynamic tumor therapy. Bioconjug. Chem. 2007, 18, 494-499. [CrossRef] [PubMed]

161. Lottner, C.; Bart, K.-C.; Bernhardt, G.; Brunner, H. Hematoporphyrin-derived soluble porphyrin-platinum conjugates with combined cytotoxic and phototoxic antitumor activity. J. Med. Chem. 2002, 45, 2064-2078. [CrossRef] [PubMed]

162. Kim, Y.-S.; Song, R.; Hyun Kim, D.; Jun, M.J.; Sohn, Y.S. Synthesis, biodistribution and antitumor activity of hematoporphyrin-platinum(II) conjugates. Biorg. Med. Chem. 2003, 11, 1753-1760. [CrossRef] 
163. Sharonov, G.V.; Karmakova, T.A.; Kassies, R.; Pljutinskaya, A.D.; Grin, M.A.; Refregiers, M.; Yakubovskaya, R.I.; Mironov, A.F.; Maurizot, J.-C.; Vigny, P.; et al. Cycloimide bacteriochlorin $p$ derivatives: Photodynamic properties and cellular and tissue distribution. Free Radic. Biol. Med. 2006, 40, 407-419. [CrossRef] [PubMed]

164. Fan, D.; Taniguchi, M.; Lindsey, J.S. Regioselective 15-bromination and functionalization of a stable synthetic bacteriochlorin. J. Org. Chem. 2007, 72, 5350-5357. [CrossRef] [PubMed]

165. Mandal, A.K.; Sahin, T.; Liu, M.; Lindsey, J.S.; Bocian, D.F.; Holten, D. Photophysical comparisons of PEGylated porphyrins, chlorins and bacteriochlorins in water. New J. Chem. 2016, 40, 9648-9656. [CrossRef] 